\title{
Human securities, sustainability, and migration in the ancient U.S. Southwest and Mexican Northwest
}

\author{
Scott E. Ingram $^{1}$ and Shelby M. Patrick ${ }^{2}$
}

\begin{abstract}
In the U.S. Southwest and Mexican Northwest region, arid-lands agriculturalists practiced sedentary agriculture for at least four thousand years. People developed diverse lifeways and a repertoire of successful dryland strategies that resemble those of some small-scale agriculturalists today. A multi-millennial trajectory of variable population growth ended during the early 1300 s CE and by the late 1400s population levels in the region declined by about one-half. Here we show, through a meta-analysis of sub-regional archaeological studies, the spatial distribution, intensity, and variation in social and environmental conditions throughout the region prior to depopulation. We also find that as these conditions, identified as human insecurities by the UN Development Programme, worsened, the speed of depopulation increased. Although these conditions have been documented within some sub-regions, the aggregate weight and distribution of these insecurities throughout the Southwest/Northwest region were previously unrecognized. Population decline was not the result of a single disturbance, such as drought, to the regional system; it was a spatially patterned, multi-generational decline in human security. Results support the UN's emphasis on increasing human security as a pathway toward sustainable development and lessening forced migration. Through these results and the approach demonstrated here, we aim to stimulate collaborations between archaeologists and others in service of modern sustainability planning.
\end{abstract}

Key Words: archaeology; depopulation; human security; Mexican Northwest; migration; sustainability; U.S. Southwest

\section{INTRODUCTION}

Maintaining the social-ecological sustainability of regions is a challenge in the present as it has been in the past. For at least 4000 years, indigenous agriculturalists in the U.S. Southwest and Mexican Northwest (SW/NW; Fig. 1) developed diverse lifeways and a repertoire of social and environmental dryland strategies (Ortiz 1979, Ingram and Hunt 2015, Cordell and McBrinn 2012). This multi-millennial trajectory of variable population growth ended during the early 1300 s CE, and by the late 1400s, well before Spanish contact, population levels in the region declined by about one-half (Dean et al. 1994, Doelle 2000, Hill et al. 2004, Robinson et al. 2021). In some places within the region, the proximate causes of the decline are fairly well documented, such as environmental challenges to food security (Gumerman 1988) and changing climate patterns (Dean 1996). In the region as a whole, however, differences in social organization, histories, lifeways, subsistence strategies, population densities, and climatic and environmental conditions were substantial. Such diversity likely resulted in an uneven landscape of human vulnerability to social perturbations and environmental hazards such that impacts would not have been uniform across the region. Why, then, did population levels substantially decline, relatively quickly, throughout this large and diverse region?

The aim of this research is to identify social and environmental conditions that contributed to the depopulation of the SW/NW during the 13th through 15 th centuries and use this knowledge to inform present and future sustainability efforts. Millions of smallholder farmers worldwide continue to practice subsistence agriculture and engage in limited market economies (Lowder et al. 2016) similar to those in the past. The depopulation of the SW/NW includes declining population levels, substantial settlement relocation, and accelerated out-migration. It is an indicator of a loss of regional-scale sustainability and an example of the problem modern sustainability efforts seek to avoid. For the purposes of this study of the past, sustainability is defined as the persistence of peoples in places. Archaeological documentation of human-environmental interactions over centuries provides an opportunity to observe social, environmental, and economic variables interacting in many contexts (van der Leeuw and Redman 2002). Outcomes of these interactions are a reservoir of insights on what worked, what did not, and why (Nelson et al. 2012, Kintigh et al. 2014, Redman 2014, Clark et al. 2019, Rick and Sandweiss 2020).

Fig. 1. Archaeological culture areas of the U.S. Southwest and Mexican Northwest, approximately 1100 CE. Once large-scale migrations (generally north to south) began in the mid- to late 1200 s, culture areas began to change dimensions and reflect substantial cultural patchiness.

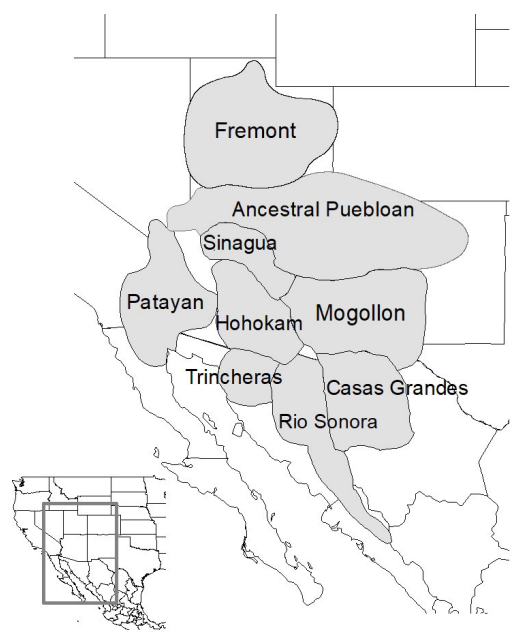


We apply the United Nations Development Programme's (UNDP) human security framework to investigate this loss of sustainability in the past and the influence of human securities on sustainability and depopulation. Improving human securities is necessary, according to U.N. leadership, for achieving Sustainable Development Goals established by the 2030 Agenda for Sustainable Development (Risse 2019). The human securities approach was developed to reduce global human insecurity by working toward freedom from fear, freedom from want, and freedom to live in dignity (UNDP 1994, UN Human Security Unit 2009, 2016, Gomez and Gasper 2013, O'Brien and Barnett 2013). This people-centered approach addresses the totality of conditions (e.g., economic, food, health, etc.) that impact human beings and recognizes that multiple interconnected and mutually reinforcing factors generate complex social phenomena such as depopulation and other humanitarian crises. The root causes of some insecurities can lead to declining population levels through famine, changes in fertility and mortality, and violence. Declining insecurities can also influence human decisions to migrate away from untenable social, environmental, and economic conditions (Vietti and Scribner 2013), the key dimensions of sustainable development. Improving human securities is expected to minimize forced migration by easing some of the pressures that influence human decisions to move or remain in place. We document human insecurities throughout the SW/NW region during the roughly 100-year period before depopulation in each sub-region. Human securities are measured and understood in the present with sets of evolving indicators. Archaeologists are well versed in identifying indicators for past human behaviors and processes and share this reliance on indicators with the sustainability policy community.

The human security framework provides a meta-language for the sustainability community and archaeologists to communicate about problems of shared interest. Investigating and contributing insights useful for lessening human suffering associated with declining securities, improving sustainability, and decreasing forced migration is not the exclusive domain of specific disciplines or actors; it is a shared disciplinary and human responsibility. From an archaeological perspective, most societal configurations eventually fail but some persist through learning and transformation. Studies of long-term (multi-generational) human-environmental interactions can inform this learning by revealing policy-relevant information. For example, complex social-ecological system behavior, including thresholds and emergent phenomena, is not evident in studies of shorter duration (van der Leeuw and Redman 2002). Current sustainability planning is already informed by institutional learning from past successes and failures. We advocate here for an expanded temporal scale that can generate insights to better understand and address modern sustainability problems. Aspiring to policies built for the present and future but informed by the past accepts our common humanity.

Identifying research questions in the present, adopting globalscale approaches and language for investigating these questions, and testing assumptions embedded in modern policies is a transdisciplinary pathway forward for archaeology. Archaeologists are increasingly communicating insights from the past to address modern concerns (Altschul et al. 2017, 2020), especially those associated with a changing climate (Cooper and Sheets 2012, Nelson et al. 2016, Rick and Sandweiss 2020, Rockman and Hritz
2020). Archaeologists also have much to learn from collaborations with the sustainability community. Recognizing past depopulations as an analog of modern sustainability concerns and analyzing these events with a current framework will generate fresh insights about the past.

\section{Southwest/Northwest depopulation and causes}

Population levels began to decline throughout the SW/NW around 1300 CE (Dean et al. 1994, Doelle 2000, Hill et al. 2004, Robinson et al. 2021). Prior to the decline, population levels in the U.S. Southwest rose for at least a millennium, peaking between 100,000 and 160,000 people around 1000 CE (Dean et al. 1994, Doelle 2000, Hill et al. 2004). By the late 1400s, population levels throughout the SW had declined $\sim 50-60 \%$ (Fig. 2 in Hill et al. 2004). Population estimates in Northwest Mexico are less well developed, but based on the available evidence, population levels there appear to have similarly declined. Although absolute population levels are notoriously difficult to estimate from archaeological data, there is a strong consensus that a millennium of population growth slowed and reversed itself around $1300 \mathrm{CE}$. There is also consensus that depopulation resulted in the archaeological invisibility of some peoples and traditions because of low population densities and relatively high mobility. Although we focus here on depopulation, people persisted in multiple areas through the depopulation, as discussed further below.

Archaeological studies of the causes of the depopulation have focused primarily on specific areas, such as the Mesa Verde region of southwestern Colorado (Glowacki 2015, Van West and Dean 2000, Kohler et al. 2010) and the Lower Salt River Valley of modern day Phoenix, Arizona (Graybill et al. 2006, Hill et al. 2015), rather than on the greater SW/NW region. Most studies have moved beyond early single cause depopulation explanations such as droughts and floods and increasingly identify complex interactions between multiple social and environmental variables, such as the relationship between rising population levels, the increasing use of lands marginal for farming, and social conflict (Schwindt et al. 2016). Migration studies have emphasized that population movements are most likely to occur when there are "push" factors at the population origin and "pull" factors (attractions) at the population destination (Anthony 1990, Cameron 1995). Several studies of large-scale population movements in the SW have identified push-pull environmental and social factors to explain sub-regional depopulations (Ahlstrom et al. 1995, Lipe 1995).

Environmental, climatic, and demographic explanations of local to near regional-scale depopulation have always been a focus in the Southwest given relatively low and variable rainfall conditions and the dependence on maize agriculture. Dean (1996) and colleagues (Gumerman 1988) documented an unprecedented convergence of conditions unfavorable for farming in the northern SW during the 1250 to 1450 period: falling alluvial water tables, floodplain erosion, drought (1275 to 1300), low temporal and spatial climatic variability, the breakdown of the bimodal summer-winter precipitation pattern in the northwest sub-region, and population levels in the northern Southwest that reached their peak around $1000 \mathrm{CE}$ followed by increasing settlement aggregation. They argue that the result was major stresses from population-resource imbalances, breaches in local carrying capacities, and large-scale migrations into the climatically more stable southeastern SW sub-region. Phillips et al. (2018) argue 
that settlement aggregation throughout the region could have triggered emerging infectious diseases responsible for the depopulation. Cooling temperatures, due to the effect of the Little Ice Age (LeBlanc 1999) and/or explosive volcanism (Salzer 2000), have been linked to declining agricultural productivity and the resulting effect of rising violence and depopulation in the northern SW. Megadroughts affecting large portions of the western U.S. have also been argued to have caused depopulation (Benson and Berry 2009, Cook et al. 2010, 2016).

There is no consensus among SW/NW archaeologists regarding the causes of the depopulation. This study combines data from many sub-regional studies to document the rise of human insecurities and examine whether these can explain the broad regional depopulation in the 14 th and 15 th centuries. Subregional studies do not capture conditions throughout the SW/ NW social-ecological system at the spatial scale at which depopulation occurred.

\section{METHODS}

Documenting human securities throughout the SW/NW region and assessing the relationship between insecurities, sustainability, and migration consists of four steps: (1) defining the spatial, analytical units (cases) for the study, (2) identifying archaeological indicators for each security, (3) coding the insecurities in eight culture areas (Fig. 1), and (4) assessing the relationship between the insecurities and the speed (duration) of depopulation in each area. We describe the procedures here, and Appendix 1 contains the insecurity coding definitions and additional information on the methods. Appendix 2 provides thorough documentation of the evidence used to assess each insecurity. Appendix 2 offers researchers the opportunity to compare results in their areas of study to regional-scale patterns and is intended to be a foundational resource for future and similar studies. Our procedures follow similar efforts developed by Hegmon (2016), Hegmon et al. (2018), and others in a special issue of the journal, Archaeological Papers of the American Anthropological Association (Hegmon 2016).

\section{Analytical units: culture areas}

The archaeological culture areas for comparison are the archaeologically and geographically identified peoples of the region: Ancestral Puebloan, Fremont, Patayan, Sinagua, Hohokam, Mogollon, Trincheras, Rio Sonora, and Casas Grandes (Fig. 1). Archaeological cultures are "abstract units of analysis defined by comparative sets of material traits" (Dongoske et al. 1997:600) and should not be equated with modern cultural, ethnic, and tribal affiliations (Dongoske et al. 1997). The culture area names and the geographical extent of the polygons are commonly used by archaeologists of the SW/NW to identify "similarities and differences in the remains people left behind and that have been preserved--for example, the houses they built, the stone tools and pottery they made, the sizes and forms of their settlements, and the foods they ate" (Cordell and McBrinn 2012:35). Similarities likely represent shared lifeways and histories of interaction. Within culture area differences in language, sociopolitical organization, and histories are expected to have been substantial, based on differences among Native peoples of the SW/NW today. The timing and duration of depopulation varied among culture areas (Table 1, Appendix 3) and the contours of the polygons (Appendix 4) began to change by 1300 , due to migration. The culture area polygons in Figure 1 represent the period prior to the initiation of the depopulation, about 1100 CE.

Table 1. Depopulation dates and the speed (duration) of depopulation by culture areas.

\begin{tabular}{lcc}
\hline \hline $\begin{array}{l}\text { Archaeological cultures } \\
\text { (culture areas) }\end{array}$ & $\begin{array}{c}\text { Depopulation } \\
\text { (approximate start and end } \\
\text { dates) }\end{array}$ & $\begin{array}{c}\text { Duration } \\
\text { (years) }\end{array}$ \\
\hline Fremont & 1150 to 1300 & 150 \\
Ancestral Puebloan ${ }^{\ddagger}$ & 1240 to 1285 & 45 \\
Mogollon & 1325 to 1450 & 125 \\
Hohokam & 1375 to 1450 & 75 \\
Sinagua and Central AZ & 1375 to 1425 & 50 \\
Trincheras & ? to 1450 & - \\
Casas Grandes & ? to 1450 & - \\
Rio Sonora and Serrana & No evidence of population \\
decline & No evidence of population \\
Patayan & decline & \\
\end{tabular}

See Appendix 3 for a description of the dates and associated references.

\$ Depopulation of the Ancestral Puebloan region includes substantial

within culture area migration and migration to other areas within the SW/ NW region.

\section{Archaeological indicators of human securities}

There are many threats to human security, but most can be considered under seven categories: economic, food, health, environmental, personal, community, and political security (UNDP 1994). We selected archaeological indicators for each category to assess the extent of insecurity in each culture area. Many of the indicators are threats that have been advanced in the scholarly literature of the SW/NW and elsewhere as social, demographic, and environmental causes of depopulation (e.g., Adler et al. 1996, Nelson and Schachner 2002, Hegmon et al. 2008, 2018, Railey and Reycraft 2008). Thus, each indicator has a plausible causal relationship with the sustainability of places, human decisions to migrate, and declining population levels (Table 2). There is no standard set of insecurity indicators in the present or archaeologically; indicators are selected based on available data, assessor judgments, and assessment objectives (U. N. Human Security Unit 2016). Indicator selection in this study was driven by the need for comparable data throughout the region and limited by the types of data and archaeological proxies available. We expect future archaeological studies will improve and rely on an expanded range of indicators. Collaborations with the human securities and sustainability planning communities could also improve past and present security indicators. We extend previous depopulation studies spatially by documenting securities throughout the SW/NW region to produce a "comprehensivemapping report" that assesses all human securities rather than an in-depth report on a specific threat (Gomez and Gasper 2013, Owen 2013, U.N. Human Security Unit 2016).

Qualitative and quantitative indicators are used to determine the extent of insecurities in each culture area (Table 2). Qualitative indicators rely on the published judgment of scholars active in each culture area, an approach applied in synthetic studies of broad geographic scope where comparable data do not exist (Hegmon et al. 2008, 2018, Nelson et al. 2016). For example, 
Table 2. Human insecurities, archaeological indicators and proxies, and plausible relationships to sustainability and depopulation.

\begin{tabular}{|c|c|c|c|}
\hline $\begin{array}{l}\text { Categories of } \\
\text { Insecurities }^{1}\end{array}$ & $\begin{array}{l}\text { Root Causes }{ }^{1} \text { of Insecurities } \\
\text { Identified in Modern } \\
\text { Contexts }\end{array}$ & $\begin{array}{l}\text { Archaeological Indicator of Insecurities, } \\
\text { Assessment Question for Coding, and Proxies } \\
\text { Used to Assess Indicator }\end{array}$ & $\begin{array}{l}\text { Some Plausible Relationships of Archaeological } \\
\text { Indicators to Sustainability and Depopulation }\end{array}$ \\
\hline Economic & $\begin{array}{l}\text { Persistent poverty, } \\
\text { unemployment, lack of } \\
\text { access to credit and other } \\
\text { economic opportunities }\end{array}$ & $\begin{array}{l}\text { Indicator: decreasing trade and exchange } \\
\text { Question: What was the extent of } \\
\text { interregional trade/exchange? } \\
\text { Proxies: extent of non-local pottery and other } \\
\text { goods in settlements }\end{array}$ & $\begin{array}{l}\text { As trade and exchange networks declined, opportunities } \\
\text { to engage social strategies for buffering risks decrease (e. } \\
\text { g., alliances, reciprocity) and economic insecurity } \\
\text { increased (Braun and Plog 1982). Risks (real or } \\
\text { perceived) that cannot be buffered can lead to strategies } \\
\text { such as migration to mitigate risks. }\end{array}$ \\
\hline Food & $\begin{array}{l}\text { Hunger, famine, sudden rise } \\
\text { in food prices }\end{array}$ & $\begin{array}{l}\text { Indicator: increasing resource depletion/ } \\
\text { degradation } \\
\text { Question: What was the extent of resource } \\
\text { depletion and degradation? } \\
\text { Proxies: declining diet breadth, change in } \\
\text { previous resource procurement strategies (for } \\
\text { example, shifting from cultivated to wild } \\
\text { foods or vice versa), increased reliance on } \\
\text { smaller or more immature mammals, } \\
\text { increasing soil degradation, bioarchaeological } \\
\text { indicators of food stress }\end{array}$ & $\begin{array}{l}\text { As resources relied on for food decrease, food insecurity } \\
\text { increased. Perceptions of better conditions elsewhere } \\
\text { can stimulate movement to lessen food insecurity } \\
\text { (Halstead and O'Shea 1989). Population levels will } \\
\text { decline when insufficient food decreases fertility and } \\
\text { increases mortality. }\end{array}$ \\
\hline Health & $\begin{array}{l}\text { Epidemics, malnutrition, } \\
\text { poor sanitation, lack of } \\
\text { access to basic health care }\end{array}$ & $\begin{array}{l}\text { Indicator: increasing settlement aggregation } \\
\text { and skeletal indicators of disease } \\
\text { Question: What was the extent of settlement } \\
\text { aggregation and evidence of disease? } \\
\text { Proxies: spatial clustering of households into } \\
\text { larger communities; skeletal indicators of } \\
\text { health/disease. }\end{array}$ & $\begin{array}{l}\text { As people lived increasingly closer together in } \\
\text { aggregated settlements, mechanisms for disease } \\
\text { transmission increased, mortality increased, health } \\
\text { insecurity increased, and decisions to migrate increased. } \\
\text { This plausible relationship is based on the link between } \\
\text { aggregation/urbanization and increases in the } \\
\text { vulnerability to infectious diseases (Martin 1994, } \\
\text { Phillips et al. 2018). }\end{array}$ \\
\hline Environmental & $\begin{array}{l}\text { Environmental degradation, } \\
\text { resource depletion, natural } \\
\text { disasters }\end{array}$ & $\begin{array}{l}\text { Indicator: increasing relative climatic dryness } \\
\text { Question: What was the extent of dryness } \\
\text { coincident with the decline, relative to dryness } \\
\text { during the period preceding decline? } \\
\text { Proxies: Average Palmer Drought Severity } \\
\text { Index (PDSI; tree-ring retrodictions) during } \\
\text { depopulation compared to average prior } \\
\text { period PDSI. }\end{array}$ & $\begin{array}{l}\text { As dryness increased, wild and cultivated food resources } \\
\text { decreased, and environmental insecurity increased. } \\
\text { Resource shortfalls (real or perceived) can stimulate } \\
\text { movement toward more productive areas (Halstead and } \\
\text { O'Shea 1989) and insufficient food decreases fertility } \\
\text { and increases mortality. Drought is also sometimes } \\
\text { linked to spiritual failures of the afflicted peoples. }\end{array}$ \\
\hline Personal & $\begin{array}{l}\text { Physical violence in all its } \\
\text { forms, human trafficking, } \\
\text { child labor }\end{array}$ & $\begin{array}{l}\text { Indicator: increasing conflict and violence } \\
\text { Question: What was the extent of conflict and } \\
\text { violence within the culture area? } \\
\text { Proxies: skeletal trauma, unburied bodies, } \\
\text { fortified and defensive structures/settlements }\end{array}$ & $\begin{array}{l}\text { As conflict and violence increased, mortality increased, } \\
\text { personal insecurity increased, and movement away from } \\
\text { dangerous conditions increased (LeBlanc 1999). }\end{array}$ \\
\hline Community & $\begin{array}{l}\text { Inter-ethnic, religious, and } \\
\text { other identity-based } \\
\text { tensions, crime, terrorism }\end{array}$ & $\begin{array}{l}\text { Indicator: increasing immigration } \\
\text { Question: What was the extent of } \\
\text { immigration from people outside of or within } \\
\text { the culture area? } \\
\text { Proxies: rising population levels above } \\
\text { internal population growth rates (using } \\
\text { compound annual growth rate calculations, } \\
\text { where possible); architectural and/or material } \\
\text { cultural differences within settlements } \\
\text { associated with immigrants }\end{array}$ & $\begin{array}{l}\text { As immigration increased within and near existing } \\
\text { communities, insecurities increased, and new social } \\
\text { strategies were necessary for resolving tensions (Clark et } \\
\text { al. 2019). These tensions likely increased because of } \\
\text { increased resource competition in marginal areas } \\
\text { (Schwindt et al. 2016). If immigration created untenable } \\
\text { social and environmental conditions within } \\
\text { communities, movement away from these conditions } \\
\text { could have lessened tensions. }\end{array}$ \\
\hline Political & $\begin{array}{l}\text { Political repression, human } \\
\text { rights violations, lack of } \\
\text { rule of law and justice }\end{array}$ & $\begin{array}{l}\text { Indicator: increasing social stratification } \\
\text { Question: To what extent did individuals/ } \\
\text { groups have different levels of access to } \\
\text { structural, ritual, or socioeconomic resources? } \\
\text { Proxies: architecture within settlements } \\
\text { increasingly differentiated, exclusive spaces, } \\
\text { unequal distribution of prestige goods, } \\
\text { differential burial treatments or grave goods. }\end{array}$ & $\begin{array}{l}\text { As social stratification increased, some portion of a } \\
\text { population had less access to political, ritual, and/or } \\
\text { socioeconomic resources (Brandt 1994) and political } \\
\text { insecurity likely increased. Movement away from these } \\
\text { conditions can lessen the perceived inequalities. }\end{array}$ \\
\hline
\end{tabular}

published and data-informed archaeological syntheses of conflict and violence are used to assess personal insecurities in each culture area. Within the UN human securities framework, the "root causes" of personal insecurity are "physical violence in all its forms, human trafficking, child labor" (Human Security Unit 2016:7). Quantitative indicators assess insecurities that could be measured with comparable datasets across the region. For example, we assess the extent and trajectory of immigration (the 
indicator of community insecurity) with compound annual population growth rates by comparing two, 50-year intervals prior to the start of depopulation in those areas with available settlement data (Hill et al. 2012). Within culture area population growth rates in excess of what can be expected from changes in fertility and mortality (Cowgill 1975) contribute to assessing the extent of immigration in those areas. Some plausible relationships between the archaeological indicators, sustainability, decisions to migrate, and declining population levels are described in Table 2.

The indicators capture the "initial conditions" of depopulation, the lived experience of people in culture areas that informed their decisions to migrate or resulted in declining population levels. We assumed that changes in these conditions affected human perceptions of security. Thus, our focus was on the extent and trajectory of insecurities in each culture area relative to previous conditions in that area. We documented conditions present during the $\sim 50$ - to 100-year period prior to each culture area depopulation (Table 1, Appendices 2 and 3). The periods varied in length because of variation in the methods used to date the conditions we were documenting. In areas where tree-ring dating of structures is possible and more precise dates are available, we were able to identify conditions closer in time to depopulation than in areas where radiocarbon or ceramic seriation are the only dating methods available.

\section{Coding insecurities}

We reviewed hundreds of published archaeological studies to identify the extent and trajectory of insecurities in each culture area and coded these insecurities as low, moderate, high, or unknown. Our procedures followed standard coding procedures developed by Ember and Ember (2009) for cross-cultural studies using the Human Relations Area Files (https://hraf.yale.edu/). Within each culture area, the insecurities are the independent variables and the speed (duration in years) of depopulation in each area are the dependent variables. To avoid bias, coders did not know values for the dependent variables or the hypothesis: as insecurities increased, the rate of depopulation increased. The authors developed both after the insecurities were coded. Each coder conducted a separate literature search to maximize the discovery and breadth of the studies considered. Coders were, however, provided with some synthetic literature for each case so that expert foundational studies were included in the coding. Specific questions and code definitions were developed to guide the coding effort (Appendix 1). At least two coders coded each insecurity, and most insecurities were coded during two distinct coding periods by different coders. As an additional step the authors obtained comments on the coding from archaeological culture area experts for most areas.

As an example of the coding effort, we coded personal insecurity as High in the Ancestral Puebloan area during the $~ 50$-year period prior to depopulation. Consistent with archaeological and anthropological understanding of the influence of conflict and violence on human decision making and mortality, we expected that as conflict and violence increased, mortality increased, personal insecurity increased, and movement away from dangerous conditions increased (e.g., LeBlanc 1999). The material indicators (proxies) of High conflict and violence include strong and widespread evidence of skeletal trauma, unburied bodies, and fortified/defensive structures. Data-informed and synthetic interpretations of the extent of conflict and violence by leading scholars of the culture area were especially influential. Our coding efforts identified at least 12 studies that found evidence of these indicators and interpreted high and increasing conflict and violence within the Ancestral Puebloan area prior to depopulation. We cite these studies to build a case for our coding decision in Appendix 2.

We acknowledge the internal diversity of conditions within the Ancestral Puebloan area (and elsewhere) and address this analytical challenge in our study. For example, in the Kayenta sub-region (NE Arizona) of the Ancestral Puebloan area, Dean (2010) argues that conflict and violence was not extensive or widespread. Haas and Creamer (1996), however, argue that warfare was increasing and endemic in the Kayenta area and throughout the Ancestral Puebloan area preceding and during depopulation. We cannot resolve these interpretive differences and we address such intra-culture area variation for all insecurities in three ways. First, we focus our coding on characterizing insecurities in areas with the highest population density within each culture area (population levels in the Kayenta area were about one-third of population levels in the central Mesa Verde area [Dean 2010], a focus of most of our coding). These "demographic centers of gravity" (see maps in Hill et al. 2010:36-44) are also usually the most well-documented areas. Thus, we have documented the dominant trends in the insecurities within culture areas and look forward to intra-culture area studies, as advocated below. Second, in addition to investigating multiple sources to document conditions, we rely on published syntheses of conditions and, in some cases, expert assessments offered to us by prominent culture area scholars. Their qualitative assessments provide a holistic understanding of conditions that inspection of published studies sometimes cannot. Third, we code and document our uncertainties in Appendix 2, including those caused by intra-culture area diversity and variation, for each assigned insecurity.

\section{Comparing insecurities and assessing the relationship between insecurities and sustainability}

To identify and compare differences in the spatial distribution, intensity, and variation in insecurities among culture areas we assign an ordinal scale code to low (1), moderate (2), and high (3) insecurities. When these codes are summed, aggregate insecurity is identified with higher values representing relatively higher insecurity and lower values representing relatively lower insecurity. In the Patayan culture area, only environmental insecurities could be assessed. Patayan is the least studied and documented culture area in the region.

To identify the relationship, if any, between human insecurities and sustainability, we investigate the correlation between aggregate (summed) insecurities and the speed (duration) of depopulation in each culture area. The speed of depopulation is a measure of the sustainability of places, with faster depopulation associated with less sustainable conditions and slower depopulation associated with more sustainable conditions. People had persisted in each culture area for at least a millennium prior to depopulation. Although depopulation occurred throughout the region, variation in depopulation speed provides a reasonable but imperfect window into the sustainability of each culture area, declining population levels, and conditions that were influencing 
human decisions to migrate. Five of the nine culture areas of the $\mathrm{SW} / \mathrm{NW}$ region, containing most of the people of the region, are included in this analysis. The Trincheras and Casas Grandes areas are excluded in this analysis because there is no data, evidence, or published argument to confidently estimate the speed of depopulation in those areas. [However, we speculate that depopulation was relatively short in these areas based on a lack of evidence of prolonged decline.] The Rio Sonora and Patayan culture areas are excluded because there is no evidence of population decline in those areas. We ranked the speed of depopulation based on the number of years of population decline from slowest (1) to fastest (5). We ranked the summed insecurity codes from lowest insecurity (1) to highest insecurity (5). If insecurities influenced the speed of depopulation, then we expect as insecurities accumulated, the speed of depopulation increased. If insecurities did not influence the speed of depopulation, we expect the speed of depopulation to be unrelated to the extent of accumulated insecurities.

\section{RESULTS}

This effort is the first systematic comparative study of social and environmental conditions associated with the 13th through 15th century depopulation at the scale of the entire SW/NW region. We hope our efforts enable increasingly refined spatial documentation of insecurities as well as further big history efforts that can be understood beyond the small community of SW/NW archaeologists.

\section{Spatial distribution, intensity, and variation of human insecurities prior to depopulation}

The spatial distribution, intensity (low, moderate, high), and variation of human insecurities prior to depopulation in each culture area are displayed in Figures 2 through 8 . The insecurities mapped in each culture area occur at different times, earlier in the north in the Fremont and Ancestral Puebloan areas and later in the south in the Mogollon, Hohokam, Sinagua/Central Arizona, Trincheras, Rio Sonora, and Casas Grandes areas (see Table 1 for depopulation date ranges). Most of the seven dimensions of human security show moderate to high insecurity in each area. Although many social and environmental conditions indicating insecurities have been documented within some sub-regions, the distribution of these conditions and their contribution to insecurities throughout the Southwest/Northwest region was previously unrecognized. Sub-regional/culture area and case studies dominate the archaeological literature. These regionalscale results allow researchers to compare results in their areas of study to regional-scale conditions and begin systematic investigations of the causes of similarities and differences.

The "weight" of aggregate insecurity (sum of all insecurities, columns; Table 3) was highest in the Ancestral Puebloan (20) and Hohokam culture areas (19), more moderate in the Mogollon (16), Trincheras (15), and Sinagua/Central Arizona (14), and lowest in the Fremont (13), Casas Grandes (12), and Rio Sonora \& Serrana (11) areas (Table 3). Data does not yet exist to document population densities across the region systematically. However, based on common assumptions and existing demographic information, this pattern suggests that culture areas with high population densities (Ancestral Puebloan and Hohokam) are associated with higher aggregate insecurity and areas with low population densities are associated with lower insecurities (Fremont and Mogollon). When insecurities are considered individually (sum of individual insecurities, rows), health (19), personal (19), political (19), and environmental (18) insecurities were highest and increasing almost everywhere across the region. Economic (16) and community (16) insecurity were more moderate and food insecurity (13) was lowest.

Fig. 2. Economic insecurity prior to depopulation (indicator: decreasing trade and exchange).

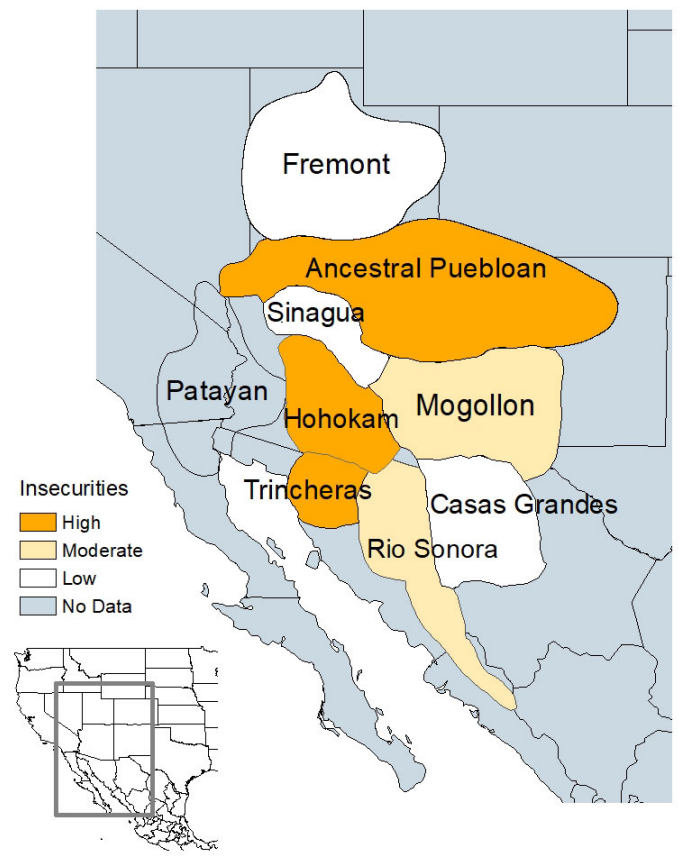

Fig. 3. Food insecurity prior to depopulation (indicator: increasing resource depletion/ degradation).

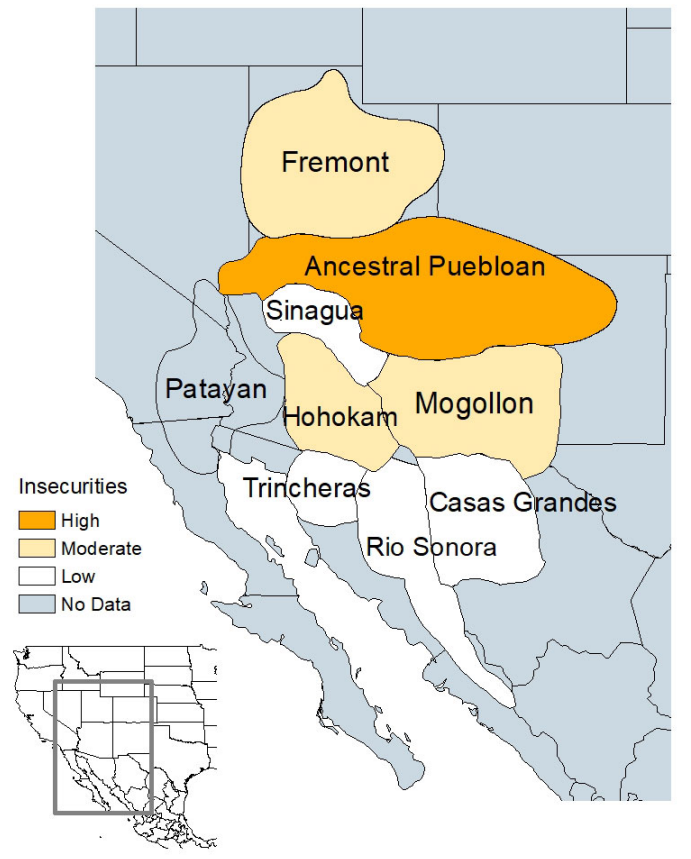


Fig. 4. Health insecurity prior to depopulation (indicator: increasing settlement aggregation and skeletal indicators of disease).

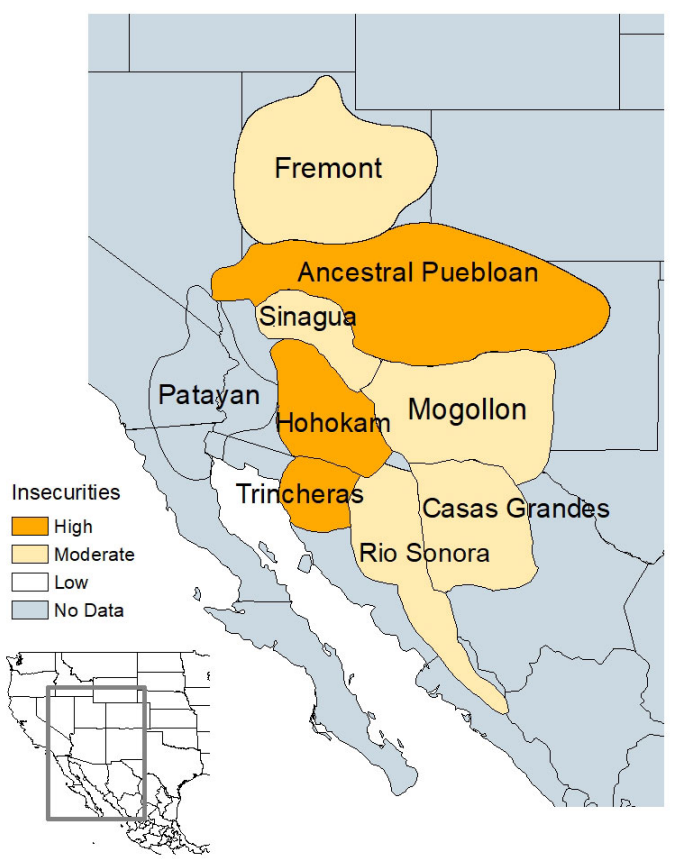

Fig. 5. Environmental insecurity prior to depopulation (indicator: increasing relative climatic dryness).

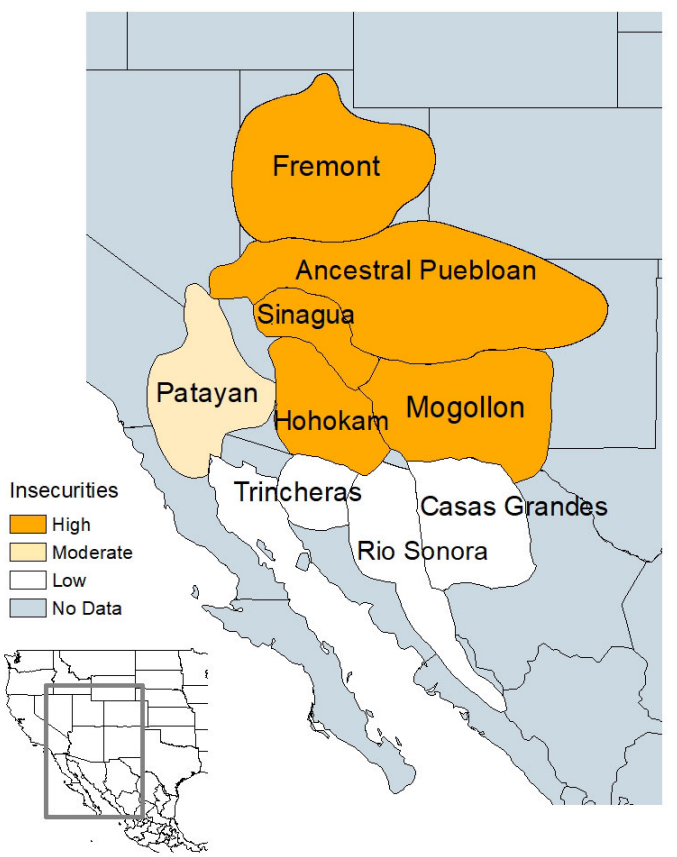

Fig. 6. Personal insecurity prior to depopulation (indicator: increasing conflict and violence).

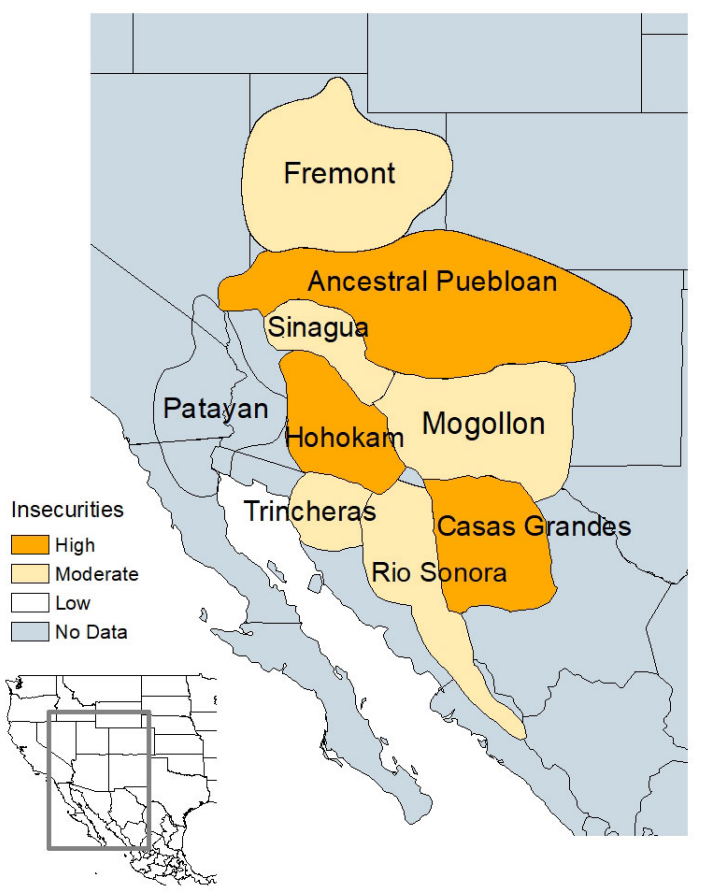

Fig. 7. Community insecurity prior to depopulation (indicator: increasing immigration).

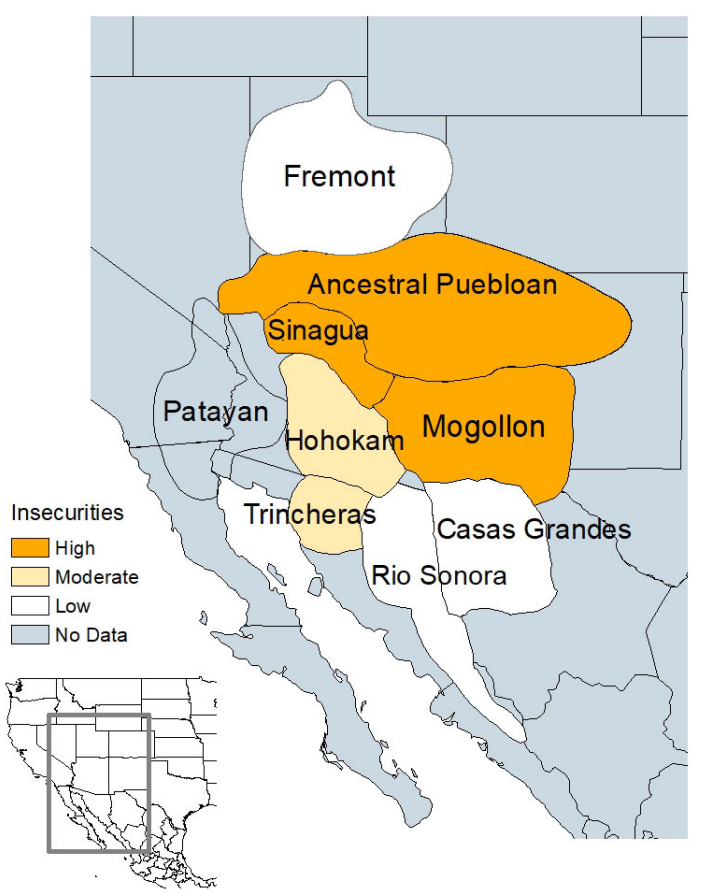


Table 3. Human insecurities by culture areas, speed of depopulation, and aggregate insecurity.

\begin{tabular}{|c|c|c|c|c|c|c|c|c|c|}
\hline Insecurities & Fremont & Mogollon & Hohokam & $\begin{array}{c}\text { Sinagua \& } \\
\text { Central AZ }\end{array}$ & $\begin{array}{l}\text { Ancestral } \\
\text { Puebloan }\end{array}$ & $\begin{array}{c}\text { Casas } \\
\text { Grandes }\end{array}$ & Trincheras & $\begin{array}{c}\text { Rio } \\
\text { Sonora \& } \\
\text { Serrana } \\
\end{array}$ & $\begin{array}{l}\text { Aggregate } \\
\text { insecurity }\end{array}$ \\
\hline Economic & Low & Moderate & High & Low & High & Low & High & Moderate & 16 \\
\hline Food & Moderate & Moderate & Moderate & Low & High & Low & Low & Low & 13 \\
\hline Health & Moderate & Moderate & High & Moderate & High & Moderate & High & Moderate & 19 \\
\hline Environmental & High & High & High & High & High & Low & Low & Low & 18 \\
\hline Personal & Moderate & Moderate & High & Moderate & High & High & Moderate & Moderate & 19 \\
\hline Community & Low & High & Moderate & High & High & Low & Moderate & Low & 16 \\
\hline Political & Moderate & Moderate & High & Moderate & Moderate & High & High & Moderate & 19 \\
\hline Speed in years & 150 & 125 & 75 & 50 & 45 & - & - & - & \\
\hline $\begin{array}{l}\text { Ranked speed of } \\
\text { depopulation, slowest (1) to } \\
\text { fastest (5) }\end{array}$ & 1 & 2 & 3 & 4 & 5 & - & - & - & \\
\hline $\begin{array}{l}\text { Sum of aggregate insecurity } \\
\text { codes }\end{array}$ & 13 & 16 & 19 & 14 & 20 & 12 & 15 & 11 & \\
\hline $\begin{array}{l}\text { Ranked sum of aggregate } \\
\text { insecurity, lowest (1) to } \\
\text { highest (5) }\end{array}$ & 1 & 3 & 4 & 2 & 5 & - & - & - & \\
\hline
\end{tabular}

Fig. 8. Political insecurity prior to depopulation (indicator: increasing social stratification).

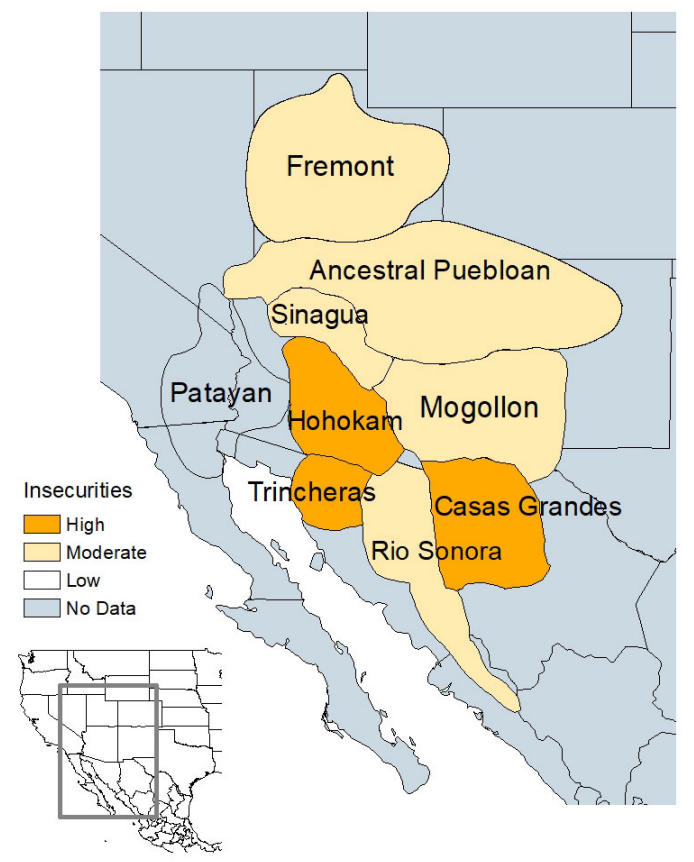

If only insecurities coded as high across the region are considered, then environmental ( 5 high codes), economic, health, personal, community, and political insecurities (each with 3 high codes) may have been more influential on decisions to migrate and conditions leading to declining population levels than food insecurity ( 1 high code). In other words (using only the indicators), the extent of climatic dryness, trade/exchange, settlement aggregation, conflict/violence, immigration, and social stratification may have been more influential on decisions to migrate and conditions leading to declining population levels than the extent of resource depletion/degradation. Comparing these results to those identified in modern security case studies may reveal combinations of insecurities most and least likely to result in large-scale migrations.

Human insecurities influenced sustainability and migration

As human insecurities accumulated and the weight of these insecurities increased, the speed of depopulation increased for most people living in the SW/NW (Fig. 9). For depopulation due to out-migration, people living in areas with the highest aggregate insecurity decided to migrate relatively quicker than people living in areas with the lowest aggregate insecurity. For depopulation due to other factors contributing to population decline (e.g., violence, decreases in fertility/increases in mortality), population levels in areas with the highest aggregate insecurity were declining relatively quicker than population levels in areas with the lowest aggregate insecurity. The positive direction and strength of the relationship between aggregated insecurities and the speed of depopulation (Spearman's rho $=0.7, p=0.19$ ) affirms the influence of insecurities on depopulation and the declining sustainability of places. Additional support for this relationship is provided by the Rio Sonora and Serrana culture area. The area was not depopulated and insecurities there were the lowest in the region. These results support the important role of the UN's holistic efforts to assess and decrease all insecurities to achieve sustainable development goals. This policy assumes "the advancement of human security results in greater resilience, peace and sustainable development" (U.N. Human Security Unit 2016:17). For archaeologists of the SW/NW, the positive relationship between accumulating insecurities and the increasing speed of depopulation validates the progress they have made toward identifying variables that influenced depopulation; the archaeological indicators of individual insecurities often are identified in arguments that seek to explain depopulation in the SW/NW.

\section{Next steps}

Through these results and the approach demonstrated here we aim to stimulate collaborations between archaeologists and others in service of modern sustainability planning. The results presented here are not intended to be the last word on human 
Fig. 9. Relationship between aggregated insecurity and the speed of depopulation by culture areas. Spearman's Rho is $0.7, p=0.19$. The low $p$-value can be explained in part by the small sample size.

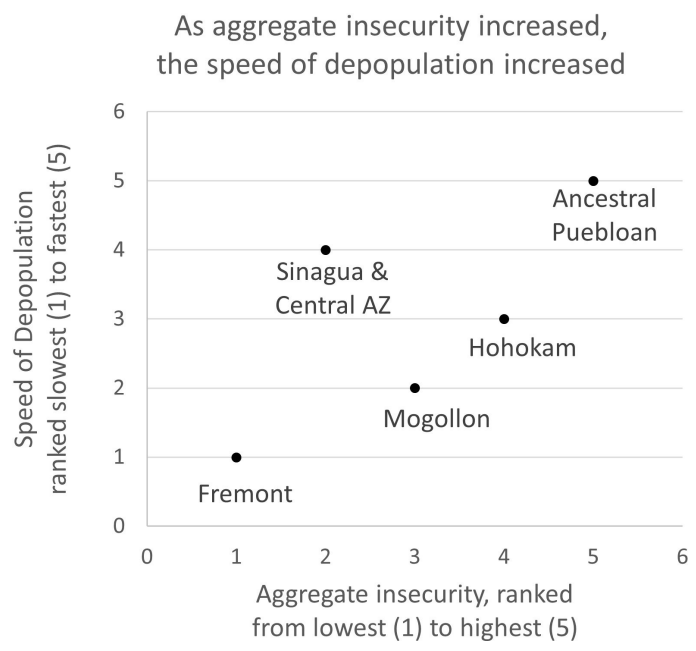

securities and their influence on SW/NW depopulation. Rather, we expect interpretations to evolve as data continue to accumulate. The global urgency of challenges to the sustainability of social-ecological systems has motivated us to intentionally push the boundaries of what has been previously attempted and is possible with the available data. For archaeologists working on depopulation issues in other regions of the world, we recommend applying the approach presented here to expand the range of cases that investigate the human securities-depopulation relationship. For archaeologists of the SW/NW, we recommend investigating the relationship between human securities and depopulation within culture areas at smaller spatial and temporal scales than we have attempted here.

We also recommend identifying conditions in the SW/NW (and elsewhere) that promoted the sustainability of places, rather than depopulation. These conditions can be identified by comparing those areas and conditions where people persisted and securities improved to those where substantial depopulation occurred. Such comparative studies of key variables and outcomes in the past (Diamond and Robinson 2010, Smith 2012) can be a rich source of insights for sustainability planning. Studies of conditions in the present can more accurately measure insecurities, identify the interaction effects of insecurities, and identify chains of causality. Whether or not securities will improve and communities persist, however, is unknown. Studies of conditions in the past have access to less specific data but the outcomes, whether or not securities improved or deteriorated and if depopulation occurred, are known. Other outcomes can also be investigated (e.g., large scale vs. small scale migrations).

\section{DISCUSSION}

\section{A contagion of insecurity as a mechanism for regional-scale depopulation}

Depopulation across the region follows a north to south pattern over time (Table 1, Fig. 1; Hill et al. 2010). Depopulation began in the mid-1100s in the Fremont area (Allison 2019) and in the mid-1200s in Ancestral Puebloan area (Varien 2010), where aggregated insecurities were the highest in the region (Table 3). Depopulation in the densely populated Mesa Verde region (SW Colorado) of the Ancestral Puebloan culture area was comprised mostly of migration south into Arizona and southeast into New Mexico (Clark et al. 2019) rather than population loss (Ortman 2012). Some research has documented greater security in one migration destination area along the northern Rio Grande River in central New Mexico (Ortman 2016). Although conditions creating insecurity can decrease when people move away from insecure places, new insecurities can result simply from being a migrant (Amnesty International 2010).

The insight that emerges from the human security framework and the results here is that perceived insecurities may have been a mechanism for increasing insecurities in destination areas. In other words, a mechanism for the progressive regional scale rather than limited northern sub-regional depopulation is a contagion of insecurity. As many as 10,000 people were moving from the northern SW into the southern SW (Clark et al. 2019) and possibly NW Mexico during the late 1200s. Even if insecurities were not untenable in destination areas, the knowledge of unprecedented numbers of people on the move likely would have generated insecurities in potential destination areas. If the sources of insecurities were primarily perceived rather than actual, this might explain, for example, why direct evidence of conflict and violence in the Phoenix basin (Hohokam culture area) does not match the substantial change in residential and community architecture to more defensible spaces (e.g., walled residential compounds with limited access). Similarly, evidence for violence in some parts of the Kayenta area (NE Arizona) of the Ancestral Puebloan region was apparently minimal (Dean 2010). People from this area, however, were not able to avoid the contagion of insecurity generated by their migrating neighbors from the north. They also later chose to migrate.

Sustainability and its depopulation indicator are multi-causal phenomena. Single-cause explanations for either likely will not be found in the past or future. Use of the human security approach in this study has clarified and documented prevalent conditions throughout the SW/NW region. The regional-scale loss of sustainability can be explained, at least in part, by the proximate cause of accumulating and interacting human insecurities. Ultimate causes of individual insecurities were not the focus here, but it seems clear that beginning in the 13th century, existing social and environmental configurations and social units (e.g., families, villages) were losing their ability to provide for the basic human needs of freedom from want, freedom from fear, and freedom to live in dignity. Many people chose to move away from the places where insecurities had taken root. This movement created a contagion of insecurity across the region resulting in human population loss, substantial settlement relocation, and accelerated migration - the loss of sustainability of place.

\section{Sustainability in the Southwest/Northwest region}

The focus of this study is depopulation and a loss of sustainability, but the history of the SW/NW is also one of persistence and continuity. The indigenous peoples of the SW/NW did not vanish during this critical period in the history of the region. There are 47 federally recognized tribes in the U.S. SW and five tribes with traditional territories in the Mexican NW (Colwell- 
Chanthaphonh 2010). Many are the descendants of those that experienced this decline and persisted. In some cases, the archaeological invisibility of persistent peoples and places limits current understanding among archaeologists of the extent and distribution of people during the late 1400s until the arrival of the Spanish in the SW, 1540. Archaeological challenges do not, however, influence the knowledge Native peoples have of their own histories. Memories of challenging periods, such as the focus of this study, are sometimes shared and interpretations offered (Teague 1993, Bahr et al. 1994, Hayes-Gilpin and Lomatewama 2013).

People continued to live in at least 10 areas in the SW/NW through the period of depopulation, a conclusion based on archaeological and historical evidence (oral and written). Places with continuity include Hopi (NE Arizona), Zuni (NW New Mexico), Acoma (west central New Mexico), along the northern Rio Grande River in central New Mexico (Hill et al. 2010), along the Colorado River separating Arizona and Nevada (Rogers 1945), the Middle Gila River in Arizona (Loendorf and Lewis 2017), and possibly in the San Pedro Valley (Hill et al. 2015). Populations also remained in many areas in the Mexican NW such as the Rio Sonora (Pailes 2017), Casas Grandes (Whalen and Minnis 2017), and Trincheras culture areas (Gallaga and Newell 2004), although many of the densely populated central places such as Paquimé and Cerros de Trincheras were depopulated. The identities of people that persisted in NW Mexico are, however, unclear because of inmigration.

\section{Speculation: insights from the past for the future}

The depopulation of the SW/NW is an indicator of a large-scale decline in the sustainability of a region and an analog for the type of problem modern efforts seek to avoid. This historical study of initial conditions and consequences allows us to reason by analogy and generate insights for a more complete understanding of the problem. What has been learned for the present and future? In response to this question, we offer some insights from this study for policy makers, sustainability scientists, and the public and assimilate more that have emerged from the work of others on depopulation in the SW/NW. These insights are meant to stimulate a deeper understanding of human behavior and historical processes and generate useful questions for sustainability policy planning.

1. Holistic efforts by the United Nations to improve human securities to enhance the sustainability of regions and decrease migration are supported by the results of this study. This analysis of long-term historic cases revealed that as insecurities accumulated, the speed of depopulation and associated migration increased. Depopulation is an ex post facto indicator of the loss of sustainability of places. We hope this finding is helpful and contributes to the accumulating case study evidence supporting the human security framework and the link between human securities, sustainable development, and migration. For the modern world where population levels are much higher it is, however, likely that if increasing security involves substantial resource investments and unlimited economic growth through consumption, a negative impact on sustainability will eventually occur.

2. The extent of migration out of sub-regions (culture areas), specifically, the proportion of people deciding to leave, need not be directly related to the extent or category of insecurities. For example, archaeological studies of sub-regional depopulations have revealed that when environmental conditions (e.g., drought) negatively impacted food security, areas of productivity remained that could have supported reduced population levels (Van West 1996, Schwindt et al. 2016). However, entire communities across large areas moved and people aggregated into new social and settlement configurations leaving vast areas unoccupied. Similarly, to the extent that conflict contributes to depopulation, SW/NW archaeologists do not observe the "winners" remaining in newly acquired territories. In other words, although we identified a moderately strong, positive linear relationship between the extent of insecurities and the speed of depopulation, the result was substantial population loss, reorganization, and out-migration throughout the region, regardless of the extent of insecurities. This suggests that social responses to widespread and increasing insecurities were not linear. Thus, sustainability research and planning efforts that identify and expect social thresholds, tipping points, and emergent behavior-the characteristics of complex adaptive systems (Carmichael and Hadžikadić 2019) — will likely be most effective.

3. Once sub-regional out-migration occurs and securities improve, people may not return. For example, a severe drought and associated environmental insecurities in the late 1200s has long been considered as one of many factors that contributed to people's decisions to move out of the northern Southwest, especially the Mesa Verde region of SW Colorado (Douglass 1929). After the drought ended ( 1299) a period of unprecedented wet conditions throughout the SW began in the early 1300 s (Ingram 2014). These favorable conditions for agricultural success, the opportunity to re-settle in their ancestral homelands (apparently unoccupied), and the relatively short distances back to these homelands did not induce people to return. We do not know why people did not return; however, this outcome does suggest the need for a better understanding of human perceptions and decision making associated with newly unsettled areas.

4. A loss of sustainability in one place can affect sustainability in distant places. Thousands of people migrated from the northern SW and we suspect the migrants created insecurities throughout their destination areas in the southern SW and NW Mexico. Although it might be convenient to focus on the sustainability of our own community, if insecurities arise in one place, responses can start to impinge on others and a contagion of insecurity can develop. If this speculation is correct, then broad-scale responses to emerging insecurities will be critical for maintaining regionalscale sustainability.

5. Simplistic, single cause explanations (e.g., drought, resource exploitation, over-population) of complex sustainability challenges such as the depopulation of the SW/NW should be replaced with an acceptance of multi-causality. This study (as well as countless other archaeological studies of the past, see for example Varien 2010) demonstrates how depopulation can only be explained by multiple and interacting factors, which themselves have their own complex causal chains. Similarly, it is important for modern planning efforts to distinguish between proximate (nearest in time and space) and ultimate causes (essential for initiating the chain of causality). The long-term, multigenerational duration of the loss of the sustainability of existing social configurations in the $\mathrm{SW} / \mathrm{NW}$ region as well as the 
archaeological consensus (and lack thereof) on the causes demonstrates that simple explanations and solutions are unwarranted. As we work and aspire toward future sustainability, approaches that pursue an "all of the above" strategy are likely the most productive. We should question political actors and policies that offer overly simple explanations and solutions to complex phenomena.

6. Loss of sustainability is a multi-generational phenomenon; it is a process, not an event. The slowest sub-regional depopulation occurred over six generations, about 150 years (Fremont culture area). The fastest depopulation occurred over about two generations (in the northern portion of the Ancestral Puebloan culture area). It will be easy for humans to defer decision making on slow-moving problems, but insecurities can continue to accumulate without action.

7. Sustainability is not just an environmental concern. If sustainability is only considered as an environmental issue, the depopulation of the SW/NW is a strong counter argument. We did not find strong evidence of extensive resource degradation (the food insecurity indicator) throughout the region, although local examples exist (Kohler and Matthews 1988, Hill et al. 2015). Systematic synthesis of available and comparable environmental data is necessary to evaluate this finding further. Drought impacts on sub-regional depopulations should, however, remain a focus of future investigations - not as ultimate causes (they were not often temporally coincident with the initiation of depopulations) but as proximate and exacerbating conditions (see the environmental insecurity indicator). The two major pulses of depopulation in the SW/NW (the late 1200s and mid-1400s) temporally coincide with "megadroughts" at 1271 to 1297 and 1435 to 1478 (Cook et al. 2016). Drought is endemic in the SW/ NW and we suspect accumulating insecurities lessened the effectiveness of existing strategies which had long-been effective, and increased vulnerability to drought.

8. Migration is a resilient strategy for maintaining the sustainability of human groups (e.g., Spielmann et al. 2011). The indigenous peoples of the SW/NW region persist, some in their ancestral homelands. Migration was and remains a way of life in the region (Naranjo 1995, Nelson and Schachner 2002, Kuwanwisiwma et al. 2018, Duwe and Preucel 2019). This view is consistent with modern sustainability approaches that recognize that migration is not always a problem to be solved but rather a process that can benefit people and host countries. This study also demonstrates that migration can be an indicator of insecurities in the area from which people migrate. Although we have used extensive out-migration as an indicator of a loss of regional-scale sustainability, migration at the scale of households and communities is a human adaptive strategy that has sustained our species and indigenous peoples of the SW/NW for millennia. Policies that unnecessarily prevent migration diminish this shared human strategy.

\section{CONCLUSION}

The work presented has multiple objectives and seeks to communicate with several audiences. First, we aspired to contribute insights toward social-ecological sustainability planning by evaluating existing policy assumptions about the relationship between human securities, sustainability, and migration. The asserted relationships were affirmed. Second, we intended to advance understanding of the 13th through 15th century SW/NW depopulation. A new, more spatially comprehensive assessment of conditions that likely influenced human decisions to migrate and were responsible for substantial population loss was identified. We provided a comprehensive source (Appendix 2) for future and improved efforts. Finally, we were inspired to respond to the questions posed by the "Grand challenges for archaeology" (Kintigh et al. 2014:880): "Can we characterize social collapse or decline in a way that is applicable across cultures?" and "What are the relationships among environment, population dynamics, settlement structure, and human mobility?" We have presented some partial answers to these questions and hope to have demonstrated rather than asserted the relevance of archaeology to modern sustainability efforts.

Responses to this article can be read online at: https://www.ecologyandsociety.org/issues/responses. php/12312

\begin{abstract}
Acknowledgments:
We thank the 13 scholars of the archaeology of the U.S. Southwest and Mexican Northwest who reviewed and commented on the paper andlor the evidence of human insecurities presented in the Appendices. We also thank the coders, named in Appendix 2, who participated in this research. All remaining errors are our own.
\end{abstract}

Data Availability:

Data are presented in the tables and included appendices.

\section{LITERATURE CITED}

Adler, M. A., T. Van Pool, and R. D. Leonard. 1996. Ancestral Pueblo population aggregation and abandonment in the North American Southwest. Journal of World Prehistory 10(3):375-438. https://doi.org/10.1007/BF02286420

Ahlstrom, R. V. N., C. R. Van West, and J. S. Dean. 1995. Environmental and chronological factors in the Mesa VerdeNorthern Rio Grande migration. Journal of Anthropological Archaeology 14:125-142. https://doi.org/10.1006/jaar.1995.1007

Allison, J. R. 2019. The northern frontier in the history of the greater Southwest. Pages 281-307 in K. G. Harry and B. J. Roth, editors. Interaction and connectivity in the greater Southwest. University Press of Colorado, Louisville, Colorado, USA. https:// doi.org/10.5876/9781607327356.c013

Altschul, J. H., K. W. Kintigh, M. Aldenderfer, E. Alonzi, I. Armit, J. A. Barceló, C. S. Beekman, P. Bickle, D. W. Bird, S. E. Ingram, E. Isayev, A. W. Kandel, R. Kiddey, H. T. KienonKaboré, F. Niccolucci, C. S. Ragsdale, B. K. Scaffidi, and S. G. Ortman. 2020. Opinion: To understand how migrations affect human securities, look to the past. Proceedings of the National Academy of Sciences 117(34):20342-20345. https://doi.org/10.1073/ pnas. 2015146117

Altschul, J. H., K. W. Kintigh, T. H. Klein, W. H. Doelle, K. A. Hays-Gilpin, S. A. Herr, T. A. Kohler, B. J. Mills, L. M. 
Montgomery, M. C. Nelson, et al. 2017. Opinion: fostering synthesis in archaeology to advance science and benefit society. Proceedings of the National Academy of Sciences 114 (42):10999-11002. https://doi.org/10.1073/pnas.1715950114

Amnesty International. 2010. Invisible victims: migrants on the move in Mexico. Amnesty International, London, UK. [online] URL: https://www.amnestyusa.org/wp-content/uploads/2017/04/ amr410142010eng.pdf

Anthony, D. W. 1990. Migration in archaeology: the baby and the bathwater. American Anthropologist 92(4):895-914. https://doi. org/10.1525/aa.1990.92.4.02a00030

Bahr, D., J. Smith, W. S. Allison, and J. Hayden. 1994. The short, swift time of gods on earth. University of California Press, Berkeley, California, USA. https://doi.org/10.1525/9780520914568

Benson, L. V., and M. S. Berry. 2009. Climate change and cultural response in the prehistoric American Southwest. Kiva 75 (1):87-117. https://doi.org/10.1179/kiv.2009.75.1.005

Brandt, E. A. 1994. Egalitarianism, hierarchy, and centralization in the pueblos. Pages 9-23 in W. H. Wills and R. D. Leonard, editors. The ancient Southwestern community. University of New Mexico Press, Albuquerque, New Mexico, USA.

Braun, D. P., and S. Plog. 1982. Evolution of "tribal" social networks: theory and prehistoric North American evidence. American Antiquity 47(3):504-525. https://doi.org/10.2307/280232

Cameron, C. M. 1995. Migration and the movement of Southwestern peoples. Journal of Anthropological Archaeology 14:104-124. https://doi.org/10.1006/jaar.1995.1006

Carmichael, T., and M. Hadžikadić. 2019. The fundamentals of complex adaptive systems. Pages 1-16 in T. Carmichael, A. J. Collins, and M. Hadžikadić, editors. Complex adaptive systems: views from the physical, natural, and social sciences. Springer Nature, Cham, Switzerland. https://doi.org/10.1007/978-3-030-20309-2_1

Clark, J. J., J. A. Birch, M. Hegmon, B. J. Mills, D. M. Glowacki, S. G. Ortman, J. S. Dean, R. Gauthier, P. D. Lyons, M. A. Peeples, et al. 2019. Resolving the migrant paradox: two pathways to coalescence in the late precontact U.S. Southwest. Journal of Anthropological Archaeology 53:262-287. https://doi.org/10.1016/ j.jaa.2018.09.004

Colwell-Chanthaphonh, C. 2010. Living histories: Native Americans and Southwestern archaeology. Altamira, Lanham, Maryland, USA.

Cook, B. I., E. R. Cook, J. E. Smerdon, R. Seager, A. P. Williams, S. Coats, D. W. Stahle, and J. V. Diaz. 2016. North American megadroughts in the Common Era: reconstructions and simulations. WIREs Climate Change 7(3):411-432. https://doi. org/10.1002/wcc.394

Cook, E. R., R. Seager, R. R. Heim Jr., R. S. Vose, C. Herweijer, and C. Woodhouse. 2010. Megadroughts in North America: placing IPCC projections of hydroclimatic change in a long-term palaeoclimate context. Journal of Quaternary Science 25:48-61. https://doi.org/10.1002/jqs. 1303

Cooper, J., and P. Sheets, editors. 2012. Surviving sudden environmental change: answers from archaeology. University Press of Colorado, Boulder, Colorado, USA. https://doi.org/10.2307/ j.ctt1wn0rbs

Cordell, L. S., and M. McBrinn. 2012. Archaeology of the Southwest: Routledge, London, UK.

Cowgill, G. L. 1975. On causes and consequences of ancient and modern population changes. American Anthropologist 77:505-525. https://doi.org/10.1525/aa.1975.77.3.02a00030

Dean, J. S. 1996. Demography, environment and subsistence stress. Pages 25-56 in J. Tainter and. B. Bagley-Tainter, editors. Evolving complexity and environmental risk in the prehistoric Southwest. CRC, Boca Raton, Florida, USA. https://doi. org/10.1201/9780429492587-2

Dean, J. S. 2010. The environmental, demographic, and behavioral context of the thirteenth-century depopulation of the northern Southwest. Pages 324-345 in M. D. Varien. T. A. Kohler, A. M. Wright, editors. Leaving Mesa Verde: peril and change in the thirteenth-century Southwest. The University of Arizona Press, Tucson, Arizona, USA.

Dean, J. S., W. H. Doelle, and J. D. Orcutt. 1994. Adaptive stress, environment, and demography. Pages 53-86 in G. J. Gumerman, editor. Themes in Southwest prehistory. School of American Research Press, Santa Fe, New Mexico, USA.

Diamond, J., and J. A. Robinson. 2010. Natural experiments of history. Harvard University Press, Cambridge, Massachusetts, USA. https://doi.org/10.2307/j.ctvjghwf6

Doelle, W. H. 2000. Tonto basin demography in a regional perspective. Pages 81-105 in J. S. Dean, editor. Salado. University of New Mexico Press, Albuquerque, New Mexico, USA.

Dongoske, K. E., M. Yeatts, R. Anyon, and T. J. Ferguson. 1997. Archaeological cultures and cultural affiliation: Hopi and Zuni perspectives in the American Southwest. American Antiquity 62:600-608. https://doi.org/10.2307/281880

Douglass, A. E. 1929. The secret of the Southwest solved by talkative tree-rings. National Geographic Magazine 56:737-770.

Duwe, S., and R. W. Preucel. 2019. The continuous path: Pueblo movement and the archaeology of becoming. University of Arizona Press, Tucson, Arizona, USA. https://doi.org/10.2307/j. ctvf34hhg

Ember, C. R., and M. Ember. 2009. Cross-cultural research methods. Altamira, Lanham, Maryland, USA.

Gallaga, E., and G. E. Newell. 2004. Introduction. Pages 1-26 in G. E. Newell and E. Gallaga, editors. Surveying the archaeology of Northwest Mexico. University of Utah Press, Salt Lake City, Utah, USA.

Glowacki, D. M. 2015. Living and leaving: a social history of regional depopulation in thirteenth-century Mesa Verde. University of Arizona Press, Tucson, Arizona, USA. https://doi.org/10.2307/ j.ctt183pddh

Gomez, O. A., and D. Gasper. 2013. Human security: a thematic guidance note for regional and national human development report teams. United Nations Development Programme, Human Development Report Office, New York, New York, USA. [online] URL: http://hdr.undp.org/en/content/human-security-guidance$\underline{\text { note }}$ 
Graybill, D. A., D. A. Gregory, G. S. Funkhouser, and F. Nials. 2006. Long-term streamflow reconstructions, river channel morphology, and aboriginal irrigation systems along the Salt and Fila rivers. Pages 69-123 in D. E. Doyel and J. S. Dean, editors. Environmental change and human adaptation in the ancient American Southwest. The University of Utah Press, Salt Lake City, Utah, USA.

Gumerman, G. J., editor. 1988. The Anasazi in a changing environment. Cambridge University Press, Cambridge, UK.

Haas, J., and W. Creamer. 1996. The role of warfare in the Pueblo III period. Pages 205-213 in M. A. Adler, editor. The prehistoric Pueblo world, AD 1150-1350. The University of Arizona Press, Tucson, Arizona, USA.

Halstead, P., and J. O'Shea, editors. 1989. Bad year economics: cultural responses to risk and uncertainty. Cambridge University Press, Cambridge, UK. https://doi.org/10.1017/CBO9780511521218

Hays-Gilpin, K., and R. Lomatewama. 2013. Some contemporary Pueblo perspectives on archaeology in the Pueblo world. Kiva 78(3):229-246. https://doi.org/10.1179/0023194013Z.0000000001

Hegmon, M. 2016. Archaeology of the human experience: an introduction. Archaeological Papers of the American Anthropological Association 27:7-21. https://doi.org/10.1111/apaa.12071

Hegmon, M., M. A. Peeples, A. P. Kinzig, S. Kulow, C. M. Meegan, and M. C. Nelson. 2008. Social transformation and its human costs in the Prehispanic U.S. Southwest. American Anthropologist 110(3):313-324. https://doi.org/10.1111/

j.1548-1433.2008.00041.x

Hegmon, M., M. A. Peeples, on behalf of the LTVP Collaboration. 2018. The human experience of social transformation: insights from comparative archaeology. PLoS ONE 13(11):e0208060. https://doi.org/10.1371/journal.pone.0208060

Hill, J. B., J. J. Clark, W. H. Doelle, and P. D. Lyons. 2004. Prehistoric demography in the Southwest: migration, coalescence, and Hohokam population decline. American Antiquity 69 (4):689-716. https://doi.org/10.2307/4128444

Hill, J. B., P. D. Lyons, J. J. Clark, and W. H. Doelle. 2010. Depopulation of the northern Southwest: a macroregional perspective. Pages 34-52 in T. A. Kohler, M. D. Varien, and A. M. Wright, editors. Leaving Mesa Verde: peril and change in the thirteenth-century Southwest. The University of Arizona Press, Tucson, Arizona, USA.

Hill, J. B., P. D. Lyons, J. J. Clark, and W. H. Doelle. 2015. The "collapse" of cooperative Hohokam irrigation in the Lower Salt River Valley. Journal of the Southwest 57(4):609-674. https://doi. org/10.1353/jsw.2015.0015

Hill, J. B., D. Wilcox, W. Doelle, and W. Robinson. 2012. Coalescent communities database version 2.0. Archaeology Southwest, Tucson, Arizona, USA.

Ingram, S. E. 2014. Climatic, demographic, and environmental influences on central Arizona settlement patterns. Pages 23-51 in D. Abbott and K. A. Spielmann, editors. Alliance and landscape on Perry Mesa in the fourteenth century. University of Utah Press, Salt Lake City, Utah, USA.
Ingram, S. E., and R. C. Hunt, editors. 2015. Traditional arid lands agriculture: understanding the past for the future. University of Arizona Press, Tucson, Arizona, USA.

Kintigh, K. W., J. H. Altschul, M. C. Beaudry, R. D. Drennan, A. P. Kinzig, T. A. Kohler, W. F. Limp, H. D. G. Maschner, W. K. Michener, T. R. Pauketat, P. Peregrine, J. A. Sabloff, T. J. Wilkinson, H. T. Wright, and M. A. Zeder. 2014. Grand challenges for archaeology. Proceedings of the National Academy of Sciences 111(3):879-880. https://doi.org/10.1073/pnas.1324000111

Kohler, T. A., and M. H. Matthews. 1988. Long-term Anasazi land use and forest reduction: a case study from southwest Colorado. American Antiquity 53(3):537-564. https://doi. org/10.2307/281216

Kohler, T. A., M. D. Varien, and A. M. Wright, editors. 2010. Leaving Mesa Verde: peril and change in the thirteenth-century Southwest. The University of Arizona Press, Tucson, Arizona, USA.

Kuwanwisiwma, L. J., T. J. Ferguson, and C. Colwell. 2018. Footprints of Hopi history: Hopihiniwtiput kukveni'at. University of Arizona Press, Tucson, Arizona, USA. https://doi.org/10.2307/ j.ctt1zxsmmc

LeBlanc, S. A. 1999. Prehistoric warfare in the American Southwest. University of Utah Press, Salt Lake City, Utah, USA.

Lipe, W. D. 1995. The depopulation of the northern San Juan: conditions in the turbulent 1200s. Journal of Anthropological Archaeology 14:143-169. https://doi.org/10.1006/jaar.1995.1008

Loendorf, C., and B. V. Lewis. 2017. Ancestral O'odham: Akimel O'odham cultural traditions and the archaeological record. American Antiquity 82(1):123-139. https://doi.org/10.1017/ aaq.2016.17

Lowder, S. K., J. Skoet, and T. Raney. 2016. The number, size, and distribution of farms, smallholder farms, and family farms worldwide. World Development 87:16-29. https://doi.org/10.1016/ j.worlddev.2015.10.041

Martin, D. L. 1994. Patterns of health and disease: stress profiles for the prehistoric Southwest. Pages 87-108 in G. J. Gumerman, editor. Themes in Southwestern prehistory. University of New Mexico Press, Albuquerque, New Mexico, USA.

Naranjo, T. 1995. Thoughts on migration by Santa Clara Pueblo. Journal of Anthropological Archaeology 14(2):247-250. https:// doi.org/10.1006/jaar.1995.1013

Nelson, M. C., M. Hegmon, K. W. Kintigh, A. P. Kinzig, B. A. Nelson, J. M. Anderies, D. A. Abbott, K. A. Spielmann, S. E. Ingram, M. A. Peeples, S. Kulow, C. A. Strawhacker, and C. Meegan. 2012. Long-term vulnerability and resilience: three examples from archaeological study in the Southwestern United States and northern Mexico. Pages 197-222 in J. Cooper and P. Sheets, editors. Surviving sudden environmental change. University Press of Colorado, Boulder, Colorado, USA.

Nelson, M. C., S. E. Ingram, A. J. Dugmore, R. Streeter, M. A. Peeples, T. H. McGovern, M. Hegmon, J. Arneborg, K. W. Kintigh, S. Brewington, K. A. Spielmann, I. A. Simpson, C. Strawhacker, L. E. L. Comeau, A. Torvinen, C. K. Madsen, G. Hambrecht, and K. Smiarowski. 2016. Climate challenges, 
vulnerabilities, and food security. Proceedings of the National Academy of Sciences 113(2):298-303. https://doi.org/10.1073/ pnas. 1506494113

Nelson, M. C., and G. Schachner. 2002. Understanding abandonments in the North American Southwest. Journal of Archaeological Research 10(2):167-206. https://doi.org/10.1023/ A:1015285822642

O'Brien, K., and J. Barnett. 2013. Global environmental change and human security. Annual Review of Environment and Resources 38:373-391. https://doi.org/10.1146/annurev-environ-032112-100655

Ortiz, A., editor. 1979. Handbook of North American Indians. Southwest. Smithsonian Institution, Washington, D.C., USA.

Ortman, S. G. 2012. Winds from the north: Tewa origins and historical anthropology. University of Utah Press, Salt Lake City, Utah, USA.

Ortman, S. G. 2016. Discourse and human securities in Tewa origins. Archeological Papers of the American Anthropological Association 27:79-94. https://doi.org/10.1111/apaa.12075

Owen, T. 2013. Human security mapping. Pages 308-318 in M. Martin and T. Owen, editors. Routledge handbook of human security. Routledge, London, UK. https://doi.org/10.4324/9781315885926. $\underline{\operatorname{ch} 24}$

Pailes, M. 2017. Northwest Mexico: the prehistory of Sonora, Chihuahua, and neighboring areas. Journal of Archaeological Research 25:373-420. https://doi.org/10.1007/s10814-017-9103-5

Phillips Jr., D. A., H. J. Wearing, and J. J. Clark. 2018. Village growth, emerging infectious disease, and the end of the Neolithic demographic transition in the southwest United States and northwest Mexico. American Antiquity 83(2):263-280. https://doi. org/10.1017/aaq.2018.3

Railey, J. A., and R. M. Reycraft, editors. 2008. Global perspectives on the collapse of complex societies. Maxwell Museum of Anthropology, Albuquerque, New Mexico, USA.

Redman, C. L. 2014. Should sustainability and resilience be combined or remain distinct pursuits? Ecology and Society 19 (2):37. https://doi.org/10.5751/ES-06390-190237

Rick, T. C., and D. H. Sandweiss. 2020. Archaeology, climate, and global change in the age of humans. Proceedings of the National Academy of Sciences 117(15):8250-8253. https://doi.org/10.1073/ pnas. 2003612117

Risse, N. 2019. Officials stress relevance of human security in SDG era. SDG Knowledge Hub, 5 March. [online] URL: https:// sdg.iisd.org/news/officials-stress-relevance-of-human-security-insdg-eral

Robinson, E., R. K. Bocinsky, D. Bird, J. Freeman, and R. L. Kelly. 2021. Dendrochronological dates confirm a Late Prehistoric population decline in the American Southwest derived from radiocarbon dates. Philosophical Transactions of the Royal Society B 376:1-8. https://doi.org/10.1098/rstb.2019.0718

Rockman, M., and C. Hritz. 2020. Expanding use of archaeology in climate change response by changing its social environment. Proceedings of the National Academy of Sciences 117 (15):8295-8302. https://doi.org/10.1073/pnas.1914213117
Rogers, M. J. 1945. An outline of Yuman prehistory. Southwestern Journal of Anthropology 1(2):167-198. https://doi.org/10.1086/ soutjanth.1.2.3628758

Salzer, M. W. 2000. Temperature variability and the Northern Anasazi: possible implications for regional abandonment. Kiva 65(4):295-318. https://doi.org/10.1080/00231940.2000.11758414

Schwindt, D. M., R. K. Bocinsky, S. G. Ortman, D. M. Glowacki, M. D. Varien, and T. A. Kohler. 2016. The social consequence of climate change in the central Mesa Verde region. American Antiquity 81(1):74-96. https://doi.org/10.7183/0002-7316.81.1.74

Smith, M. E., editor. 2012. The comparative archaeology of complex societies. Cambridge University Press, New York, New York, USA. https://doi.org/10.1017/CBO9781139022712

Spielmann, K. A., M. Nelson, S. Ingram, and M. A. Peeples. 2011. Sustainable small-scale agriculture in semi-arid environments. Ecology and Society 16(1):26. https://doi.org/10.5751/ES-03814-160126

Teague, L. S. 1993. Prehistory and the traditions of the O'odham and Hopi. Kiva 58(4):435-454. https://doi.org/10.1080/00231940.1993 .11758220

United Nations Development Programme. 1994. Human development report 1994. Oxford University Press, Oxford, UK.

United Nations Human Security Unit. 2009. Human security in theory and practice; application of the human security concept and the United Nations Trust Fund for Human Security. United Nations Trust Fund for Human Security, New York, New York, USA.

United Nations Human Security Unit. 2016. Human security handbook: an integrated approach for the realization of the sustainable development goals and the priority areas of the international community and the United Nations system. United Nations Trust Fund for Human Security, New York, New York, USA.

van der Leeuw, S., and C. Redman. 2002. Placing archaeology at the center of socio-natural studies. American Antiquity 67 (4):597-605. https://doi.org/10.2307/1593793

Van West, C. R. 1996. Agricultural potential and carrying capacity in southwestern Colorado, A.D. 901 to 1300. Pages 214-227 in M. A. Adler, editor. The prehistoric Pueblo world, A. D. 1150-1350. University of Arizona Press, Tucson, Arizona, USA.

Van West, C. R., and J. S. Dean. 2000. Environmental characteristics of the A.D. $900-1300$ period in the Central Mesa Verde region. Kiva 66(1):19-44. https://doi.org/10.1080/0023194$\underline{0.2000 .11758420}$

Varien, M. D. 2010. Depopulation of the northern San Juan region: historical review and archaeological context. Pages 1-33 in T. A. Kohler, M. D. Varien, and A. M. Wright, editors. Leaving Mesa Verde: peril and change in the thirteenth-century southwest. The University of Arizona Press, Tucson, Arizona, USA.

Vietti, F., and T. Scribner. 2013. Human insecurity: understanding international migration from a human security perspective. Journal on Migration and Human Security 1(1):17-31. https://doi. org/10.1177/233150241300100102 
Whalen, M. E., and P. E. Minnis. 2017. Chihuahuan archaeology. Pages 397-410 in B. J. Mills and S. Fowles, editors. The Oxford handbook of Southwest archaeology. Oxford University Press, Oxford, UK. https://doi.org/10.1093/oxfordhb/9780199978427.013.20 
Appendix 1: Insecurities Coding: Relationships, Proxies, Questions, Definitions, Uncertainties

Appendix 1 provides additional information on the coding procedures for the seven human securities categories in eight culture areas. There is no standard set of insecurity indicators in the present or archaeologically; indicators are selected based on available data, assessor judgments, and assessment objectives (Human Security Unit 2016). Indicator selection in this study was driven by the need for comparable data throughout the region and limited by the types of data and archaeological proxies available. We expect future archaeological studies will improve and rely on an expanded range of indicators.

\section{Economic insecurity (Indicator: decreasing trade and exchange)}

Plausible relationship with sustainability and depopulation: As trade and exchange networks declined, opportunities to engage social strategies for buffering risks decrease (e.g., alliances, reciprocity) and economic insecurity increased (Braun and Plog 1982). Risks (real or perceived) that cannot be buffered can lead to strategies such as migration to mitigate risks.

Proxies used to assess indicator: extent of non-local pottery and other goods in settlements

Assessment question for coding: What was the extent of interregional trade/exchange relative to previous periods? (Note that a coding of "Low" insecurity reflects a high level of trade and exchange.)

Low: Abundant evidence of non-local artifacts in quantities likely exceeding those for individual or household consumption.

Moderate: Evidence of the presence of multiple non-local artifact classes in moderate quantities likely for individual or household consumption.

High: Evidence of primarily localized production of primary artifact classes (e.g., pottery, lithics) or the presence of a limited amount of non-local artifacts from only a few artifact classes (e.g., minimal quantities of non-local sherds).

\section{Food insecurity (Indicator: increasing resource depletion/degradation)}

Plausible relationship with sustainability and depopulation: As resources relied on for food decrease, food insecurity increased. Perceptions of better conditions elsewhere can stimulate movement to lessen food insecurity (Halstead and O'Shea 1989). Population levels will decline when insufficient food decreases fertility and increases mortality.

Proxies used to assess indicator: declining diet breadth, change in previous resource procurement strategies (for example, shifting from cultivated to wild foods or vice versa), 
increased reliance on smaller or more immature mammals, increasing soil degradation, bioarchaeological indicators of food stress.

Assessment question for coding: What was the extent and severity of resource depletion and degradation relative to previous periods?

Low: Little to no shift in dietary breadth or subsistence strategies and or minimal bioarchaeological evidence of nutritional stress.

Moderate: Limited evidence of shifting subsistence strategies on a local level and limited bioarchaeological evidence of nutritional stress.

High: Abundant bioarchaeological evidence of nutritional stress, evidence of shifting subsistence strategies (ex. increased reliance on wild foods, decreased prevalence of former staple crops), evidence for significant soil degradation, evidence for decreased availability local arable land.

\section{Health insecurity (Indicator: increasing settlement aggregation and bioarchaeological evidence of disease)}

Plausible relationship with sustainability and depopulation: As people lived increasingly closer together in aggregated settlements, mechanisms for disease transmission increased (Martin 1994:105; Phillips et al. 2018:266), mortality increased, health insecurity increased, and decisions to migrate increased. This plausible relationship is based on the link between aggregation/urbanization and increases in the vulnerability to infectious diseases.

Proxies used to assess indicator: spatial clustering of households into larger communities; skeletal indicators of health/disease.

Assessment question for coding: What was the extent of settlement aggregation and bioarchaeological evidence of disease relative to previous periods?

Low: Little to no change in the extent of settlement aggregation

Moderate: Evidence of settlement aggregation but settlement sizes are not substantially increasing from previous periods. Some bioarchaeological evidence may be available for increasing levels of disease or infection.

High: Evidence of increasing settlement aggregation with relatively large settlement sizes and bioarchaeological evidence for increasing diseases compared to prior periods.

Note: In addition to coding this insecurity based on published scholarly assessments of the extent of aggregation, we calculated an aggregation index for each culture area using settlement data in the Coalescent Communities Database (Hill et al. 2012). Our index is: total number of documented rooms (within settlements and used as an indicator of population levels) in a culture area divided by the total number of settlements in each area. The percent change in the index 
from the 50-year interval prior to depopulation and during the initiation of depopulation informs the coding. Where settlement data are available, we present these percentage changes in the evidence to support the coding.

\section{Environmental insecurity (Indicator: increasing relative climatic dryness)}

Plausible relationship with sustainability and depopulation: As dryness increased, wild and cultivated food resources decreased, and environmental insecurity increased. Resource shortfalls (real or perceived) can stimulate movement toward more productive areas (Halstead and O'Shea 1989) and insufficient food decreases fertility and increases mortality.

Proxies used to assess indicator: Average Palmer Drought Severity Index (PDSI) during depopulation compared to average prior period PDSI. Summer (June, July, August) growing season precipitation retrodictions from tree-rings are used to identify PDSI (Cook et al. 2010, data available at: http://drought.memphis.edu/NADA/)

Assessment question for coding: What was the extent of climatic dryness coincident with the decline, relative to dryness during the period preceding decline?

Unlike other indicators, this measure assesses conditions prior to the initiation of depopulation and during the depopulation interval. Based on a previous study of the temporal correspondence between major social transformations and multi-year droughts in the SW (Kintigh and Ingram 2017), we did not expect the onset of drought to match the start of depopulation in most regions. Due to the endemic risks of food provisioning in the highly variable climate of the SW/NW, we expected that environmental insecurity would be highly variable and more influential when people were deciding to move or remain in place rather than during the $\sim 50$ to 100 years prior to these decisions. Thus, our indicator, in a broad sense, answers the question, "Were conditions during the depopulation less secure (dryer), more secure (wetter), or about the same (no change) compared to conditions prior to depopulation?"

Proxy: Method of calculation: The duration of the decline in each culture area (e.g., 1375 to $1450=75$ years) determines the duration of the period preceding decline used to compare relative dryness (e.g., 1299 to $1374=75$ years). Entire culture area Palmer Drought Severity Indices are calculated for both periods using the North American Drought Atlas (Cook et al. 2009) and the associated database (http://drought.memphis.edu/NADA/). Prior interval and depopulation interval and percent change between the intervals are presented for each culture area in Appendix 2. Differentiating Moderate from High environmental insecurity was based on the range and distribution of the percentage change in relative dryness among all culture areas. High insecurity was assigned to areas with an increase in relative dryness between $89 \%$ and $169 \%$ and Moderate insecurity was assigned to areas with an increase between $45 \%$ and $71 \%$.

Low: Growing season precipitation levels were wetter (creating more secure conditions) during depopulation than during the period prior to depopulation, based on a comparison of tree-ring retrodicted average annual June/July/August PDSI in the culture area. 
Moderate: Growing season precipitation levels somewhat drier during depopulation than during the period prior to depopulation, based on a comparison of tree-ring retrodicted average annual June/July/August PDSI (Palmer Drought Severity Index) in the culture area.

High: Growing season precipitation levels were substantially drier during depopulation than during the period prior to depopulation, based on a comparison of tree-ring retrodicted average annual June/July/August PDSI (Palmer Drought Severity Index) in the culture area.

Uncertainty: Moderate: Reconstructions of growing season precipitation (June, July, August) based on tree-ring retrodicted and geographically interpolated Palmer Drought Severity Indices (PDSI) in the North American Drought Atlas (Cook et al. 2010) provide a strong relative comparison of the extent of dryness in each archaeological culture area. This provides some knowledge of the supply of water for food resources (wild and cultivated) but does not address the demand for this water based on population levels, densities, and uses. When water demand exceeds supply, insecurity likely results. Projecting water supply relative to demand is beyond the scope of this study.

\section{Personal insecurity (Indicator: increasing conflict and violence)}

Plausible relationship with sustainability and depopulation: As conflict and violence increased, mortality increased, personal insecurity increased, and movement away from dangerous conditions increased (LeBlanc 1999).

Proxies used to assess indicator: skeletal trauma, unburied bodies, fortified and defensive structures/settlements

Assessment question for coding: What was the extent and trajectory of conflict and violence within the culture area relative to previous periods?

Low: Little to no evidence of skeletal trauma, unburied bodies, fortified and defensive structures/settlements

Moderate: Some evidence of skeletal trauma, unburied bodies, fortified and defensive structures/settlements

High: Extensive evidence of skeletal trauma, unburied bodies, fortified and defensive structures/settlements

\section{Community insecurity (Indicator: increasing immigration):}

Plausible relationship with sustainability and depopulation: As immigration increased within and near existing communities, insecurities increased, and new social strategies were necessary for resolving tensions (Clark et al. 2019). These tensions likely increased due to increased resource competition in marginal areas (Schwindt et al. 2016). If immigration created untenable social and environmental conditions within communities, movement away from these conditions could have lessened tensions. 
Proxies used to assess indicator: rising population levels above internal population growth rates (using compound annual growth rate calculations, where possible); architectural and/or material cultural differences within settlements associated with immigrants

Note: Compound Annual Growth Rate (CAGR) formula: CAGR $=(\mathrm{p} 2 / \mathrm{p} 1)^{1 / \mathrm{n}}-1$. In this study, $\mathrm{p} 2$ and $\mathrm{p} 1$ are the number of identified rooms in, for example, the 1300 to 1349 interval and in the 1250 to 1299 interval, respectively, and $n$ is the number of years in the interval. For example, if depopulation begins in 1350, we use room counts during the 1250 to 1299 and 1300 to 1349 intervals to identify the trajectory and level of growth rates prior to the start of depopulation. Growth rates greater than 0.7 percent exceed what can be expected from changes in fertility and mortality (Cowgill 1975), and thus in-migration is strongly implicated. We calculate growth rates where settlement data is available in the Coalescent Communities Database (Hill et al. 2012). Where data is not available, we rely on assessments by scholars active in those sub-regions.

Assessment question for coding: What was the extent of in-migration from people outside the culture area relative to previous periods?

Low: Compound Annual Growth rates within a range $(<0.3)$ not associated with strong evidence of in-migration. Little to no evidence of intra-community, ethnic-based architectural and material cultural differences identified.

Moderate: Compound Annual Growth rates within a range (0.3 to 0.7) associated with changes in fertility/mortality of growing populations. Limited evidence of exogenous material culture or architectural signatures associated with groups from outside the culture area. Some evidence of intra-community, ethnic-based architectural and material cultural differences identified.

High: Compound Annual Growth rates in excess of what can be expected from changes in fertility and mortality (>0.7) with in-migration strongly implicated (Cowgill 1975). Evidence of exogenous material culture or architectural signatures associated with groups from outside the culture area were identified.

\section{Political insecurity (Indicator: increasing social stratification)}

Plausible relationship with sustainability and depopulation: As social stratification increased, some portion of a population had less access to political, ritual, and/or socioeconomic resources (Brandt 1994) and political insecurity likely increased. Movement away from these conditions can lessen the perceived inequalities.

Proxies used to assess indicator: architecture within settlements increasingly differentiated, exclusive spaces, unequal distribution of prestige goods, differential burial treatments or grave goods

Assessment question for coding: To what extent did individuals/groups have different levels of access to structural, ritual, or socioeconomic resources relative to previous periods? 
Low: Little to no evidence of differentiation in domestic architecture (e.g., size/shape/access) within settlements, unequal distribution to prestige goods, or substantial differences in grave goods or burial treatments.

Moderate: Recurring evidence of differentiation in domestic architecture (e.g., size/shape/access) within settlements, unequal distribution to prestige goods, and substantial differences in grave goods or burial treatments.

High: Extensive evidence of differentiation in domestic architecture (e.g., size/shape/access) within settlements), unequal distribution to prestige goods, and substantial differences in grave goods or burial treatments.

\section{CODING UNCERTAINTIES}

We code and describe/support our uncertainty assessment for each insecurity category by culture area in Appendix 2. Conflicting interpretations by scholars and/or limited information on a security and its indicator were among the factors affecting uncertainty. This is not a problem unique to archaeology but endemic in the analysis of most complex and large-scale social phenomenon. For non-archaeologists, we clarify that archaeological data accumulates and interpretations evolve to accommodate new data. The uncertainties disclosed in this document are an inherent property of all interpretations of archaeological data. Most new research and advancements in archaeological interpretations of the past arise from acknowledged uncertainties. We did not allow uncertainties to prevent our analysis or change its spatial scale, given the urgency of local to global-scale sustainability challenges and our desire to contribute insights from the past. It will take several lifetimes before data quality improves in some areas.

Data quality is uneven throughout the region. We know most about depopulation of the Mesa Verde region (within the Ancestral Puebloan culture area) and much less about Fremont, Casas Grandes, Rio Sonora, Trincheras, and Patayan areas. Data were insufficient to document most insecurities in the Patayan region, but we retain the culture area in the main text to emphasize the analytical importance of the entire SW/NW region and interactions therein. Inclusion of the Patayan area will hopefully stimulate further research in that area.

\section{Uncertainty Codes:}

Low: There is strong supporting evidence and consensus in the literature that justifies the coding.

Moderate: There is some supporting evidence and consensus in the literature that justifies the coding.

High: There is high coding uncertainty due to minimal evidence and/or conflicting interpretations of the evidence. 


\section{LITERATURE CITED}

Braun, D. P. and S. Plog. 1982. Evolution of "tribal" social networks: theory and prehistoric North American evidence. American Antiquity 16:301-313.

Clark, J. J., J. A. Birch, M. Hegmon, B. J. Mills, D. M. Glowacki, S. G. Ortman, J. S. Dean, R. Gauthier, P. D. Lyons and M. A. Peeples. 2019. Resolving the migrant paradox: Two pathways to coalescence in the late precontact US Southwest. Journal of Anthropological Archaeology 53:262-287.

Cook, E. R., R. Seager, R. R. Heim Jr., R. S. Vose, C. Herweijer and C. Woodhouse. 2010. Megadroughts in North America: Placing IPCC projections of hydroclimatic change in a longterm palaeoclimate context. Journal of Quaternary Science 25:48-61.

Cowgill, G. L. 1975. On causes and consequences of ancient and modern population changes. American Anthropologist 77:505-525.

Halstead, P. and J. O'Shea, editors. 1989. Bad year economics: cultural responses to risk and uncertainty. Cambridge, Cambridge University Press.

Hill, J. B., D. Wilcox, W. Doelle and W. Robinson. 2012. Coalescent Communities Database version 2.0. Tucson, Archaeology Southwest.

Human Security Unit. 2016. Human security handbook: an integrated approach for the realization of the sustainable development goals and the priority areas of the international community and the United Nations system. United Nations Trust Fund for Human Security, United Nations.

Kintigh, K. W. and S. E. Ingram. 2018. Was the drought really responsible? Assessing statistical relationships between climate extremes and cultural transitions. Journal of Archaeological Science 89:25-31.

LeBlanc, S. A. 1999. Prehistoric warfare in the American Southwest. Salt Lake City: University of Utah Press.

Martin, D. L. 1994. Patterns of health and disease: Stress profiles for the Prehistoric Southwest. Pages 87-108 in G. J. Gumerman, editor. Themes in Southwestern prehistory. Albuquerque, University of New Mexico Press.

Phillips Jr., D. A., H. J. Wearing and J. J. Clark. 2018. Village growth, emerging infectious disease, and the end of the Neolithic demographic transition in the southwest United States and northwest Mexico. American Antiquity 83(2):263-280.

Schwindt, D. M., K. Bocinsky, S. G. Ortman, D. M. Glowacki, M. D. Varien and T. A. Kohler. 2016. The social consequence of climate change in the central Mesa Verde region. American Antiquity 81(1):74-96. 


\section{Appendix 2: Evidence Supporting Insecurities Coding}

The information, citations, and interpretations contained in Appendix 2 are intended to serve as a foundational source for future studies of depopulation and the insecurities associated with the $13^{\text {th }}$ through $15^{\text {th }}$ century period in the U.S. Southwest and Mexican Northwest (SW/NW). No comparable source of SW/NW data exists. For archaeologists, the interpretations and citations allow local conditions (settlement to community scale) to be compared to culture area and regional-scale conditions. Systematic investigations of the causes of similarities and differences in conditions within and between culture areas will of substantial interest. We especially recommend identifying conditions associated with peoples and places that did not experience substantial depopulation.

\section{ANCESTRAL PUEBLOAN}

Note: The Ancestral Puebloan area contains at least four areas of persistence, places where people remained and in some cases population levels increased through the depopulation of the SW/NW. These areas of persistence include Hopi, Zuni, Acoma, and along the northern Rio Grande River.

\section{Economic Insecurity}

Indicator: trade and exchange.

Question: What was the extent of interregional trade/exchange relative to previous periods? Sample proxies: extent of non-local pottery and other goods in settlements.

\section{Coding: High}

Evidence supporting high economic insecurity preceding depopulation in the Ancestral Puebloan sub-region includes:

1. Minimal externally produced goods: Glowacki (2015:91-94) and sources therein note the lack of exotic materials (e.g., copper bells, macaws from northern New Mexico, obsidian, and turquoise) appearing in Ancestral Pueblo settlements during and after the collapse of Chaco. Robert Neily (1983) is also referenced by Glowacki (2015) as finding that there was "decreasing stylistic diversity" in pottery "and a decline in the frequency of exotic...lithic procurement," both of which indicate decreasing participation in long-distance trade networks (Glowacki 2015:92).

2. Increased local interaction. Due to declining agricultural productivity, Kohler and Van West (1996) suggest that it was more worthwhile for populations in the Colorado Plateau to pool their resources locally instead of engaging in trade with those farther away. They also state that everyone in the region would have likely had less to trade because less food was being produced. 
3. Collapse of Chaco Canyon trading system: As Chaco collapsed, trade within the Ancestral Pueblo region became more localized and intensified (Glowacki 2015:91-94).

4. Archaeological syntheses: Varien et al. (1996:99 and references therein) states that "In general, there is little evidence of interregional exchange [in their SW Colorado and SE Utah study area] during the thirteenth century in comparison to earlier centuries."

\section{Uncertainty: Low}

A weakness of the evidence noted above is that it is dominated by work conducted in the central Mesa Verde regions with less representation from areas outside of that area. For example, in the Kayenta region (NE Arizona), Gumerman and Dean (1989:126) note that trade intensified after $1250 \mathrm{CE}$ (during the depopulation interval) and was "widespread." The people in this region were also thought to have traded for luxury goods such as turquoise, copper bells, shell, and ceramics (Gumerman and Dean 1989:126).

\section{Food Insecurity}

Indicator: resource depletion/degradation.

Question: What was the extent and severity of resource depletion and degradation?

Sample proxies: declining diet breadth, change in previous resource procurement strategies (for example, shifting from cultivated to wild foods or vice versa), increased reliance on smaller or more immature mammals, increasing soil degradation, bioarchaeological indicators of food stress.

\section{Food insecurity: High}

Evidence supporting high food insecurity preceding depopulation in the Ancestral Puebloan subregion includes:

1. Declining wild and domesticated food resources. Kuckelman et al. (2010:506) argues that the prevalence of domesticated turkeys, a main food source, declined in the later Ancestral Puebloan occupational period based on the faunal remains at Sand Canyon Pueblo. Kuckelman et al. (2010:506) also calculated turkey and artiodactyl indices which indicate an increased reliance on wild game and a declining amount of domesticated turkey. Additionally, a consequence of the lower availability of staple foods such as maize and domesticated animals was an increased reliance on non-domesticated plants and animals (Kohler et al. 2008:153; Kuckelman et al. 2010:503-509; Adams et al. 2007). Smaller game animals also became a predominant wild food source instead of artiodactyls (Muir and Driver 2002; Driver 2002 as cited in Kantner 2004:202).

2. Declining maize productivity. Van West and Dean (2000) detail several environmental factors that would have challenged successful agricultural productivity prior to and during the depopulation: declining alluvial water tables, floodplain degradation by stream channel entrenchment, and increasing spatial variability in climate. Schwindt and colleagues (2016), 
relying on modeled maize niche size and variability developed by Bocinsky and Kohler (2014), reconstructed population densities in several sub-regions of the central Mesa Verde region. Their results demonstrate that during climate driven declines in agricultural productivity, there was not enough maize-producing land to feed people living in some subregions.

3. Reduced mobility. Warfare and the threat of violence likely prevented smaller communities from being able to hunt wild game, a steadily growing food source (Muir and Driver 2002:190).

4. Bioarchaeological evidence of nutritional stress. Martin (1994:100) found that bioarchaeological data shows evidence of increased nutritional stress at Canyon de Chelly and Mesa Verde during the period prior to depopulation.

5. Water shortages. Gumerman and Dean (1989:123) note that during the Pueblo III phase (1250-1300 C.E.), the Kayenta region experienced water shortages. This trend has also been documented at Kiet Siel in the late 1300s (Dean 2006:165).

6. Deforestation and declining fuel wood. Based on archaeobotanical evidence for changing fuel sources, Kohler and Matthews (1988) and Stiger (1979) have proposed that the Ancestral Puebloans' agricultural practices contributed to deforestation. Stiger (1979:139) also stresses that this deforestation was likely accompanied by increased soil degradation. Johnson et al.'s (2005:102) simulation of household fuel-wood consumption in a portion of southwestern Colorado provides additional evidence for deforestation, as the results demonstrate that areas near habitations become quickly depleted of deadwood followed by substantial areas depleted of both deadwood and living wood.

7. Increasing food storage facilities as a response to shortages. At Kiet Siel during the Tsegi Phase, there was an increase in the amount of food storage which Dean (2006:170-175) interprets as a response to food shortages.

\section{Uncertainty: Moderate}

In detailed investigations of archaeobotanical and faunal data from the Sand Canyon Archaeological Project involving multiple sites during the period leading up to and including depopulation, Duff et al. 2010:157 find, "overall, pressure on food and nonfood resources increased over time ...yet these impacts were relatively subtle and seem unlikely to have precipitated or required depopulation."

\section{Health Insecurity}

Indicator: settlement aggregation, bioarchaeological evidence (where/when available) Question: What was the extent of settlement aggregation and bioarchaeological evidence of disease, if any?

Sample proxies: spatial clustering of households into larger communities; skeletal indicators of health/disease. In addition to coding this insecurity based on published scholarly assessments of the extent of aggregation, we calculated an aggregation index for each culture area using 
settlement data in the Coalescent Communities Database (Hill et al. 2012). Our index is: total number of rooms in a culture area divided by the total number of settlements in each area. The percent change in the index from one 50-year interval to the next, informs the coding.

\section{Coding: High}

Evidence supporting a high level of settlement aggregation preceding depopulation in the Ancestral Puebloan sub-region includes:

1. Architectural evidence. Both the architecture and the layout of Ancestral Puebloan communities indicate higher levels of aggregation in the years preceding migration out of the region (Varien 2006:41; Dean 2010:335; Varien et al. 2007:283; Glowacki 2010:209; Varien 2010:25; Lipe 2006:311, 312). Specifically, large communal structures became more prevalent than in earlier times (Glowacki 2010:209; Varien 2010:25; Lipe 2006:311, 312). There is also evidence that populations became more concentrated in the canyon regions during this time (Lipe 1995:153; Glowacki 2010:203, 214; Varien 2010:25, 27).

2. Bioarchaeological evidence for declining health. In her analysis of 64 skeletal remains from sites in the Dolores Archaeology Program area and 466 skeletal remains from the Mesa Verde area, Stodder (1987:366) saw declining health in Ancestral Puebloan populations towards the end of occupation. Cummings' (1994 as cited in Kantner 2004:167) analysis of coprolites at Hoy House and Lion House also found pinworms in all of the coprolites, which Kantner (1994) attributes to aggregation.

3. Aggregation index (Total number of rooms/total number of settlements in culture area): During the 1250-1299 interval, the index increased by $35 \%$.

4. Archaeological syntheses. Varien et al. (1996:98) determined that "Between A.D. 1200 and 1250 there appears to have been an overall increase in population density, size, and degree of settlement aggregation, at least in the central [Mesa Verde] area, and there was a dramatic increase in site size and number (figure 7.8)." Kantner (2004:163-166 and sources therein) discusses the aggregation that was occurring in the Mesa Verde region and Sand Canyon in the 1200s. Gumerman and Dean (1989:122) also note that from 1250 C.E. on, the Kayenta region was organized into a few, highly dense settlements.

\section{Uncertainty: Moderate}

There is strong architectural evidence for increasing settlement aggregation prior to decline (Varien 2006:41; Dean 2010:335; Varien et al. 2007:283; Glowacki 2010:209; Varien 2010:25; Lipe 2006:311, 312). However, Kantner (2004:180) discusses the lack of aggregation occurring in the San Juan Basin during the mid-1200s. The bioarchaeological data also does not provide a definitive link between declining health and settlement aggregation. While Stodder (1989) does observe worsening health in Ancestral Puebloan populations, Martin (1994:104) concluded that health in the later occupation periods was a "continuation of the trends in poor health noted previously." Furthermore, much of the discussion surrounding declining health is focused on how changes in nutrition are associated with trends in health, rather than aggregation. Although 
both Stodder (1989) and Martin (1994) state that increasing aggregation was likely a major factor in declining health due to poor sanitation, there is little skeletal evidence that directly correlates declining health with increasing aggregation in comparison to the strong association found with nutritional stress. Furthermore, Stodder (1989:409) states that "infectious conditions are rarely observed in the skeletons from the Mesa Verde area." Overall, while it is certainly possible that declining health is tied to increased aggregation, an equally plausible link can be made with nutritional stress.

\section{Environmental Insecurity}

Indicator: drought and dryness.

Question: What was the extent of drought/dryness coincident with the decline, relative to drought/dryness during the period preceding decline?

Proxy: Comparison of prior interval dryness to depopulation interval dryness (see Environmental Insecurity in Insecurities, Archaeological Indicators, Coding Questions and Definitions above).

\section{Coding: High}

Evidence supporting high environmental insecurity includes:

1. Extent of dryness index:

a. Prior interval, 1194 to 1239 : Average PDSI $=0.6$

b. Depopulation interval, 1240 to 1285 : Average PDSI $=-0.4$,

i. $169 \%$ drier than the prior interval

2. Declining maize consumption. Perhaps due to declining maize productivity caused by unfavorable climactic shifts (Van West and Dean 2000; Schwindt et al. 2016), there is also evidence of declining maize consumption toward the final years of occupation. Maize accounted for $10 \%$ of the Ancestral Puebloans' diet, a dramatic decrease from previous years where maize was the main plant food consumed by the Ancestral Puebloans (Adams et al. 2007; Kohler et al. 2008:150, 152).

\section{Uncertainty: Moderate.}

Discussed above in Insecurities Coding: Definitions and Methods, Environmental insecurity section.

\section{Personal Insecurity}

Indicator: conflict and violence.

Question: What was the extent and trajectory of conflict and violence within the culture area? Sample proxies: skeletal trauma, unburied bodies, fortified and defensive structures/settlements

Coding: High 
Evidence supporting high conflict and violence preceding depopulation in the Ancestral Puebloan sub-region includes:

1. Increasing evidence of skeletal remains with violence. At Castle Rock pueblo, skeletons showed evidence of cranial fractures, broken teeth, and tibia fractures with at least forty-one individuals likely experiencing a violent death (Kuckelman et al. 2002:494; Kohler et al. 2008:153). Additionally, there are skulls with fractures on the backside, indicating that the individuals were potentially attacked while fleeing (Kuckelman 2010:190; Kuckelman 2006:132). Evidence of violent death can also be found at Salmon, where 45 to 55 individuals were found burned in a kiva, and at Sand Canyon Pueblo where disarticulated skeletal remains were found (Irwin-Williams and Shelley 1980 as cited in Kantner 2004:169, 170; Kuckelman 2010; Kuckelman and Martin 2007). There was also evidence of violent death at site 5MT993 in the larger Mesa Verde region (Lambert 1999:141 as cited in Billman 2008:65). Skeletal remains at the La Plata region also showed evidence of trauma, although it is unclear when in the occupation period those traumas occurred (Martin et al. 2008). See also sites from the Dolores Archaeological Program area (Stodder 1987:362, 363) and sites discussed by Turner (2011).

2. Increasing prevalence of defensive architecture. Varien et al. (1996:99) identify a "clear increase" in sites located in easily defended locations. At Sand Canyon Pueblo, defensive architecture in the form of large enclosing walls, towers for increased visibility, and an increase in cliff dwellings can be seen (Kuckelman 2010:499; Kuckelman 2006:129). Similar patterns are found throughout the Mesa Verde region and at the Kayenta site of Long House Valley (Glowacki 2015; Haas and Creamer 1996 as cited in Kantner 2004:178). Billman (2008:66) also notes an increasing use of defensive architecture in the Mesa Verde region prior to depopulation.

3. Differing burial practices. In conjunction with abandonment contexts and other evidence of violence, human remains that are not carefully buried and whose burials depart from traditional Ancestral Puebloan burial customs are also thought to have possibly died violent deaths even if that is not apparent in the skeletal remains (Cameron 2006:141; LeBlanc 1999; Kuckleman 2010:502; Kuckelman et al. 2002).

4. Archaeological syntheses. In the late period of Ancestral Puebloan occupation, violence increased significantly (LeBlanc 1999; Kohler et al. 2014; Kohler et al. 2008). Haas and Creamer (1996:205) argue "that warfare was endemic throughout the northern Southwest in the thirteenth century, and that any explanations of settlement, political relations, and abandonment must incorporate warfare as a central causal variable." Billman (2008:64, 66, 67 ) also states that raiding occurred in the Mesa Verde region during the 1200 s.

5. Wall art depicting violence. The wall art from that time period includes violent images of warriors and basket shields, a likely reflection of violence in the area at that time (Kuckelman 2006:132; Varien 2010:10). An example of this wall art can be found at Castle Rock Pueblo (Kantner 2004:171, Figure 6.5).

Uncertainty: Low 
There is a consensus among archaeologists that violence increased immediately preceding demographic decline in the Mesa Verde region. Significant bioarchaeological evidence, changes in architecture, burials inconsistent with traditional customs, and wall art support this claim (see above). We have not encountered any evidence that contradicts this claim. A weakness of the evidence presented above is that it centers on a few sites mostly around the central Mesa Verde sub-region. As a known exception, Dean (2010:338) has identified no evidence of large-scale violence in the Kayenta portion of the Ancestral Puebloan region which contradicts Haas and Creamer's (1996) argument on violence in that sub-region.

\section{Community Insecurity}

Indicator: immigration.

Question: What was the extent of in-migration from people outside the culture area?

Sample proxies: rising population levels above changes in internal population growth rates, intracommunity, ethnic-based architectural and material cultural differences.

Note: Given the large geographical area of the Ancestral Puebloan region, intra-culture area migration is considered.

\section{Coding: High}

Evidence supporting high immigration preceding depopulation in the Ancestral Puebloan subregion includes:

1. Rising population levels due to immigration in select locations within the culture area. "In AD 1200 the Mesa Verde region [SW Colorado] was the most densely populated portion of the ancestral Puebloan world" (Ortman 2012:264). Population levels peaked in the Northern San Juan region (includes the Mesa Verde region) at about 1225 and then began to rapidly decline (Varien 2010:Table 1.1 and the Village Ecodynamics Project; see Varien et al. 2007 and Ortman 2012, Fig. 4.8 for similar results). Glowacki (2010) identifies population movements from the western portion of the northern San Juan district to eastern portions of the district and associated social changes likely stimulated by the population consolidations.

2. Increases in population growth rates above those expected from changes in fertility and mortality: The compound annual growth rate between the 1200 to 1249 and 1250 to 1299 intervals was $0.90 \%$, above a level expected from changes in fertility and mortality (Cowgill 1975). For calculation methods, see explanation in Appendix 1.

3. There is evidence of increasing immigration into Tsegi Canyon and the Kiet Siel region during the late 1200s (Dean 2006:166).

\section{Uncertainty: Moderate}

Although the northcentral portion of the Ancestral Puebloan culture area (Village Ecodynamics Project) shows substantially increased population levels during the 1225 to 1260 interval 
compared to the 1180 to 1225 interval (Varien 2010:16, Table 1.1), the origins of people moving into the area may be from within the large Ancestral Puebloan area. Whether from within or outside the area, insecurities due to the influx of newcomers likely increased.

\section{Political Insecurity}

Indicator: social stratification.

Question: To what extent did individuals/groups have different levels of access to structural, ritual, or socioeconomic resources?

Sample proxies: architecture within settlements increasingly differentiated, exclusive spaces, differential burial treatments.

\section{Coding: Moderate}

Evidence supporting moderate social stratification preceding depopulation in the Ancestral Puebloan sub-region includes:

1. Architectural evidence of stratification. There was increasing presence of multi-walled structures, which are defined as "circular or D-shaped with a courtyard for one or two kivas...surrounded by a single or double row of rooms" (Glowacki 2010:215) within the cliff dwellings (Glowacki 2010:115; Lipe and Ortman 2000:110, 111). Only certain community members were allowed to enter these areas, specifically those with ritual importance (Lipe and Ortman 2000:95; Glowacki 2010:215, 2015:170; Arakawa 2012:50; Reed 1958:55; Vivian 1959:77). For example, some people had access to these spaces based on their familial status (Glowacki 2015:170; Arakawa 2012:50). Glowacki (2015) also describes a three-tiered system of access to structures in Ancestral Puebloan sites. At Sand Canyon Pueblo, one roomblock has been suggested to represent the presence of sodalities, although if present they were likely weak (Lipe 2002).

2. Faunal remains. After analyzing faunal remains in middens from Sand Canyon Pueblo, Muir (1999:159) concluded that there were not significant differences in subsistence between various community members. However, he also discusses the differentiation between faunal assemblages at Sand Canyon and those at smaller sites, indicating that those at Sand Canyon may have had a certain level of prestige (1999:159). Larger birds of prey associated with ritual activities were also more commonly found at large sites, such as Sand Canyon, which has been interpreted to represent a consolidation of ritual activities at these sites (Muir 1999:160).

2. Relegation of certain groups to poor agricultural land. At Sand Canyon Pueblo, Adler (1996:354, 355 as cited in Kantner 2004:167) determined that those living at smaller sites were forced to use low quality land compared to those living at larger residences. He also discusses the possibility that land was passed down through families.

3. Bioarchaeological evidence of gender differences. Martin and Akins (2001 as cited in Kantner 2004:172) found that females from the La Plata area experienced more violence than their male counterparts and they characterize this as an "overall decrease in the status of women." 
They attribute this to an increasingly "patrilocal" social organization, where women were often moving to unfamiliar places after marriage (Martin and Akins 2001 as cited in Kantner 2004:172). This gender difference in the amount of trauma in the La Plata region is also noted by Martin et al. (2008).

4. Evidence of social stratification through trade. Upham (1982 as cited in Gumerman and Dean 1989:128) states that the Western Anasazi region was characterized by a group of elites controlling trade.

\section{Uncertainty: Moderate}

Studies of $13^{\text {th }}$ century community organization by Varien and colleagues (1996:99), including Sand Canyon Pueblo, found "little material evidence for the presence of a well-differentiated elite." They (Varien et al. 1996:99-100) further state, "There may, however, have been important inequalities between community members that fall short of the establishment of institutionalized elites." Kantner (2004:175) contradicts the evidence that there was social stratification and states that Ancestral Puebloan communities had "leveling mechanisms" that prevented social stratification. He believes that, if present, hierarchies only existed between larger and smaller sites, not within a site (Kanter 2004:175). Gumerman and Dean (1989:100-103) also note that western Ancestral Puebloan society was "generally egalitarian" and relied on cooperation and coordination. It is important to note that the argument and evidence noted above is dominated by work conducted in the central Mesa Verde region with less representation from areas outside of that area.

\section{FREMONT}

\section{Economic Insecurity}

Indicator: trade and exchange.

Question: What was the extent of interregional trade/exchange relative to previous periods? Sample proxies: extent of non-local pottery and other goods in settlements.

As trade/exchange networks decrease, opportunities to engage social strategies for buffering risks decrease (e.g., alliances, reciprocity). Risks (real or perceived) that cannot be buffered can lead to strategies such as migration to mitigate risks.

\section{Coding: Low}

Evidence supporting low economic insecurity preceding depopulation in the Fremont sub-region includes:

1. Consistent and increasing trade through time. In a synthetic analysis of spatial patterning of local and exotic goods, Janetski (2002) finds mostly consistent and likely increasing trade in exotic goods (marine shell, turquoise, jet, Anasazi ceramics), local minerals, and non-local Fremont ceramics over time, although there are sample size biases. Specifically, Janetski 
2002:365 states, "between AD 500 or so and 1300, quantities of exotics, and perhaps trade generally, increased in the Fremont region..." Based on stylistic analyses and differential distributional patterns of exotics, ceramics, and obsidian, Janetski (2011) also argues for possible community ranking of central places.

2. Presence of non-local goods. Stewart (2006:29) notes that the turquoise and shell found in some Fremont pithouses was not prevalent in previous years. This may indicate that trade was increasing prior to decline (Stewart 2006:29). Ure and Stauffer (2010:6) also found "pendants, various saltwater shell beads, and clay anthropomorphic figures."

3. Imports from the San Rafael Swell area. In addition to other non-local goods, Madsen and Simms (1998:309) note the presence of ceramics in the Tavaputs Basin in eastern Utah and western Colorado that were made from basalt originating in the San Rafael Swell area in south-central Utah. They argue these goods represent direct evidence of trade specifically between the Fremont and the San Rafael Swell region.

\section{Uncertainty: Moderate}

In contrast to Stewart (2006) and Ure and Stauffer (2010), Gunnerson (1960:374) states that nonlocally produced pottery sherds are "rare" at Fremont sites. Also, there has been limited work done in the Fremont region in comparison to other cultural groups discussed in this paper.

\section{Food Insecurity}

Indicator: resource depletion/degradation.

Question: What was the extent and severity of resource depletion and degradation?

Sample proxies: declining diet breadth, change in previous resource procurement strategies (for example, shifting from cultivated to wild foods or vice versa), increased reliance on smaller or more immature mammals, increasing soil degradation, bioarchaeological indicators of food stress.

As resources are depleted or degraded, food and resource insecurity increased. Perceived better conditions elsewhere can stimulate movement and insufficient food decreases fertility and increases mortality.

\section{Coding: Moderate}

Evidence supporting moderate resource depletion preceding depopulation in the Fremont subregion includes:

1. Bioarchaeological evidence of nutritional stress. $33 \%$ of the 86 skeletons found in the Great Salt Lake Wetlands showed evidence of nutritional stress (Coltrain and Leavitt 2002:458, 478 and references therein). However, the remains are from a variety of time periods at each site and are not individually listed by date, therefore it is unclear whether this increased immediately preceding depopulation (Coltrain and Leavitt 2002:458). 
2. Decline in wild food sources. After analyzing faunal remains at Fremont sites, Janetski (1997 as cited in Madsen and Simms 1998:283,284) argues that foraging became less productive for the Fremont in later periods.

3. Transition to farming maize to compensate for decreased availability of foraged food. Madsen and Simms (1998:279, 281) state that the Fremont transition from foraging to farming maize during the Formative period was a behavioral shift in order to accommodate the depletion of staple wild foods. However, they also note that farming is no longer visible in the archaeological record at 500 B.P, or $\sim 1450$, and bioarchaeological analysis supports the argument that the Fremont switched back to foraging (Madsen and Simms 1998:323; Simms and Stuart 2002:79). This ability to adapt by switching between farming and foraging is discussed in detail by Madsen and Simms (1998) and Simms (1986).

\section{Uncertainty: Low}

Multiple lines of evidence demonstrate that the Fremont region likely experienced resource stress prior to decline. There was no evidence found that contradicted this interpretation.

\section{Health Insecurity}

Indicator: settlement aggregation, bioarchaeological evidence (where/when available) Question: What was the extent of settlement aggregation and bioarchaeological evidence of disease, if any?

Sample proxies: spatial clustering of households into larger communities; skeletal indicators of health/disease. In addition to coding this insecurity based on published scholarly assessments of the extent of aggregation, we calculated an aggregation index for each culture area using settlement data in the Coalescent Communities Database (Hill et al. 2012). Our index is: total number of rooms in a culture area divided by the total number of settlements in each area. The percent change in the index from one 50-year interval to the next, informs the coding.

\section{Coding: Moderate}

Evidence supporting moderate settlement aggregation preceding depopulation in the Fremont sub-region includes:

1. Architectural evidence of aggregation. Allison (2010:146) notes that Fremont sites, particularly in the eastern Great Basin, show signs of aggregation. He gives the sites of Baker Village and Five Finger Ridge as examples due to the large amounts of "contemporaneous habitations" found there (Allison 2010:146, 147).

2. Radiocarbon dates indicating increased aggregation. Using radiocarbon dates from the area, Talbot and Wilde (1989:9) found that from AD 880 to AD 1040 the Fremont began to move out of the Uinta Basin and eastward. From AD 1250 to AD 1350, settlements were "concentrated into a few choice areas" (Talbot and Wilde 1989:9). 
Uncertainty: Low

Increasing aggregation in the Fremont area has been consistently observed.

\section{Environmental Insecurity}

Indicator: drought and dryness.

Question: What was the extent of drought/dryness coincident with the decline, relative to drought/dryness during the period preceding decline?

Proxy: Comparison of prior interval dryness to depopulation interval dryness (see Environmental Insecurity in Insecurities, Archaeological Indicators, Coding Questions and Definitions above).

As dryness increased, wild and cultivated food resources decreased. Resource shortfalls (real or perceived) can stimulate movement and insufficient food decreases fertility and increases mortality.

Coding: High

Evidence supporting high environmental insecurity includes:

1. Extent of dryness index:

a. Prior interval, 999 to 1149: Average PDSI, -0.20

b. Depopulation interval, 1150 to 1300 : Average PDSI, -0.41

i. $109 \%$ drier than prior interval.

2. Reduced maize yield due to climate shift. Thomson et al. (2019) simulated what maize growth would have looked like for the Fremont in the Great Salt Lake and Uinta Basin subregions. He found that reduced temperatures between 1100 and 1200 AD likely slightly reduced maize production (Thomson et al. 2019:103).

Uncertainty: Moderate.

Discussed above in Insecurities Coding: Definitions and Methods, Environmental insecurity section.

\section{Personal Insecurity}

Indicator: conflict and violence.

Question: What was the extent and trajectory of conflict and violence within the culture area? Sample proxies: skeletal trauma, unburied bodies, fortified and defensive structures/settlements

\section{Coding: Moderate}

Evidence supporting moderate personal insecurity preceding depopulation in the Fremont subregion includes: 
1. Presence of defensive architecture. Boomgarden et al. (2014:27) details defensive architecture and defensive food storage systems. Defensive architecture in the form of structures built in inaccessible areas, such as rock outcrops, and isolated food storage can also be seen in the Tavaputs plateau (Spangler 1999a and 1999b as cited in Madsen and Simms 1998:306, 307).

2. Bioarchaeological evidence. Novak $(1995,1998)$ and Shields (1967) (all as cited in Madsen and Simms 1998:309) suggest that cannibalism may have occurred in the Sevier River Valley, Uinta Basin, and at the Turner-Look site. Wormington (1955:87) also notes bioarchaeological evidence for violence, such as deliberately broken bones in association with fireplaces and intentionally damaged crania, at the Turner-Look site. Excavations at Backhoe Village revealed skeletal remains with "disarticulation, broken and splintered long bones, burning, green stick fracturing, and cut and scratch marks" (Madsen and Lindsay 1977:78).

3. Rock art depicting violence. Madsen and Simms (1998:308) note the presence of rock art that depicts violence in the Tavaputs plateau.

\section{Uncertainty: Moderate}

Evidence is consistent but limited.

\section{Community Insecurity}

Indicator: immigration

Question: What was the extent of in-migration from people outside the culture area?

Sample proxies: rising population levels above changes in internal population growth rates, intracommunity, ethnic-based architectural and material cultural differences.

As in-migration increased within and near existing communities, new social strategies were necessary for resolving tensions. These tensions likely increased due to increased resource competition in marginal areas. Out-migration lessens untenable social and environmental conditions.

\section{Coding: Low}

Evidence supporting low immigration preceding depopulation in the Fremont sub-region includes:

1. Possible immigration of the Numic people. The Numa people are thought to have migrated into the region and had superior subsistence and adaptative strategies, resulting in them "outcompeting" the Fremont (Coltrain and Leavitt 2002:456). This interpretation is based on studies of linguistic divergence in the region, although the time period of the initial Numic expansion into the region has not been confirmed (Coltrain and Leavitt 2002:456; Lamb 1958; Madsen and Simms 1998:314). Due to the evidence relying on linguistic divergence, the exact timing is difficult to determine. 
2. Competition with foragers. Madsen and Simms (1998:314) suggest that immigrants to the region who practiced farming were in direct competition with Fremont foragers, although they do not state who the immigrants were or what cultural tradition they were associated with.

3. Mountain migration route. Seymour (2012:155) discusses the possibility that when the Athabascan people migrated from the north into the Colorado Plateau, part of the Fremont region, they actually took a route through the mountains, instead of the plains, resulting in more possible contact with the Fremont.

\section{Uncertainty: High}

Allison (2019:297-300) argues there was a population influx into the Fremont area in the early 1000s from the Four-Corners area as people moved away from the expanding Chaco system. This increase in immigration is outside of the $\sim 100$ year coding window prior to depopulation but may have created rising community insecurity over time. Overall, the Fremont region does not have evidence for the standard markers of immigration such as architectural or material culture differences. Instead, most of the evidence is based on possible migration routes in the region.

\section{Political Insecurity}

Indicator: social stratification.

Question: To what extent did individuals/groups have different levels of access to structural, ritual, or socioeconomic resources?

Sample proxies: architecture within settlements increasingly differentiated, exclusive spaces, differential burial treatments.

As social stratification increased, some portion of a population had less access to political, ritual, and/or socioeconomic resources. Out-migration lessens socially untenable, unequal conditions.

\section{Coding: Moderate}

Evidence supporting moderate social stratification preceding depopulation in the Fremont subregion includes:

1. Skeletal and burial evidence for high-status males at Site 42WB324. Coltrain and Leavitt (2002:474) report that males at site 42WB324 ate a diet rich in C14, had more elaborate burials, and also had "reduced skeletal robusticity", all of which indicate higher status individuals.

2. Exclusive community architecture at Wolf Village. Johansson et al. (2014:49) concludes that some events held in communal structures at Wolf Village likely would have been exclusive spaces with some community members denied entry into the space during certain events. There is also a possible central structure which likely would have been reserved for certain religious and community leaders (Ure and Stauffer 2010:13; Johansson et al. 2014:49). 
3. Differences in burial goods. Janetski and Talbot (1997 as cited in Madsen and Simms 1998:310) note that several Fremont sites had burials where there was a difference in the amount of burial goods, indicating some level of social differentiation. The Median Village and Parowan Valley sites also contains burials with differing amounts of grave goods (Madsen and Lindsay 1977:78; Watkins 2010; Dodd 1982, Meighan et al. 1956, Janetski et al. 2000 as cited in Watkins 2010:7). Watkins $(2016: 5,6)$ notes that avian remains were found in two of the burials at Evans Mound, whereas this is not present in other burials.

4. Presence of non-local goods. Stewart (2006:29) notes that turquoise and shell have been found in some Fremont pithouses, which may indicate that some had higher status than others. Ure and Stauffer (2010:6) also found "pendants, various salt water shell beads, and clay anthropomorphic figures" although the authors do not state if the objects indicate any form of social differentiation.

5. Interaction with smaller villages. Madsen and Simms (1998:323) note that smaller Fremont villages likely interacted with larger settlements and a system of exchange facilitated the development of some social stratification.

6. Settlement hierarchy. Fremont sites during the Late Fremont period were organized in a settlement hierarchy which is a marker of increasing organizational complexity (Talbot 2019). A settlement hierarchy likely signals increasingly differentiated political influence.

7. Archaeological synthesis: In a synthesis of architectural variation and layout in three Fremont villages, Richards et al. (2019:2014) summarize there results by stating, "houses vary in ways that indicate differences among households in social status or wealth; and each village includes public architecture, reflecting the organization of households into larger communities." They specifically identify "unusual residential structures in close association with communal architecture." They interpret this layout as possible evidence that leaders may have had privileged access to stored goods in the public communal structures and monitored activities in those structures.

\section{$\underline{\text { Uncertainty: Low }}$}

There are multiple lines of evidence suggesting a moderate amount of social stratification and no conflicting evidence has been found. However, some of the evidence could have multiple interpretations besides indicating social stratification, such as the goods noted by Ure and Stauffer (2010).

\section{HOHOKАM}

\section{Economic Insecurity}

Indicator: trade and exchange. 
Question: What was the extent of interregional trade/exchange relative to previous periods? Sample proxies: extent of non-local pottery and other goods in settlements.

As trade/exchange networks decrease, opportunities to engage social strategies for buffering risks decrease (e.g., alliances, reciprocity). Risks (real or perceived) that cannot be buffered can lead to strategies such as migration to mitigate risks.

\section{Coding: High}

Evidence supporting high economic insecurity preceding depopulation in the Hohokam subregion includes:

1. Decreasing communal architecture: Communal ball courts were abandoned, and the Hohokam started to build walled platform mounds instead, indicating that communal architecture was being abandoned in favor of exclusive spaces (Abbott 2003:209, 210; Bayman 2001:285; Craig and Woodson 2017:341). Previously ball courts were indicative of a vibrant regional economy (Craig and Woodson 2017:335). Clark and Abbott (2017:359) state that platform mounds are "the most apparent emblems of that new and divided social order." The change in architecture to focus on platform mounds has also been noted by Fish (1989:31).

2. Increasing local production: Prior to the $13^{\text {th }}$ century, the Hohokam acquired pottery, shells, and obsidian from other cultural groups, but this declined as craft making became centralized around platform mounds (Abbott 2003:209-210; Bayman 2001:285). In a process that likely continued throughout the Classic period (1200 to 1450), "The early Classic period in the lower Salt and middle Gila River valleys of the Phoenix Basin is characterized by an organization retraction from the open and hospitable networks of the Sedentary period. They were replaced by social and economic fragmentation, a kin-based structure, and dependence on locally controlled resources" (Clark and Abbott 2017:357).

3. Less trading of Hohokam produced goods: After $1050 \mathrm{CE}$, there is less evidence of Hohokam buff ware pottery outside of the Phoenix Basin (Craig and Woodson 2017:341; Clark and Abbott 2017:355, 358; Wallace and Doelle 2001:260). Fish (1989:33) also notes that Hohokam produced red-on-buff pottery becomes less prevalent prior to depopulation.

4. Decreased presence of non-local goods. During the Classic period, macaws, copper bells, mosaic mirrors, and Strombus trumpets were not found as frequently at Hohokam sites compared to previous periods (Crown 1991:387). Although intrusive ceramics can still be found at Hohokam sites during the Classic period, they are from fewer regions than in previous periods (Crown 1991:388). Crown (1991:388) also states that the usage of non-local minerals, except for obsidian, decreased during the Classic period.

\section{Uncertainty: Moderate}

Mills et al. (2013:5788, 5789, Figure 4) compared the prevalence of obsidian before and after 1300 in Arizona and concluded that there was more trade after 1300 C.E. Sites (1983 as cited in 
Crown 1991:388) also observes that obsidian and intrusive ceramics from southern Arizona and Hopi-occupied areas continued to be found during the Civano and Polvoron phases. After analyzing pottery at Pueblo Grande, Abbott and Walsh-Anduze (1995:105-106), argued that thousands of pots were imported during the Classic period and that the Hohokam were heavily involved in pottery exchange, instead of producing most locally.

\section{Food Insecurity}

Indicator: resource depletion/degradation.

Question: What was the extent and severity of resource depletion and degradation?

Sample proxies: declining diet breadth, change in previous resource procurement strategies (for example, shifting from cultivated to wild foods or vice versa), increased reliance on smaller or more immature mammals, increasing soil degradation, bioarchaeological indicators of food stress.

As resources are depleted or degraded, food and resource insecurity increased. Perceived better conditions elsewhere can stimulate movement and insufficient food decreases fertility and increases mortality.

\section{Coding: Moderate}

Evidence suggesting a moderate amount of resource depletion preceding depopulation in the Hohokam sub-region includes:

1. Degradation of irrigation systems: Hill et al. (2015) conducted soil analysis on Salt River Adobes in the Lower Salt River Valley and found an increasing distance between habitation sites and irrigation canals. As a result of this finding, Hill et al. (2015:633-637) argues that the intense irrigation used by the Hohokam had degraded the land, possibly through increased soil salinization, and forced people to move farther away in search of viable land).

2. Shifts in subsistence strategies: Kwiatkowski $(2003: 62,79-80)$ found evidence that the availability of many of the Hohokam's staple animal protein sources, such as deer, large freshwater fish, and small game, declined significantly by the Late Classic Period. Through analyzing faunal assemblages and calculating diversity indices for lagomorphs, aquatic and semi-aquatic prey, small terrestrial animals, flying birds, and artiodactyls, Dean (2007) concludes that the Hohokam did experience resource stress prior to decline. This resource stress led to "intensification of resource procurement" and the addition of wild foods outside of the normal Hohokam staples (Dean 2007:128). However, Dean's (2007:128) study was limited to the Salt and Gila river valleys and thus may not be applicable to other Hohokam communities. Similarly, based on cottontail to jackrabbit ratios it is likely that less vegetation cover existed during the Classic period (James 2003:76, 77).

3. Bioarchaeological evidence of nutritional stress: Through analysis of subadult skeletal remains at Pueblo Grande, Sheridan (2003) concluded that the population experienced considerable nutritional stress. Chemical analysis of the bones also supported this conclusion (Sheridan 2003:100-105). 
4. Reduction in arable land. Waters (2006:33) notes that during the Tanque Verde Phase, the southern and western parts of the Southern Arizona floodplain were not favorable for agriculture. As a result, people moved to more productive, arable land in the northern and eastern sections of the floodplains (Waters 2006:33). This process continued into the subsequent Tucson phase where the amount of arable land was further reduced (Waters 2006:34).

5. Reduction in tree availability: Fewer trees were available along the lower Salt River and in the Tonto Basin during the Classic period (Kwiatkowski 2003:57).

\section{Uncertainty: Low}

Fish (1989:46) notes that the Hohokam were adept at managing their resources and were not very vulnerable to climactic shifts. After analyzing the skeletal remains from Pueblo Grande, McClelland (2015:503-506) does not believe the bioarchaeological or paleodemographic evidence is strong enough to conclude that the Hohokam experienced significant nutritional stress. In regard to a declining birth rate, McClelland (2015:505) states that there is "insufficient evidence" to attribute the decline to nutritional stress. Furthermore, much of the bioarchaeological analysis was contained to Pueblo Grande and thus may not be fully representative of Hohokam resources; however, the irrigation and subsistence strategies have been investigated in a variety of locations. If there was not considerable resource depletion, we would expect more evidence in support of this conclusion.

\section{Health Insecurity}

Indicator: settlement aggregation and bioarchaeological data Question: What was the extent of settlement aggregation and bioarchaeological evidence of disease, if any?

Sample proxies: spatial clustering of households into larger communities; skeletal indicators of health/disease. In addition to coding this insecurity based on published scholarly assessments of the extent of aggregation, we calculated an aggregation index for each culture area using settlement data in the Coalescent Communities Database (Hill et al. 2012). Our index is: total number of rooms in a culture area divided by the total number of settlements in each area. The percent change in the index from one 50-year interval to the next, informs the coding.

\section{Coding: High}

Evidence supporting high health insecurity preceding depopulation in the Hohokam sub-region includes:

1. Archaeological synthesis. Based on multiple bioarchaeological studies, Hill and colleagues (2004:707, see also references therein) state, "Evidence from large sites such as Pueblo Grande indicates that aggregation and agricultural intensification in the Phoenix Basin led to a severe decline in health and life expectancy." Increasing aggregation prior to decline can be 
seen in the Tucson, Picacho, and Tonto areas (Fish 1989:34 and references therein; Waters 2006:42).

2. Increasing aggregation index: Aggregation increased 27\% between the 1300 to 1349 and 1350 to 1399 intervals. Depopulation likely began during the 1350 to 1399 interval (see Appendix 3).

3. High population density. The Hohokam culture area "supported the largest and most concentrated population in the U.S. Southwest throughout much of the pre-contact sequence" and the highest density of population was in the Phoenix basin, near the confluence of the Salt and Gila rivers (Clark and Abbott 2017:353). Between 30,000 and 75,000 people lived in southern Arizona during the 1200 to 1450 interval (Clark and Abbott 2017:353).

4. Canal systems and disease transmission. Fink $(1991: 63,64)$ argues that the structure of Hohokam irrigation, such as cross-cut canals, and the density of aggregation near these canals create an environment where disease could spread rapidly due to the vast amount of connectivity. The presence of pottery sherds and other refuse in the canal systems indicate that they may have been used for refuse disposal. If so, disease could be introduced to the canal system and traveled to many segments of the population (Fink 1991:67).

5. Increased use of platform mounds and multi-room compound structures. The rise of platform mounds and enclosed residential compound architecture in the lower Salt River basin (modern-day Phoenix, AZ) during the Classic period (ca. 1100 to 1375) is one indicator of increasing settlement density and aggregation (Abbott 2003). Platform mound construction also began in the Tucson Basin, specifically at the Marana site, during the Classic period (Doelle and Wallace 1991:325; Fish 1989:37). Additionally, Doelle and Wallace (1991:158, $164,293,325,327)$ note the minimal distance between platform mounds as evidence for a "strong trend toward settlement aggregation." Wallace and Holmlund (1984) also note that population in the Tucson Basin was "concentrated in a few locations." Changes in architectural style resulted in the disuse of courtyards that were subsequently converted into multi-room structures, which again signals increasing aggregation (Clark and Abbott 2017:355). Cordell et al. (1994:124) also identifies changing structure styles as a signal of increasing aggregation.

6. Oral history from the Akimel O'Odham people: Loendorf and Lewis (2017:125-126) and Teague (1993:435-452), detail Akimel O'Odham oral histories that describe high populations, conflict, flooding, and ideological shifts all consistent with causal explanations of settlement aggregation.

\section{Uncertainty: Moderate}

See McClelland (2015) for a critique of the extent of declining health in the Phoenix basin. Architectural evidence, high population density, and the aggregation index supports the interpretation of increasing settlement aggregation occurring in the Hohokam region prior to depopulation of the culture area. 


\section{Environmental Insecurity}

Indicator: drought and dryness.

Question: What was the extent of drought/dryness coincident with the decline, relative to drought/dryness during the period preceding decline?

Proxy: Comparison of prior interval dryness to depopulation interval dryness (see Environmental Insecurity in Insecurities, Archaeological Indicators, Coding Questions and Definitions above).

\section{Coding: High}

Evidence support high environmental insecurity includes:

1. Dryness index - PDSI

a. Prior interval, 1299 to 1374: Average PDSI, 0.7

i. Depopulation interval, 1375 to 1450: Average PDSI, 0.08, 1. $89 \%$ increase in dryness compared to the prior interval.

2. Dryness index - Average Salt, Tonto, Verde River streamflow (Graybill et al. 1989)

a. Prior interval, 1299 to 1374: Average Z scores of annual streamflow, 9.6

b. Depopulation interval, 1375 to 1450 : Average $Z$ scores of annual streamflow, -3.1

3. Graybill et al. (2006:89) also identified multiple periods of low streamflow at the Salt River from the mid-1200s to the mid-1300s.

\section{Uncertainty: Moderate.}

Discussed above in Insecurities Coding: Definitions and Methods, Environmental insecurity section.

\section{Personal Insecurity}

Indicator: conflict and violence.

Question: What was the extent and trajectory of conflict and violence within the culture area? Sample proxies: skeletal trauma, unburied bodies, fortified and defensive structures/settlements

As conflict and violence increased, mortality increased and movement away from dangerous conditions increased.

\section{Coding: High}

Evidence supporting high personal insecurity preceding the demographic decline in the Hohokam culture area includes:

1. Architectural evidence: Rice $(2001: 309 ; 318,319,322)$ notes the increasing use of wall compounds during the Classic period and platform mounds during the Late Classic period. 
LeBlanc (1999:256) also cites raised platform mounds and walled compounds constructed at sites along the Salt and Gila rivers, such as the Casa Buena and Casa Grande sites, during the Classic period as evidence of defensive architecture. Although not widespread, there is also architectural evidence for cerro de trincheras style sites in the Hohokam region (Downum et al. 2009). These site types have been identified as defensive sites, but Downum et al. (2009) do not believe that the Hohokam cerro de trincheras were primarily used for defensive purposes. This interpretation is based on the lack of soil appropriate for defensive platform construction, the orientation of the terraces, and the location of the cerro de trincheras sites on the outskirts of larger Hohokam settlements (Downum et al. 2009:269-270). Wallace and Doelle (2001) and Wilcox et al. (2001) also present evidence for increasingly fortified settlements during the Hohokam classic period. Additional architectural evidence includes walls at hilltop settlements that had holes to shoot arrows through and small entryways (Rice 2001:321).

2. Burned buildings and artifacts. At the Marana cluster of sites both buildings and wooden artifacts were burned, which Rice (2001:324) interpreted as a sign of warfare. Burned buildings have also been observed in the Tonto Basin and Globe-Miami areas (Waters 2006:42; LeBlanc 1999:257).

3. War as a means of water distribution. Rice $(2001: 305,306)$ argues that the organization of the Hohokam's irrigation system prompted the use of war as a means to "manage the distribution of water" and that settlements along the same canal system would band together. He notes that the Hohokam were engaged in warfare into $12^{\text {th }}, 13^{\text {th }}$, and $14^{\text {th }}$ centuries, although the intensity gradually decreased due to changes in settlement patterns and the increased use of defensive architecture (Rice 2001:305).

4. Bioarchaeological evidence. At the Las Colinas and La Ciudad sites LeBlanc (1999:260) details skeletal remains that show evidence of a violent death, such as embedded projectile points. Wilcox and Haas (1994) also note that of the five Hohokam platform mounds that have been excavated, $40 \%$ of the skeletal remains they found showed evidence of a violent death. Skeletal remains found at Brazaletas Pueblo also had evidence of violent death and trauma (Valehrach and Valehrach 1971 as cited in Wilcox et al. 2001; Rice 2001:322). In the Tonto Basin, a site contained skeletal remains of three people with cranial trauma in an intentionally burned room (Whittlesey 1994; Turner et al. 1994 as cited in Waters 2006:42).

5. Possible presence of war clubs. Rice $(2001: 324,325)$ also noted the presence of burned wooden artifacts at the Marana cluster sites and interpreted these to be war clubs. He discusses these artifacts' similarity to Maricopan and Piman war clubs.

6. Oral History from Akimel O'Odham people. Teague (1993) recounts oral traditions that describe violence during the Hohokam Classic period. See also Hill et al. (2015:640-641) and references therein.

Uncertainty: High 
Differing interpretations of the evidence (and lack thereof) of violence has resulted in varying beliefs as to the extent of conflict and violence. For example, Hill and colleagues $(2015: 614)$ point out that "little material evidence has been recovered from the lower Salt relative to other parts of the Southwest, raising questions about the role of conflict in demographic decline." Similarly, Wallace and Doelle (2001:273) note the lack of bioarchaelogical evidence for violent death, although they cite the limited excavation of platform mounds as a possible reason for the lack of evidence. We were persuaded by the rise of compound architecture, which signals at least the perception of personal insecurity, if not actual conflict and violence as well as by the oral histories containing stories of violence.

\section{Community Insecurity}

Indicator: immigration.

Question: What was the extent of in-migration from people outside the culture area?

Sample proxies: rising population levels above changes in internal population growth rates, intracommunity, ethnic-based architectural and material cultural differences.

As in-migration increased within and near existing communities, new social strategies were necessary for resolving tensions. These tensions likely increased due to increased resource competition in marginal areas. Out-migration lessens untenable social and environmental conditions.

\section{Coding: Moderate}

Evidence supporting moderate community insecurity preceding depopulation in the Hohokam sub-region includes:

1. Archaeological synthesis: Hill et al. (2010:44-45) states that "The presence of Pueblo migrants is mostly clearly documented in the Tonto and Safford basins and the lower San Pedro Valley, along the eastern perimeter of the largest Hohokam concentrations in the Phoenix basin." Evidence for migrants also includes changing architectural and ceramic styles and technology and changing land use (Hill et al. 2010:44-45 and references therein).

2. Population increase. Loendorf and Lewis (2017:130) note a two to threefold population increase as a result of migration along the Salt and Gila, such as in the Tonto Basin area and at Pueblo Grande. However, they also believe that migrants likely came from within the Hohokam cultural area and this interpretation is supported by the Hohokam region's cultural continuity (Loendorf and Lewis 2017:130).

3. Immigration into the Tonto Basin. Stark et al. (1995) concluded that early Classic period [1150 to 1350] migrations into the Tonto Basin involved a $25 \%$ increase in the local population.

4. Immigration into the Tucson Basin. Hill et al. (2004:706) notes the increasing presence of perforated plates, Maverick Mountain series ceramics, and mealing bins and suggest that these indicate northern groups immigrating to the Tucson Basin. Additionally, they suggest 
that groups from the northern Tucson Basin eventually moved south and joined the populations there (Hill et al. 2004:706).

5. Changes in material culture. Previous interpretations of immigration to the region have cited changes in material culture, such as the appearance of Salado pottery, to represent intrusion by distinct cultural groups (Abbott 2003:9). For example, the increased prevalence of Roosevelt Red ware, perforated plates, Maverick Mountain series ceramics, obsidian, and new architectural styles is presented as evidence of immigration from the Kayenta/Tusayan region into the lower San Pedro Valley, Safford Basin (Hill et al. 2004:702, 706). However, the attribution of "Salado" polychrome pottery and mortuary practices to indigenous Hohokam rather than migrants is strong evidence that population growth due to immigration at sites like Pueblo Grande was caused by settlement aggregation rather than immigration from a different cultural group (Abbott 2003:9). The interpretation of aggregation over immigration is also supported by cultural continuity in the region (Loendorf and Lewis 2017:130).

6. Increases in population growth rates in the Phoenix basin, Canal System 2. Through an analysis of all documented "houses" associated with Canal System 2 (the best documented Hohokam system), Ingram (2008:148-149) identified decreasing population growth rates between the Sacaton ( 975 to $1174 \mathrm{CE}$ ) and Soho (1175 to 1324) temporal/cultural phases followed by increasing population growth rates implying immigration between the Soho (1175 to 1234) and Civano (1325 to 1450) phases.

7. Increases in population growth rates in the Hohokam culture area: The CCD data (Hill et al. 2012) identify the 1250 to 1299 and 1300 to 1349 intervals as period of substantial immigration, with 0.66 and 0.42 compound annual growth rates, respectively. Growth rates declined during the 1350 to 1399 (-0.36) and 1400 to 1449 intervals (-3.14). For calculation methods, see explanation in Appendix 1.

\section{Uncertainty: Low}

Immigration from the Kayenta/Tusayan region into the Lower Salt River Valley, Tonto Basin, Lower San Pedro Valley, and Safford Basin has been well documented and described (Clark et al. 2019). Total numbers of immigrants, however, were relatively small compared to total population levels in the Hohokam culture areas, especially the densely populated Phoenix basin.

\section{Political Insecurity}

Indicator: social stratification.

Question: To what extent did individuals/groups have different levels of access to structural, ritual, or socioeconomic resources? Was it increasing?

Sample proxies: architecture within settlements increasingly differentiated, exclusive spaces, differential burial treatments. 


\section{Coding: High}

Evidence supporting high political insecurity preceding depopulation in the Hohokam sub-region includes:

1. Differentiated ballcourts, increasing use of platform mounds, and restricted ceremonial spaces: The prevalence of platform mounds themselves are indicative of a political or religious stratification, with access to ritual sites more limited than during the Preclassic Period, where ritual ballcourts were publicly accessible (Bayman 2002:78). LeBlanc (1999:199) and Rice (2001:319) also note that some lived on top of platform mounds where others were relegated to pit houses. Elite platform mounds were also typically more fortified (Rice 2001:319). Crown and Fish (1996) and Elson (1998) argue that ceremonial spaces were becoming increasingly exclusive during the Classic period.

2. Differential burial treatment: Cremation burials were common, and some were adorned with marine shells and "stylized craft goods," potentially representing inequality and reflecting "increased social distinctions" (Bayman 2001:273, 279, 287). At Snaketown, prestige goods were present at 3 out of 24 cremation burials (Nelson 1981:468 as cited in Fish 1989:50).

3. Social Network Analysis: Pailes (2014) conducted social network analysis by calculating both the Lorenz curve-based Gini coefficient and centrality scores. His analysis indicated an emerging elite class and increasing differentiation as well as overlap between ritual and economic inequality (Pailes 2014:482).

4. Elite control of trade. The similar type of prestige items and their concentration at Hohokam sites, such as Snaketown, led Nelson (1981) and McGuire (1983) to interpret that the elites controlled the influx of exchange items (both as cited in Fish 1989:49).

\section{Uncertainty: Low}

According to Pailes (2014:468), archaeological findings suggest a lack of the material inequality that is generally taken as evidence of social inequality or class stratification, such as differences in the types of artifacts burial sites. This contradicts the majority of the evidence we found, which does detail material inequality and status differentiation.

\section{SINAGUA AND CENTRAL ARIZONA}

\section{Economic Insecurity}

Indicator: trade and exchange.

Question: What was the extent of interregional trade/exchange relative to previous periods? Sample proxies: extent of non-local pottery and other goods in settlements 


\section{Coding: Low}

Evidence supporting low economic insecurity preceding depopulation in the Sinagua/Central Arizona sub-region includes:

1. Presence of non-locally produced goods. Reid and Whittlesey (1997:224) and Plog (1989:276) note the presence of non-local pottery and artifacts in the southern Sinagua region from $1100 \mathrm{CE}$ on. Kamp and Whittaker (1990) also analyzed the clay composition of ceramics found at Sinagua sites and determined they originated outside the local area. Turquoise, shell jewelry, and lithic raw materials from other areas was documented at the Lizard Man site (Kamp and Whittaker 1990:110-113). Turquoise originating from New Mexico and Colorado, rather than Arizona, has also been identified at other Sinagua sites (Plog 1989:274). It is also thought that the "Hopi Macroenonomy" (Wilcox and Holmlund 2007) linked the Verde Confederacy with the Hopi as well as the Chavez Canyon settlement. This allowed for the regular movement of resources, particularly Hopi yellow-ware and Obsidian (Wilcox and Holmlund 2007:101), into Perry Mesa. This active trade lasted well into the 14th century, dissolving with the Hopi Macroeconomy by 1400 (Wilcox and Holmund 2007). Multiple non-local ceramic styles and non-local shells have also been found throughout Tuzigoot sites and Tuzigoot-era burials (Pilles 2015:108, 109; Spurr and Deats 2015:38). In the Perry Mesa region, approximately $25 \%$ of plain-ware pottery was likely made elsewhere and brought into the region (Abbott et al. 2012:56).

2. Agricultural surplus for trade. By estimating the potential agricultural yield of the land in the Sinagua area compared to the population size, Pilles (2015:109-111) argues that the Sinagua could have produced a surplus for trade.

3. Obsidian trade. Hantman (1983 as cited in Plog 1989:274) describes how obsidian from as far away as Chihuahua and Utah was found at Sinagua sites in Arizona.

\section{Uncertainty: Low}

There is significant evidence of non-locally produced goods at a variety of Sinagua sites. We have not encountered evidence that contradicts this interpretation that the Sinagua cultural group was engaged in extensive trade prior to demographic decline.

\section{Food Insecurity}

Indicator: resource depletion/degradation.

Question: What was the extent and severity of resource depletion and degradation?

Sample proxies: declining diet breadth, change in previous resource procurement strategies (for example, shifting from cultivated to wild foods or vice versa), increased reliance on smaller or more immature mammals, increasing soil degradation, bioarchaeological indicators of food stress. 


\section{Coding: Low}

Evidence supporting low resource depletion preceding depopulation in the Sinagua sub-region includes:

1. Degradation of floodplain. Increased aggregation along the Verde Valley floodplain resulted in overuse of the land for agricultural production (Pilles 2015:102).

2. Population-resource imbalance. Berlin et al. (1990:13) suggests that the growing population during the Elden phase could have reached the carrying capacity of the area and resulted in a population-resource imbalance. He also posits a relationship between agricultural intensification during this period and the increasing pressure of a population-resource imbalance (Berlin et al. 1990:13).

3. Tree death. Kamp and Whittaker (2009:289) note that the modern-day Flagstaff region experienced drought and tree death in the later years of Sinagua occupation.

4. Increased hunting and gathering. Pilles (2015:102) suggests that due to an increasingly sparse agricultural environment, the Sinagua likely had to increase the amount of hunting and gathering to compensate for the resource deficit.

\section{Uncertainty: Moderate}

Pilles (2015:109-111) calculated the potential yield and consumption figures for areas in the Verde Valley and concluded that the available land would have been able to support the population; however, this conclusion is not in alignment with the archaeological evidence presented throughout the rest of the paper.

\section{Health Insecurity}

Indicator: settlement aggregation, bioarchaeological evidence (where/when available) Question: What was the extent of settlement aggregation and bioarchaeological evidence of disease, if any?

Sample proxies: spatial clustering of households into larger communities; skeletal indicators of health/disease. In addition to coding this insecurity based on published scholarly assessments of the extent of aggregation, we calculated an aggregation index for each culture area using settlement data in the Coalescent Communities Database (Hill et al. 2012). Our index is: total number of rooms in a culture area divided by the total number of settlements in each area. The percent change in the index from one 50-year interval to the next, informs the coding.

Coding: Moderate

Evidence supporting moderate levels of settlement aggregation preceding depopulation in the Sinagua sub-region includes: 
1. Architectural evidence. The New Caves site had approximately 200 rooms which is an increase in site size from previous periods (Kamp and Whittaker 2009:286). The layout at the New Caves site is also comprised of clusters which Kamp and Whittaker (2009:287) interpret as a signal of aggregation. The Stone Camp Pueblo site also has a very high density of habitations with one occurring "every 50 to 100 m" (Courtright and Neily 2012:229, 239).

2. Archaeological syntheses. Pilles (2015:102-105) provides the data and summarizes aggregation in the Verde Valley during the Tuzigoot phase (1300 to $1400 \mathrm{CE}$ ). Descriptions of growing pueblos can also be found in Reid and Whittlesey (1997:218), Doyel (2006:140), and Kruse-Peeples and Strawhacker (2012:264-268).

3. Multiple burials. Pilles (2015:112) discusses how pot-hunters at some Sinaguan sites have found burials with multiple bodies stacked together, which may be an indication that the community suffered from infectious disease.

4. Aggregation index. Comparing the extent of aggregation during the 1300 to 1349 interval to the 1350 to 1399 interval (the period when depopulation began) the extent of aggregation is the same. Aggregation during the 1300 to 1349 period was less than during the 1250 to 1299 interval.

\section{Uncertainty: Moderate}

While there is architectural evidence that suggest settlement aggregation was occurring, there is little to no direct evidence of increased disease transmission prior to decline. More bioarchaeological investigation in the region is needed in order to identify patterns of disease transmission, although this type of work presents many ethical challenges.

\section{Environmental Insecurity}

Indicator: drought and dryness.

Question: What was the extent of drought/dryness coincident with the decline, relative to drought/dryness during the period preceding decline?

Proxy: Comparison of prior interval dryness to depopulation interval dryness (see Environmental Insecurity in Insecurities, Archaeological Indicators, Coding Questions and Definitions above).

Coding: High

Evidence supporting high environmental insecurity includes:

1. Extent of dryness index:

a. Prior interval, 1299-1374: Average PDSI, 0.8

b. Depopulation interval, 1375-1450: Average PDSI, 0.01

i. a $99 \%$ increase in dryness from the prior interval

Uncertainty: Moderate. 
Discussed above in Insecurities Coding: Definitions and Methods, Environmental insecurity section.

\section{Personal Insecurity}

Indicator: conflict and violence.

Question: What was the extent and trajectory of conflict and violence within the culture area?

Sample proxies: skeletal trauma, unburied bodies, fortified and defensive structures/settlements

\section{Coding: Moderate}

Evidence supporting moderate conflict and violence preceding depopulation in the Sinagua subregion includes:

1. Increasing presence of defensive architecture. Kamp and Whittaker (2009:288, 289) note the Great Wall, a large enclosing wall at the New Caves site, and infer that it served a defensive purpose due to the isolated location and the large boulders used to construct the wall. Guebard (2016) has documented oral histories of violence at Montezuma's Castle and Castle A. Defensive architecture in the form of hilltop sites can be seen in both the Agua Fria and Perry Mesa regions during the Pueblo III period (Wilcox et al. 2001a; Wilcox et al. 2001b). There was also an increased building of hill-top forts, roof entries, and defensive walls which have been interpreted as defensive strategies. Multiple communication outposts as well as perimeter walls with loopholes were also present at the Horseshoe Peak site in the Perry Mesa region (Russell et al. 2012:171-173, 175).

2. Skeletal evidence of violent death. Several skeletons at the Castle A site at Montezuma Castle National Monument had cut marks and fractures, which Guebard (2016) provides as examples of violent death.

3. Evidence of burned structures. Guebard $(2016: 261,262)$ states that the Castle A structure was destroyed in a large fire. He also notes that skeletal remains with trauma were found within the burned structure (Guebard 2016:262). Rooms at Montezuma Castle also had evidence of burning (Guebard 2016:265).

4. Oral histories. Guebard $(2016: 262,264)$ describes Native American oral histories recount violence occurring at Montezuma's Castle and Castle A, and this oral history corresponds with the archaeological record at Castle A. A member of the Hopi tribe also associates the burning of buildings with violence (Guebard 2016:265). These oral histories cite violence as a main motive for emigration out of the region (Guebard 2016:266, 270).

\section{Uncertainty: Moderate}

Guebard (2016) does not demonstrate mass violence at Castle A, rather there are a few skeletons with evidence of violent death. Pilles (2015:111) also notes the variety of other reasons, besides defense, why elevated sites and other architectural characteristics may be preferable. Additionally, he identifies a Sinaguan tradition of burning structures, such as at Elden Pueblo, 
which casts doubt on the interpretation that the fire at Castle A was associated with violence (Pilles 2015:111). Pilles (2015:111) also challenges the presence of warfare based on the continuing existence of trade networks, which are relationships that normally weaken during times of violence. Furthermore, it is uncertain how much of the visible archaeological record at the Horseshoe Peak site is within the pre-Hispanic period, versus later occupation by other groups (Russell et al. 2012:176).

\section{Community Insecurity}

Indicator: immigration.

Question: What was the extent of in-migration from people outside the culture area?

Sample proxies: rising population levels above changes in internal population growth rates, intracommunity, ethnic-based architectural and material cultural differences.

\section{Community insecurity: High}

Evidence supporting high immigration preceding depopulation in the Sinagua sub-region includes:

1. Migrants from the north and central Southwestern regions. Immigration from northeastern Arizona into the Sinagua and Central Arizona areas was substantial during the late 1200s and early 1300s (Ingram 2014:32). Immigrants from the Tusayan and Kayenta subregions of the Ancestral Puebloan culture are thought to have migrated into the area (Clark 2001). Immigration from these areas has also been noted in the Perry Mesa region (Abbott et al. 2012:48).

2. Planned immigration. Wilcox, Roberston, and Wood (2001a) believe immigration into the Sinagua area to be a deliberate, coordinated, and planned act on the part of the people who made up the Central Arizona Tradition (CAT) in the late 1200s CE.

3. Use of integrative practices. Russell and Nez (2012) discuss how the people living in the Perry Mesa region practiced "reductive reorientation" as a way to try and integrate immigrants into the larger community. An example of this is the use of ritual racetracks.

4. Increases in population growth rates: The compound annual growth rate between the 1250 to 1299 and 1300 to 1349 intervals was $0.49 \%$, indicating moderate population growth rates with declining rates occurring during the 1350 to 1399 interval. For calculation methods, see explanation in Appendix 1.

5. Immigration after the eruption of Sunset Crater, 1085 CE. People are thought to have moved into the region after the eruption of Sunset Crater (Reid and Whittlesey 1997:215, 216; Colton 1946 as cited in Preucel 2005:181). This immigration precedes the insecurities coding period but is important to note.

\section{Uncertainty: Low}


Multiple sources attribute the high population growth rates to increasing immigration in the region. While immigration is not disputed, the exact origin of migrants is unclear.

\section{Political Insecurity}

Indicator: social stratification.

Question: To what extent did individuals/groups have different levels of access to structural, ritual, or socioeconomic resources? Was it increasing?

Sample proxies: architecture within settlements increasingly differentiated, exclusive spaces, differential burial treatments.

\section{Coding: Moderate}

Evidence supporting moderate social stratification preceding depopulation in the Sinagua subregion includes:

1. Differential burial treatment. Kamp and Whittaker (1990), citing Hohmann (1983), detail the varying number of offerings present at Sinagua, with some burials receiving upwards of twenty offerings whereas the majority received between zero and three offerings. Subadult burials with multiple offerings are also presented as evidence of hereditary status (Kamp and Whittaker 1990:114). Spurr and Deats (2015:39) also cite Anderson (1992) who states that some burials had increased amounts of jewelry or other artifacts, indicating some level of status, but overall, he does not believe there was a "strict social ranking." Hohmann's (1983 as cited in Plog 1989:277) analysis of burials in the Flagstaff area also revealed differential burial practices.

2. Presence of rare goods. Kamp and Whittaker (1990) posit that the "the sorts and quantities of goods" present at Lizard Man Village indicate that the site was influential in the larger Sinagua system.

3. Agricultural surplus. Berlin et al. (1990:13) suggests that the agricultural intensification that occurred during the Elden Phases was in order to create a food surplus due to the development of social hierarchies.

4. Archaeological synthesis. Pilles (1996:71) states that "Concomitant with the aggregation process, there is also evidence for the development of clans, societies, and high-status individuals."

\section{Uncertainty: Low}

There appears to be an archaeological consensus that some amount of social stratification was present, although it was likely not a strict hierarchy. 


\section{PATAYAN}

Note: According to Rogers (1945) and Aaron Wright (2020, personal communication) the Patayan culture area did not experience depopulation similar to other culture areas within the SW/NW. Environmental insecurities can be coded, however, for descriptive purposes using the North American Drought Atlas PDSI data used to measure the extent of dryness in other culture areas. People of the Patayan culture area interacted with people in the adjacent Hohokam area; therefore, we use depopulation intervals there to calculate the extent of dryness.

\section{Environmental Insecurity}

Indicator: drought and dryness.

Question: What was the extent of drought/dryness coincident with the decline, relative to drought/dryness during the period preceding decline?

Proxy: Comparison of prior interval dryness to depopulation interval dryness (see

Coding: Moderate

Evidence supporting moderate environmental insecurity includes:

1. Extent of dryness index:

a. Prior interval, 1299 to 1374 , Average PDSI, 0.8

b. Depopulation interval, 1375 to 1450 , Average PDSI, 0.23

i. A $71 \%$ increase in dryness compared to the prior interval

Uncertainty: Moderate.

Many people in the Patayan culture area lived nearby or had access to the perennial Colorado River. Summer PDSI may, therefore, be a weaker measure of environmental insecurity than variation in Colorado River streamflow (see Meko et al. 2007). See also uncertainties, discussed above in Insecurities Coding: Definitions and Methods, Environmental insecurity section.

\section{MOGOLLON}

\section{Economic Insecurity}

Indicator: trade and exchange.

Question: What was the extent of interregional trade/exchange relative to previous periods?

Sample proxies: extent of non-local pottery and other goods in settlements

As trade/exchange networks decrease, opportunities to engage social strategies for buffering risks decrease (e.g., alliances, reciprocity). Risks (real or perceived) that cannot be buffered can lead to strategies such as migration to mitigate risks.

Coding: Moderate 
Evidence supporting moderate economic insecurity preceding depopulation in the Mogollon subregion includes:

1. Presence of non-local goods. Macaws, copper bells, and shell ornaments from outside the Mogollon region have been found at Grasshopper Pueblo, although in low quantities which is indicative of an "informal" trading system (Reid 1989:88). Gilman et al. (2014) also note that macaw skeletal remains and macaw imagery were found at multiple Classic period sites and discusses their importation from Mesoamerica.

2. Presence of non-local ceramics. Ceramics from the Ancestral Puebloan, Hohokam, and Chihuahua area, as well as White Mountain Redware have been found in Mogollon ceramic assemblages from the Late Late Pueblo period (Nisengard 2006:89; Reid 1989:88, 89).

3. Archaeological synthesis. Compared to the Classic phase, which had a distinct lack of nonlocal pottery, trade increased during the Postclassic Phase (Hegmon et al. 1998:151; Hegmon et al. 2016:58). LeBlanc (1999) and Nelson and LeBlanc (1996 as cited in Nisengard 2006:83) note that during the Late Pueblo Period there was increased interaction with nonMogollon communities.

4. Scale of Grasshopper Pueblo. Reid (1989:79) states that, due to its size, Grasshopper Pueblo would have likely had the means to import items.

\section{Uncertainty: High}

Hegmon et al. (2016:61) also suggest that the Mogollon began to remove themselves from the Hohokam trading network and were not involved in the Chacoan trading system. Nelson and Hegmon (2001:216) classifies non-local goods as "rare." For example, at the NAN Ranch Ruin, Shafer (2003:187) found that "less than one half of 1 percent" of the pottery was non-local. There is significant conflicting evidence as to the extent that the Postclassic Mogollon participated in trade and exchange.

\section{Food Insecurity}

Indicator: resource depletion/degradation.

Question: What was the extent and severity of resource depletion and degradation?

Sample proxies: declining diet breadth, change in previous resource procurement strategies (for example, shifting from cultivated to wild foods or vice versa), increased reliance on smaller or more immature mammals, increasing soil degradation, bioarchaeological indicators of food stress.

\section{Coding: Moderate}

Evidence supporting moderate resource depletion preceding depopulation in the Mogollon subregion includes: 
1. Reduction in agricultural land. By determining the predicted amount of agricultural land available using GIS, Schollmeyer (2011) found that after 1120 A.D., the Mogollon would have had to use less desirable and/or more distant land to grow crops. However, although the land was less desirable, there was still enough arable land to support the population (Schollmeyer 2011:7).

2. Shift to agriculture. At Chodistaas Pueblo, there was a shift from hunting and gathering to an increased emphasis on agriculture in the late $13^{\text {th }}$ century (Reid 1989:77, 78).

3. Bioarchaeological evidence of nutritional stress. During the Dispersion Period (1330-1400 CE), skeletal remains at Grasshopper Pueblo showed signs of "increased physical stress" (Hinkes 1983 as cited in Reid et al. 2006:131).

4. Increased hunting of immature deer. Olsen (1990 as cited in Reid et al. 2006:132) notes that during the Dispersion Period at Grasshopper Pueblo, the inhabitants began to hunt increasingly younger mule deer due to declining agricultural productivity.

\section{Uncertainty: High}

Nisengard (2006:87) does note a decrease in agricultural production during the Early Late Pueblo period but suggests this is simply due to less people living in the area than due to environmental causes. During the Late Late Pueblo period, the larger sites, such as Grasshopper Pueblo, were still successfully cultivating foods (Nisengard 2006:92). Reid (1989:82) also states that in the Grasshopper Pueblo region, the Mogollon did not change their technology in an attempt to increase food production. LeBlanc $(1989: 199,200)$ also does not see evidence that the Mogollon experienced resource stress during the Late Pueblo period and notes that even if there was a climactic shift, the Mogollon had sufficient land available to adapt to those changes.

\section{Health Insecurity}

Indicator: settlement aggregation, skeletal indicators (where/when available) Question: What was the extent of settlement aggregation and bioarchaeological evidence of disease, if any?

Sample proxies: spatial clustering of households into larger communities; skeletal indicators of health/disease. In addition to coding this insecurity based on published scholarly assessments of the extent of aggregation, we calculated an aggregation index for each culture area using settlement data in the Coalescent Communities Database (Hill et al. 2012). Our index is: total number of rooms in a culture area divided by the total number of settlements in each area. The percent change in the index from one 50-year interval to the next, informs the coding.

Coding: Moderate 
Evidence supporting moderate health insecurity preceding depopulation in the Mogollon subregion includes:

1. Decreasing prevalence of communal structures. Nisengard (2006:119) looked at the prevalence of communal structures and concluded that the period from 1300 to 1450 had less communal structures than the previous periods. In general, Mogollon sites during the Late Pueblo period appeared to be smaller than in previous periods (Anyon and LeBlanc 1984 and Nelson and LeBlanc 1986 both as cited in Nisengard 2006:84; Nisengard 2006:86, 89).

2. Larger distance between sites. The Postclassic period featured more spread out habitation sites compared to the Classic Mimbres period where Blake et al. (1986:460, 461) describes how sites in the valley-bottom began to increase in size, potentially even doubling in size (Hegmon et al. 1998:157, 158).

3. Increasing health. Compared to the Classic period, Lippmeier (1991 as cited in Hegmon et al. 2016:57) argues that Postclassic populations were healthier.

4. Concentration in the Mimbres Valley. During the Black Mountain and Cliff phases, Blake et al. (1986:461) states that the "very large sites were abandoned", but that the remaining population was concentrated in the Mimbres Valley.

5. Increasing aggregation index. Between the 1350 to 1399 and 1400 to 1449 interval, aggregation increased $22 \%$. The index is the total number of rooms in the culture area divided by the number of settlements.

\section{Uncertainty: Moderate}

Site size is highly variable between the Mimbres Valley and Mogollon sites in Arizona, with the sites in Arizona being larger than in the previous period and the Mimbres Valley sites are smaller (Cordell 1997:378; Reid 1989 as cited in Nisengard 2006:85). For example, Grasshopper Pueblo, Turkey Creek pueblo, and Point of Pines Pueblo are large sites that were occupied during the Late Late Pueblo period (Nisengard 2006:90, 91; Reid 1989:75, 80). Reid (1989:80) believes that a major architectural shift and aggregation was occurring during the Late Pueblo Period but notes that this aggregation occurred at different times depending on the site. Hinkes (1983:184) also did see bioarchaeological evidence that subadults living in the later period at Grasshopper Pueblo did show some increase in stress markers, which contradicts the improving health identified by Lippmeier (1991 as cited in Hegmon et al. 2016:57).

\section{Environmental Insecurity}

Indicator: drought and dryness.

Question: What was the extent of drought/dryness coincident with the decline, relative to drought/dryness during the period preceding decline?

Proxy: Comparison of prior interval dryness to depopulation interval dryness (see Environmental Insecurity in Insecurities, Archaeological Indicators, Coding Questions and Definitions above). 
Coding: High

Evidence supporting high environmental insecurity includes:

1. Extent of dryness index:

a. Prior interval, 1299 to 1374 , Average PDSI: 0.8

b. Depopulation interval, 1375 to 1450 , Average PDSI: 0.1

i. An $85 \%$ increase in dryness compared to the prior interval

Uncertainty: Moderate.

Discussed above in Insecurities Coding: Definitions and Methods, Environmental insecurity section.

\section{Personal Insecurity}

Indicator: conflict and violence.

Question: What was the extent and trajectory of conflict and violence within the culture area?

Sample proxies: skeletal trauma, unburied bodies, fortified and defensive structures/settlements

\section{Coding: Moderate}

Evidence supporting moderate resource depletion preceding depopulation in the Mogollon subregion includes:

1. Archaeological syntheses. LeBlanc (1999:250, 251) notes that warfare was occurring in the Southern Mogollon area during the Late Pueblo period.

2. Sites build in easily defensible locations. LeBlanc (1999:245) has noted that some Late Late Pueblo period sites were constructed at easily defensible locations. Reid (1989:81, 89) and LeBlanc (1999:245) also describe smaller settlements in the Grasshopper Pueblo area that were built on hills and with clear vantage points. Tuggle and Reid (2001 as cited in Reid et al. 2006:131) also noted that sites were increasingly built in defensible locations.

3. Bioarchaeological evidence. Baustian et al. (2012) conducted an analysis of skeletal remains at Grasshopper Pueblo and found that a high proportion of the remains had cranial depression fractures. They have suggested an attack on Grasshopper Pueblo as the cause of these injuries (Baustian et al. 2012:109). Additionally, Cordell (1997:375-383 as cited in Nisengard 2006:93) notes skeletal evidence of violence during the Late Late Pueblo period. LeBlanc (1999:245) describes unburied bodies found at the Kinishba site. At Nuvakwewtaqa, Allen et al. (1985 as cited in Martin et al. 2008:120, 121) found evidence of scalping.

4. Burned buildings. At Point of Pines Pueblo, seventy rooms are thought to have been burned as a way to forcefully remove the people living there (Haury 1985 as cited in Reid 1989:75). Chodistaas Pueblo was also burned at the time of abandonment, although it is not known whether this was a result of violence (Reid 1989:77, 78; LeBlanc 1999:245). Of three 
excavated sites dating from the 1300 C.E. to the 1400s C.E., all three were burned (Reid 1989:81).

\section{Uncertainty: Low}

Allen et al. (1985 as cited in Kantner 2004:222) only found 3 skeletal remains that suggested violent death at Grasshopper Pueblo.

\section{Community Insecurity}

Indicator: immigration.

Question: What was the extent of in-migration from people outside the culture area?

Sample proxies: rising population levels above changes in internal population growth rates, intracommunity, ethnic-based architectural and material cultural differences.

\section{Coding: High}

Evidence supporting high community insecurity preceding depopulation in the Mogollon subregion includes:

1. Possible immigration from the Ancestral Puebloan region. Evidence of site unit intrusions have been found in the Mogollon highlands, which have been attributed to immigration from the Kayenta region (Cameron and Ortman 2017:716). Haury (1985:388) notes that during the Carrizo phase (from approximately 1100 C.E. to 1200 C.E. [Nisengard 2006:65]), the Tla Kii site began to incorporate more Puebloan cultural elements and he suggests that Ancestral Puebloan immigration into the region may be the cause of this growing influence. At the Point of Pines Pueblo, Haury (1985 as cited by Reid 1989:75) states that immigrants from the Ancestral Puebloan region were living there in the late 1200s. In general, Reid (1989:80) also notes that aggregation during the Late Pueblo Period was partially due to immigration from the Ancestral Puebloan region. Burials at Grasshopper Pueblo also indicated that people from the Ancestral Pueblo region had migrated there (Reid 1989:87). The presence of Ancestral Puebloan immigrants has also been documented by Ezzo and Price (2002), Riggs (2001), Lowell (2010), and Longacre (1975) (all as cited in Baustian et al. 2012:103). Stone (2003) and Kantner (2004:209-212) also discuss immigration from the Kayenta region into Silver Creek, Grasshopper Pueblo, and Point of Pines Pueblo.

2. Switch from kivas to plazas. Graves and Van Keuren (2011 as cited in Baustian et al. 2012:103) have argued that the Mogollon's switch from using kivas to plazas was an attempt to integrate the community.

3. Growth of Grasshopper Pueblo. Reid (1989:83) notes that the growth of Grasshopper Pueblo from 1300 C.E. to 1330 C.E. is due to immigration.

4. Bioarchaeological evidence of immigration. Based on cranial deformation, it is thought that at least Ancestral Puebloan and Mogollon groups resided at Grasshopper Pueblo (Reid 
1989:87). Strontium isotope analysis of tooth enamel at Grasshopper Pueblo also indicated that some of the residents had moved there (Price et al. 1994 as cited in Stone 2003:51).

1. Substantial increases in population growth rates: The compound annual growth rate between the 1250 to 1299 and 1300 to 1349 intervals was $0.65 \%$, at the high end of what can be expected from internal changes in fertility and mortality (Cowgill 1975). In-migration (0.7 and above annual growth rates) is greater in the southern portion of the large Mogollon culture area (Ingram 2014:32). For calculation methods, see explanation in Appendix 1.

\section{Uncertainty: Moderate}

Although immigration has been suggested by a variety of sources as the reason for more Ancestral Puebloan elements, trade may also explain this (Haury 1985).

\section{Political Insecurity}

Indicator: social stratification.

Question: To what extent did individuals/groups have different levels of access to structural, ritual, or socioeconomic resources? Was it increasing?

Sample proxies: architecture within settlements increasingly differentiated, exclusive spaces, differential burial treatments.

\section{Coding: Moderate}

Evidence supporting moderate political insecurity preceding depopulation in the Mogollon subregion includes:

1. Differential burial treatments. At Grasshopper Pueblo, males were buried with more artifacts than women and ritual items were only found with male burials, which Reid interprets as a sign that males had a higher status (Reid 1989:86, 87). One male burial at Grasshopper Pueblo, had a high number of ceremonial artifacts and has been interpreted to have been a community leader (Reid 1989:87; Kantner 2004:223).

2. Sodality system. Reid (1989:87) details the gender-exclusive sodalities that existed at Grasshopper Pueblo, although it is unclear if there was a status difference between the sodalities. The sodality system is thought to be a part of the larger sequential hierarchy system that existed at Grasshopper Pueblo (Reid 1989:88). See also Kantner's (2004:230, 231) description of this system at Grasshopper Pueblo.

3. Exclusionary religious architecture. At Grasshopper Pueblo, Whittlesey and Reid (2001:69 as cited in Kantner 2004:225, 226) found that some groups had private ritual spaces and that only select spaces were open to the entire population for ceremonial use.

4. Presence of lineage households. Reid (1989:86) describes a hierarchy of kin groups at Grasshopper Pueblo and describes them as "structuring major divisions of the community". 
5. Status of Ancestral Puebloan immigrants. The Ancestral Puebloan population residing at Grasshopper Pueblo was thought to have "greater wealth and prestige" than most Mogollon residents at the site (Reid 1989:88).

\section{Uncertainty: Moderate}

In the southern Mogollon area, there did not appear to be an elite group or sodalities during the Cliff phase and the time period is categorized as "egalitarian" (LeBlanc 1989:197, 198).

Additionally, a bioarchaeological analysis of skeletons from Grasshopper Pueblo did not indicate that any subgroups were present or that one sex experienced more violent trauma than the other (Baustian et al. 2012). Baustian et al. $(2012: 108,109)$ also did not see large differences in the amount of grave goods between burials. Overall, Baustian et al. (2012:109) did not think that the Mogollon at Grasshopper Pueblo used violence in order to maintain social stratification. A weakness of this data is that it is only drawn mainly from Grasshopper Pueblo and the surrounding area. There is limited data available from many other Postclassic Mogollon sites and we have used Grasshopper Pueblo as a representative site.

\section{TRINCHERAS}

Note: Most of the data used to characterize the Trincheras culture area is from the Cerro de Trincheras site, the largest site in the tradition, founded sometime between 1250 and 1300 . There is little knowledge of the tradition in the years immediately preceding the founding of this central place.

\section{Economic Insecurity}

Indicator: trade and exchange.

Question: What was the extent of interregional trade/exchange relative to previous periods? Sample proxies: extent of non-local pottery and other goods in settlements

\section{Coding: High}

Evidence supporting a low level of trade and exchange preceding depopulation in the Trincheras sub-region includes:

1. Minimal non-local goods. Based on excavations at Cerro de Trincheras, the largest and most thoroughly documented site in the sub-region, McGuire and Villalpando (1998; 2011; 2016) found few exotic, imported ceramic sherds at the site. Although evidence of craft production is present at the site, McGuire and Villalpando $(1998 ; 2016: 19)$ interpret jewelry production as primarily for local consumption.

2. Lack of control of trade. Vargas (2004:75) states that "Given the lack of evidence for control of shell acquisition, production, or distribution by the inhabitants of the Cerro de 
Trincheras, it appears that this economic realm of activity was not a significant basis of power for residents of the center." Rather, she argues it was more likely in the ritual realm, based on relatively higher frequencies of Conus tinklers compared to surrounding sites and the relationship between Conus tinklers and ritual elsewhere.

3. Trincheras pottery found at other sites. At Playa Noriega, a contemporaneous ancestral Comca'ac site, there was Trincheras red-on-purple pottery, which Carpenter et al. (2015:250) take as evidence for trade between the two communities.

\section{Uncertainty: Moderate}

The largest and best documented site is Cerro de Trincheras. Because inter-regional trade was low, we are assuming it was low in this culture area prior to the ca. $1300 \mathrm{CE}$ formation of this site. Contrary to McGuire and Villalpando (1998; 2016), Gallaga and Newell (2004:7) state that the production of locally decorated ceramic types ceased because archaeologists have found only foreign types originating mostly from the southern portion of the American Southwest and the Paquimé area.

\section{Food Insecurity}

Indicator: resource depletion/degradation.

Question: What was the extent and severity of resource depletion and degradation? Sample proxies: declining diet breadth, change in previous resource procurement strategies (for example, shifting from cultivated to wild foods or vice versa), increased reliance on smaller or more immature mammals, increasing soil degradation, bioarchaeological indicators of food stress.

\section{Coding: Low}

No evidence has been identified to suggest resource depletion or degradation. The most extensive work has been conducted at Cerros de Trincheras (McGuire and Villalpando 2011; 2016)

\section{Uncertainty: High}

\section{Health Insecurity}

Indicator: settlement aggregation, bioarchaeological evidence (where/when available) Question: What was the extent of settlement aggregation and bioarchaeological evidence of disease, if any?

Sample proxies: spatial clustering of households into larger communities; skeletal indicators of health/disease. In addition to coding this insecurity based on published scholarly assessments of the extent of aggregation, we calculated an aggregation index for each culture area using settlement data in the Coalescent Communities Database (Hill et al. 2012). Our index is: total 
number of rooms in a culture area divided by the total number of settlements in each area. The percent change in the index from one 50-year interval to the next, informs the coding.

Coding: High

Evidence supporting high community insecurity preceding the demographic decline in the Trincheras sub-region includes:

1. Settlement aggregation. McGuire and Villalpando (2015:431) state that the construction of Cerro de Trincheras was a result of aggregation into the Rio Magdalena area in Sonora. Cerro de Trincheras was estimated to have a population of over 1,000 (McGuire and Villalpando 1998:3). Settlement aggregation is thought to have begun during the 1300 to 1450 period, as the number and variety of sites decreased and sites that persisted were larger in size (Gallaga and Newell 2004:7; McGuire and Villalpando 2015:437)--this is when Cerro de Trincheras was built and the El Cerro phase began (McGuire and Villalpando 2015:437).

\section{Uncertainty: Low}

Only one site, Cerro de Trincheras, informs this assessment. There is also no bioarchaeological evidence of declining health.

\section{Environmental Insecurity}

Indicator: drought and dryness.

Question: What was the extent of drought/dryness coincident with the decline, relative to drought/dryness during the period preceding decline?

Proxy: Comparison of prior interval dryness to depopulation interval dryness (see Environmental Insecurity in Insecurities, Archaeological Indicators, Coding Questions and Definitions above).

Coding: Low

Evidence supporting high environmental insecurity includes:

1. Extent of dryness index:

a. Prior interval, 1399 to 1424 , Average PDSI, -0.4

b. Depopulation interval, 1425 to 1450 , Average PDSI, -0.09

i. A $79 \%$ increase in wetness, toward average conditions, compared to the prior interval.

Uncertainty: Moderate.

Discussed above in Insecurities Coding: Definitions and Methods, Environmental insecurity section.

\section{Personal Insecurity}

Indicator: conflict and violence. 
Question: What was the extent and trajectory of conflict and violence within the culture area? Sample proxies: skeletal trauma, unburied bodies, fortified and defensive structures/settlements

\section{Coding: Moderate}

Evidence supporting moderate personal insecurity preceding depopulation in the Trincheras subregion includes:

1. Defensive motivation for hilltop and cerro de trincheras construction: Hill top terraces and walls are interpreted as defensive works by McGuire and Villalpando (2015, 2016:19). This interpretation relies on the expectation that if terraces, walls, and other features increased the costs of movement for domestic purposes, they can be inferred to be defensive. GIS leastcost movement analysis at several sites determined that the significantly increased the cost of climbing and moving through the hills made communities more defendable. They also argue for the presence of redoubts as refuges. Kowalewski (2007) also notes the defensive aspects of cerro de trincheras and believes specific sites' role in larger social structures may have played a role in their usage.

\section{Uncertainty: High}

Trincheras architecture is only an indirect indicator of conflict and violence. Other functions and benefits (e.g., ritual/ceremonial, agricultural) have been argued and documented (e.g., Downum et al. 1994 and Phillips 2009). Trincheras sites span almost three millennia (1250 to $1450 \mathrm{CE}$ ) and are found in a large geographical area, beyond the Trincheras culture area (Fish et al. 2018).

\section{Community Insecurity}

Indicator: immigration.

Question: What was the extent of in-migration from people outside the culture area?

Sample proxies: rising population levels above changes in internal population growth rates, intracommunity, ethnic-based architectural and material cultural differences.

\section{Community insecurity (immigration): Moderate}

Evidence supporting moderate community insecurity preceding depopulation in the Trincheras sub-region includes:

1. Site formation due to Hohokam immigration. McGuire and Villalpando (2016) interpret the construction of the Cerro de Trincheras site as a response to the arrival of Hohokam immigrants in Sonora's Altar valley.

2. Possible presence of captive Hohokam women. Sells Plain, a Hohokam ware, is present at Cerro de Trincheras but produced with local materials and the local manufacturing method. A hybrid pottery type, Lisa $3 \mathrm{~A}$, blends paddle-and-anvil and coil-and-scrape manufacturing techniques in the same vessel. Chiykowski (2016:20) interprets this as evidence of the 
presence of Hohokam women producing pottery at Cerro de Trincheras and their efforts to fit in to their new homes.

3. Attraction to agricultural land. Fish and Fish (2004:63) speculate that a major portion of population growth near Cerro de Trincheras during the El Cerro phase (1300 to 1450) "was the result of in-migration to irrigable floodplains and lower basin alluvial fans where intensification could be most readily achieved."

\section{Uncertainty: Low}

The presence of Hohokam pottery techniques indicates that a unique cultural group migrated into the region and brought aspects of their culture with them. We have found no contradicting evidence that suggests immigration was not a factor in the forming of the primate center.

\section{Political Insecurity}

Indicator: social stratification.

Question: To what extent did individuals/groups have different levels of access to structural, ritual, or socioeconomic resources? Was it increasing?

Sample proxies: architecture within settlements increasingly differentiated, exclusive spaces, differential burial treatments.

\section{Coding: High}

Evidence supporting high political insecurity preceding depopulation includes:

1. Intrasite settlement patterns. Villalpando and McGuire (2017:389) argue that the site of Cerro de Trincheras was home to elites who exerted control over agriculture, craft production, and ritual activities in the region. They interpret sites at the top of the hill as elite homes and/or specialized ceremonial areas (McGuire and Villalpando 2016:19; McGuire and Villalpando 1998:5; McGuire and Villalpando 2015:440, 448).

2. Elaborate architecture styles at Cerro de Trincheras. Fish and Fish (2004:63) state that the "Expanded hierarchy and institutions cross-cutting social constituencies appear to be reflected by the elaboration and complexity of residential, public, and ceremonial precincts at the Cerro de Trincheras."

3. Presence of prestige items. In homes on the top of hills, McGuire and Villalpando (2016:19; 2015:448) note the presence of prestige items such as parrots, shell, polychrome pottery, cloud-blower pipes, and animal remains.

\section{Uncertainty: High}

Gallaga's (2004:91) research on shell ornaments and polychrome ceramics "fail[ed] to support the existence of a central power or sector at the site that controlled the acquisition, production, and distribution of the shell and the acquisition-distribution of the polychrome ceramics..." 
When discussing Trincheras burial rituals, Cerezo-Roman (2016:22) notes that burial goods did not appear to differ between burials of different ages, sexes, or genders. At the Tio Benino and La Hormiga sites, McGuire and Villalpando $(2015: 437,438)$ did not find evidence of social differentiation in the form of elite residences or artifacts.

\section{RIO SONORA AND SERRANA}

NOTE: Based on the best available evidence, populations persisted in the Rio Sonora and Serrana culture areas without evidence of significant population loss (Matthew Pailes, personal communication 1 February 2020; see also Pailes 2017). Thus, this culture area is a case of persistence and demographic stability. We coded the conditions for the ca. 1200 to 1450 period for their descriptive value and to contribute to the geographical comprehensiveness of this study. Those conditions documented in the Rio Sonora area identified low or moderate insecurities, as expected based on the continuity without substantial depopulation in the area.

\section{Economic Insecurity}

Indicator: trade and exchange.

Question: What was the extent of interregional trade/exchange relative to previous periods? Sample proxies: extent of non-local pottery and other goods in settlements

\section{Coding: Moderate}

Evidence supporting moderate economic insecurity in the Rio Sonora culture area during the period of SW/NW depopulation includes:

1. No evidence for extensive long distance exchange; mostly intra-regional exchange. Marine shells, Paquimé polychrome pottery, and obsidian from the northern regions was found at the Buenavista site (Carpenter and Sanchez 2016:13). While in the Moctezuma Valley, some imported goods have been found, Pailes (2016:15) notes that trade, specifically of obsidian, may have been restricted to a few sites. Newell and Gallaga (2004:10 and references therein) have also noted turquoise, pottery, shells, and copper bells that indicate some long-distance trade was occurring, mostly with Paquimé and the American Southwest. Pailes et al. (2021:9, 18-22) did find pottery originating from Casas Grandes in the Sahuaripa valley, however it only comprised $1.5 \%$ of that assemblage, and in the Fronteras valley. Pailes (2015:538-540) also notes that obsidian was also imported to the Rio Sonora area and, at Teonadepa, at least $25 \%$ of the ceramics there were imported. R. A. Pailes (1984:321-323) and Doolittle (1988) have also found evidence of imported goods in the Rio Sonora region. When discussing projectile point morphology, Pailes et al. (2021:12) also find further evidence of regional variability in the intensity of trade with other communities. Overall, Pailes et al. (2021:7) describe "discontinuous patterns" of regional activity and exchange, which likely accounts for the intraregional variation in artifact prevalence. 
2. Possible centralized trade centers. Doolittle (1984 and sources therein) discuss the possibility that larger settlements developed due to a need for regional trading centers based on their relative location to other sites. Doolittle $(1988: 41,60)$ also discusses this possibility, but notes that many of the sites do not conform to how regional trading centers normally develop. Overall, Doolittle (1984:23; 1988:60) thinks that the trading aspects of this sites were a secondary development.

3. Association with Casas Grandes and Trincheras. Villalpando and McGuire (2017:392) state that the Rio Sonora culture traded with Casas Grandes and functioned as an "intermediary in the exchange between the Paquimé and Cerro de Trincheras."

4. Cranial modification similar to West Mexican practices. Pailes et al. (2021:11-12) note a skeleton with evidence of cranial modification found at the Rancho Los Zopoquis site in the Onavas valley by Hernández-Espinoza (2017 as cited in Pailes et al. 2021:12). The type of cranial modification has been likened to that found in the West Mexican area of Huatabmpo (Watson and Garcia 2016:228-230; Ekholm 1939 as cited in Pailes et al. 2021:11-12) and this similarity has been inferred to represent possible interaction between the two communities (Pailes et al. 2021:12).

\section{Uncertainty: High}

Despite his conclusion that obsidian was brought into the region, Pailes (2015:545) later states that there is "no evidence" that the people in Rio Sonora participated in long-range trade. Doolittle (1988:59) also critiques R. A. Pailes' (1980) and R. A. Pailes and Reff's (1985) earlier interpretations of ceramics found in the Sonoran area and believes that Pailes overestimated the amount of non-local ceramics found in the Valley of Sonora. Pailes et al. (2021:23) also note that some sites in the northern area of Sonora are "fully Casas Grandes in character." Overall, there is substantial variability in the types of trade occurring within the Rio Sonora area (Pailes et al. 2021:7-14,22) and the data is limited.

\section{Food Insecurity}

Indicator: resource depletion/degradation.

Question: What was the extent and severity of resource depletion and degradation?

Sample proxies: declining diet breadth, change in previous resource procurement strategies (for example, shifting from cultivated to wild foods or vice versa), increased reliance on smaller or more immature mammals, increasing soil degradation, bioarchaeological indicators of food stress.

\section{Coding: Low}

Evidence supporting low food insecurity in the Rio Sonora culture area during the period of SW/NW depopulation includes: 
1. High artiodactyl indices. Pailes (2017) analyzed the faunal assemblages present at the El Nogal, Teonadepa, and Los Mineros sites and calculated an artiodactyl index. In the Moctezuma Valley the index was .85 and in the Sonora Valley it was .66 (Pailes 2017:140). These high indices are associated with a low level of resource insecurity (Pailes 2017:145, 146).

2. Double cropping. Pailes (personal communication, 2020) notes that double or triple cropping was practiced in the region. R.A. Pailes (1984:315) also notes that the Rio Sonora area was "easily amenable to double cropping." Double cropping enhances food production and possibly food security and is an indirect indicator that resource depletion/degradation was likely not threatening food security in the area.

3. Approaching the area's carrying capacity. Doolittle (1980:341) argues that the region was beginning to approach carrying capacity during the late phase of occupation. Population growth has also been cited as a possible stressor by Grigg (1976) and Cohen (1977) (both as cited in Doolittle 1988:51).

4. Increased use of floodplain agriculture. Doolittle (1988:51) states that the increased use of floodplain agriculture in the later years of occupation would have resulted in the decreased availability of wild food resources. However, he does think that there was enough agricultural productivity to compensate (Doolittle 1988:51).

5. Shift to northern part of the valley due to resource stress. In the early phase of occupation, Doolittle (1988:58) suggests that resource stress prompted the population to migrate to the northern half of the valley.

\section{Uncertainty: High}

Evidence is minimal to interpret food insecurity in the culture area.

\section{Health Insecurity}

Indicator: settlement aggregation.

Question: What was the extent of settlement aggregation and bioarchaeological evidence of disease, if any?

Sample proxies: spatial clustering of households into larger communities; skeletal indicators of health/disease. In addition to coding this insecurity based on published scholarly assessments of the extent of aggregation, we calculated an aggregation index for each culture area using settlement data in the Coalescent Communities Database (Hill et al. 2012). Our index is: total number of rooms in a culture area divided by the total number of settlements in each area. The percent change in the index from one 50-year interval to the next, informs the coding.

\section{$\underline{\text { Health insecurity: Moderate }}$}

Evidence supporting moderate health insecurity in the Rio Sonora culture area during the period of SW/NW depopulation includes: 
1. Change in settlement patterns. In eastern Sonora, two large, late phase sites were identified and included large-scale public architecture (Doolittle 1984). Most sites, however, were composed of eight or fewer houses (Doolittle 1984:19). 2.5\% of sites were also determined to be nucleated villages comprised of 26 to 100 habitations (Doolittle 1984:20). Doolittle (1988:39) notes a decrease in the amount of settlements but an increase in site size which he interprets as aggregation.

\section{Uncertainty: High}

Doolittle $(1984 ; 1988 ; 2008)$ interprets the presence of two-story structures in some settlements. McGuire and Villalpando (1989) question this interpretation. Refined settlement data supported by excavation will clarify the extent of settlement aggregation in this culture area.

\section{Environmental Insecurity}

Indicator: drought and dryness.

Question: What was the extent of drought/dryness coincident with the decline, relative to drought/dryness during the period preceding decline?

Proxy: Comparison of prior interval dryness to depopulation interval dryness (see Environmental Insecurity in Insecurities, Archaeological Indicators, Coding Questions and Definitions above).

\section{Coding: Low}

Evidence supporting low environmental insecurity includes:

1. Extent of dryness index:

a. Prior interval, 1299 to 1349 , Average PDSI, 0.5

b. Depopulation interval, 1350 to 1400 , Average PDSI, 0.3

i. A $45 \%$ increase in wetness compared to the prior interval.

\section{Uncertainty: Moderate.}

Discussed above in Insecurities Coding: Definitions and Methods, Environmental insecurity section.

\section{Personal Insecurity}

Indicator: conflict and violence.

Question: What was the extent and trajectory of conflict and violence within the culture area? Sample proxies: skeletal trauma, unburied bodies, fortified and defensive structures/settlements

\section{Coding: Moderate}


Evidence supporting moderate personal insecurity in the Rio Sonora culture area during the period of SW/NW depopulation includes:

1. Archaeological synthesis: "Warfare was likely a primary characteristic of the inferred balkanized landscape from approximately AD 1100 until contact" (Pailes 2017:395). Although warfare was common, it was not necessarily lethal (Pailes 2020, personal communication).

2. Spanish accounts of war. Based on early Spanish accounts, people of the Moctezuma valley frequently fought small wars (Pailes 2016).

3. Presence of defensive sites and cerro de trincheras. Phillips (1989:389) states that there were some defensive sites in the region with Doolittle (1988:33) also noting the presence of cerros de trincheras and in the Valley of Sonora. Pailes et al. $(2021: 5,6)$ also infer that walled compounds in the Sahuaripa area were increasingly built as a response to a perceived need for defense.

4. Communication system used for defensive purposes. Doolittle (1988:32-33) discusses the possibility of a communication system in the valley that could have been used for defensive purposes.

Note: Although conflict and violence appear to be endemic to the culture area, there is no evidence that insecurities due to conflict/violence increased during the late precontact period. Thus, we code this variable as moderate rather than high.

\section{Uncertainty: Moderate}

Evidence for conflict and violence is primarily inferred rather than direct. Pailes et al. (2021:22) also characterize the interactions between the Rio Sonora and Casas Grandes areas as "relatively peaceful." Pailes further states that there is "essentially no" bioarchaeological evidence of warfare (Pailes 2020:9).

\section{Community Insecurity}

Indicator: immigration.

Question: What was the extent of in-migration from people outside the culture area?

Sample proxies: rising population levels above changes in internal population growth rates, intracommunity, ethnic-based architectural and material cultural differences.

\section{Coding: Low}

Evidence supporting low community insecurity in the Rio Sonora culture area during the period of SW/NW depopulation includes:

1. Archaeological analyses. Doolittle (1984:23-24; 1997) states that the Rio Sonora area was increasing in population without immigration as a contributing factor. Pailes (2015:545) also 
notes that it is unlikely that "substantial immigration" occurred in the Rio Sonora area. However, in a previous article, R. A. Pailes (1984:321) determined that immigration did play a role in the development of social hierarchy in the Rio Sonora area.

\section{Uncertainty: Low/Moderate}

Doolittle (1988:55) critiques R. A. Pailes (1984) interpretation that immigration was a factor of the population growth of the Rio Sonora region and concludes that Pailes did not fully understand the source he was basing his interpretation on. Doolittle (1988:55) further states that immigration "need not be interjected to explain population growth."

\section{Political Insecurity}

Indicator: social stratification.

Question: To what extent did individuals/groups have different levels of access to structural, ritual, or socioeconomic resources? Was it increasing?

Sample proxies: architecture within settlements increasingly differentiated, exclusive spaces, differential burial treatments.

\section{Coding: Moderate}

Evidence supporting moderate political insecurity in the Rio Sonora culture area during the period of SW/NW depopulation includes:

1. Prestige goods. After analyzing the potential trade networks, Pailes (2016:15) concluded that although there likely were high-status individuals, they did not use the exchange of prestige goods as a way to exert control. However, Pailes (2015:539) does argue that only certain people in the Rio Sonora area were able to procure obsidian due to the item's status as a prestige good. Pailes (2020:44) also infers that "competitive gifting" was used by elites to demonstrate power.

2. Statelet system. Doolittle (1984:19) concluded that the Rio Sonora area was comprised of statelets, with one larger settlement surrounded by smaller settlements who took part in cultural activities at the larger site (c.f., Pailes below).

3. Ceramic analysis. Through ceramic analysis, Pailes (2015:540) suggests that high-status individuals were constrained to either El Nogal or Teonadepa given the "exclusive traditions" seen in ceramic design.

\section{Uncertainty: Moderate}

Pailes (2015:536) concluded that there was a lack of primate centers in the Rio Sonora area based on rank-size correlation analysis. He also notes that it is unlikely a few people were able to control agriculture in the region and that religion was also not an area controlled by only a few people (Pailes 2015:545). The region also lacks public architecture normally associated with exclusion and inequality (Pailes 2015:545). Pailes et al. (2016:7) state that there were likely only "weak institutional mandates for positions of authority." 


\section{CASAS GRANDES}

\section{Economic Insecurity}

Indicator: trade and exchange.

Question: What was the extent of interregional trade/exchange relative to previous periods? Sample proxies: extent of non-local pottery and other goods in settlements

\section{Coding: Low}

Evidence supporting low economic insecurity preceding depopulation in the Casas Grandes subregion includes:

1. Presence of imported goods. Exotic items such as parrots, copper, turquoise, shell, and decorated pottery were found at Casas Grandes (Minnis and Whalen 2003:1; Douglas 1992 and sources therein; Whalen 2013; Doolittle 1993:133). Douglas (1992:13) analyzed 214 rooms at Casas Grandes and found that a mean of $2.1 \%$ of the ceramics there were non-local. The majority of the shells found at Casas Grandes likely originated in the Gulf of California, meaning that they had to have been brought into Casas Grandes (Whalen 2013:625). Ravesloot (1988:72) also noted the presence of non-locally produced goods in burials at Casas Grandes. Kelley and Searcy (2015:36-38) also discuss Casas Grandes' increased control over the flow of exotic goods into the region during the Medio period.

2. Exported Ramos polychrome. While Ramos polychrome was produced at Paquimé, it appears to have been circulated throughout the larger region (Whalen and Minnis 2017).

\section{Uncertainty: Low}

Minnis (1989 as cited in Douglas 1992) has argued that prestige items were more likely for internal elite consumption than for trade with other groups. Whalen (2013:629) also suggests that while Casas Grandes was receiving large amounts of shell, they were not then exporting worked shell as had previously been stated by Di Peso.

\section{Food Insecurity}

Indicator: resource depletion/degradation.

Question: What was the extent and severity of resource depletion and degradation?

Sample proxies: declining diet breadth, change in previous resource procurement strategies (for example, shifting from cultivated to wild foods or vice versa), increased reliance on smaller or more immature mammals, increasing soil degradation, bioarchaeological indicators of food stress.

\section{Coding: Low}


Evidence supporting low food insecurity preceding depopulation in the Casas Grandes subregion includes:

1. Archaeological synthesis: During their discussion of Casas Grandes' food economy, Minnis and Whalen (2015) did not note that Casas Grandes experienced food stress during the Medio period.

2. Soil degradation. There is no evidence to show that the Casas Grandes region suffered from soil degradation (Minnis and Whalen 2015:55). After conducting chemical and physical analyses on the soil, none of the classic markers of soil degradation were found (Minnis and Whalen 2015:55).

3. Deforestation. There is no evidence to suggest that the region experienced deforestation. Wood charcoal from a variety of species is frequently found at sites along the Rio Casas Grandes, which one would not expect to find if large-scale deforestation had occurred (Minnis and Whalen 2015:55).

4. Presence of food surpluses. Minnis and Whalen $(2015: 47,55)$ credit the availability of food surpluses as part of the reason Casas Grandes was able to grow into such a large site. Minnis and Whalen (2003:3) also note that people at Casas Grandes were able to produce large amounts of crops, such as corn and agave and that elites during the Medio period were still able to produce large amounts of food for feasts.

\section{Uncertainty: Low}

The Casas Grandes region has been the subject of many studies and we have not found evidence that indicates a moderate or high amount of resource depletion prior to decline. However, a weakness of this evidence is that most of the research focuses on the Paquimé site, rather than the whole Casas Grandes region.

\section{Health Insecurity}

Indicator: settlement aggregation, bioarchaeological evidence (where/when available) Question: What was the extent of settlement aggregation and bioarchaeological evidence of disease, if any?

Sample proxies: spatial clustering of households into larger communities; skeletal indicators of health/disease. In addition to coding this insecurity based on published scholarly assessments of the extent of aggregation, we calculated an aggregation index for each culture area using settlement data in the Coalescent Communities Database (Hill et al. 2012). Our index is: total number of rooms in a culture area divided by the total number of settlements in each area. The percent change in the index from one 50-year interval to the next, informs the coding.

\section{Coding: Moderate}

Evidence supporting moderate health insecurity preceding depopulation in the Casas Grandes sub-region includes: 
1. Large site size inferred from architectural elements. Whalen et al. (2010:547) estimated the population of Paquimé based on the site's architecture and concluded that it was an "outstandingly large population." Casas Grandes has also been proposed to be a main site in the middle of a larger, regional cluster (Minnis 1989 as cited in LeBlanc 1999:252; Whalen and Minnis 1996).

2. Increased population growth encouraged by agricultural practices. According to Douglas and MacWilliams (2015:144), aggregation increased during the Medio period and this trend was encouraged by agricultural choices such as "a combination of moderate-scale irrigation in the river valleys and widespread expansion of runoff agricultural field systems."

3. Bioarchaeological evidence of disease. Of 238 Medio period burials, Rakita (2001:211) found that $26 \%$ had some sort of pathology, although he does not attribute a specific origin to the diseases.

4. Increased presence of outdoor burials. Rakita (2001:276) also associated an increase in indoor burials in private locations with aggregation of outside groups into the region. He argues that these groups were trying to maintain a group identity through their burial practices.

5. Archaeological analysis. Phillips (2008:7-8) notes that aggregation was occurring in the region and cites this as a possible reason for decline. LeBlanc (1999:62) also notes that Casas Grandes was "much larger than any other contemporary site in the region."

5. Aggregation index (Total number of rooms/total number of settlements in culture area): Comparing the extent of aggregation during the 1350 to 1399 interval to the 1400 to 1449 interval (the period when depopulation began) the extent of aggregation is virtually unchanged (1\% increase).

\section{Uncertainty: Moderate}

Many lines of evidence demonstrate that Casas Grandes was one of the largest sites in the Southwest/Northwest and was also surrounded by a cluster of many, smaller sites. There is evidence for disease in the population, but a link between this and settlement aggregation cannot be established.

Notes:

Paquimé was a large urban center but substantial changes and increases in aggregation at Paquimé or within the Casas Grandes culture area prior to depopulation, the focus of the coding, was not documented.

Although they agree that Paquimé was still a major cultural center, Whalen et al. (2010:547-548) did conclude that Paquimé was actually a smaller site in terms of population than previously 
thought and notes that a smaller population size is more in line with the organizational strategies seen at the site.

\section{Environmental Insecurity}

Indicator: drought and dryness.

Question: What was the extent of drought/dryness coincident with the decline, relative to drought/dryness during the period preceding decline?

Proxy: Comparison of prior interval dryness to depopulation interval dryness (see Environmental Insecurity in Insecurities, Archaeological Indicators, Coding Questions and Definitions above).

\section{Coding: Low}

Evidence supporting low environmental insecurity includes:

1. Extent of dryness index:

a. Prior interval, 1399 to 1424 Average PDSI, -0.8

b. Depopulation interval, 1425 to 1450 Average PDSI, 0.3

i. A $177 \%$ increase in wetness compared to the prior interval

\section{Uncertainty: Moderate.}

Discussed above in Insecurities Coding: Definitions and Methods, Environmental insecurity section.

\section{Personal Insecurity}

Indicator: conflict and violence.

Question: What was the extent and trajectory of conflict and violence within the culture area?

Sample proxies: skeletal trauma, unburied bodies, fortified and defensive structures/settlements

Coding: High

Evidence supporting high personal insecurity preceding depopulation in the Casas Grandes subregion includes:

1. Use of warfare to acquire non-local goods. Douglas (1992:20) theorizes that, given the unexpected patterning of nonlocal ceramics at Casas Grandes, their prestige may have come from how they were acquired. It has been argued that goods procured from warfare are inherently more valuable (Helms 1979 as cited in Douglas 1992:20)

2. Presence of watchtowers. During his investigation of Casas Grandes, Di Peso (1974 as cited in Swanson 2003:753) noted a regional system of watchtowers (atalayas) that he inferred to have been used for fire signaling. Spanish explorers and other visitors to the region also saw watchtowers in the region (Hammond and Rey 1928, Bartlett 1854, Blackiston 1906, 1908, 
Brand 1933 as cited in Swanson 2003:755-756). A survey by Swanson (2003:758, 764) identified 24 possible signaling structures in the Casas Grandes region that were likely used for defensive and ritual purposes.

3. Bioarchaeological evidence for post-mortem processing, skeleton trophies, and cannibalism. Casserino (2009:72, 89, 94-97) found that $28.6 \%$ of the skeletal remains he analyzed at Paquimé had evidence of post-mortem processing, which he presents as evidence of endo and exo-cannibalism. At Burial 44-13, the skeletal remains had evidence of cut marks, peeling, spiral fracturing, and pot polish (White 1992 and Turner and Turner 1999 as cited in Waller et al. 2018:415). This type of post-mortem processing can be seen in Mesoamerican sacrificial victims as well (Graulich 2000; Medina Martin and Sánchez Vargas 2007; Tiesler 2007:Table 2.1 as cited in Waller et al. 2018:416). Through isotopic analysis, one of the people interred was determined to have only come to Paquimé a few years prior and it has been suggested that they were a captive from raiding (Offenbecker 2018:199; Offenbecker et al. 2015 as cited by Waller et al. 2018:418). DiPeso (1974 as cited in LeBlanc 1999:87) also found skulls with holes drilled in the top which were inferred to be used to suspend the skulls as trophies, and Rakita (2001) also noted this. Ravesloot (1988:76) describes skeletal remains with trauma and who had likely been hit in the head. LeBlanc (1999:252), using Di Peso's (1974) data, calculated the number of unburied bodies to be around 1,000 people. Rakita (2001:63, 64, 192-195) notes that a large period of violence is thought to have occurred around the end of occupation at Paquimé, and the shift in burial age ratio aligns with this idea. An increase in corpse processing is also seen during this time period (Rakita 2001:266).

4. Goods made from human bone. Di Peso (1974 as cited in LeBlanc 1999:87) found jewelry and utilitarian items such as dishes made from human bone during his exploration of Casas Grandes. Ravesloot and Spoerl (1987 as cited in Ravesloot 1988:71) also notes the presence of artifacts made from human bone and discusses their association with warfare.

5. Oral history. Phillips (2008:6, 7) details an indigenous narrative that describes the people of Casas Grandes being pushed to the north due to violence and other populations entering the area.

\section{Uncertainty: Moderate}

Casserino $(2009: 69,70)$ analyzed the skeletal remains at Paquimé and found that only $7 \%$ showed signs of ante or peri-mortem fractures. Ravesloot (1988:76) does mention that there is evidence of skeletal trauma and unburied bodies, but if those were results of warfare he says is "impossible to evaluate." There are also no paintings or murals of violence found at Casas Grandes (Ravesloot 1988:76). In dealing with control of exchange routes, Douglas and MacWilliams (2015:147) do speculate that force could have been used but ultimately state that "less violent...tactics were the norm."

\section{Community Insecurity}

Indicator: immigration.

Question: What was the extent of in-migration from people outside the culture area? 
Sample proxies: rising population levels above changes in internal population growth rates, intracommunity, ethnic-based architectural and material cultural differences.

\section{Coding: Low}

Evidence supporting low community insecurity preceding depopulation in the Casas Grandes sub-region includes:

1. Archaeological analysis. Whalen and Pietzel (2015) analyzed the settlement patterns of the larger Casas Grandes area and did not report any evidence of outside populations moving into the region.

2. Increase in indoor burials. Rakita (2001:276) associated an increase in indoor burials in private locations with immigration of outside groups into the region. He argues that these groups were trying to maintain a group identity through their burial practices.

3. No evidence of substantial immigration based on settlement data. Based on the limited settlement data available in the Coalescent Communities database (Hill et al. 2012), compound annual growth rates between the 1350 to 1399 and 1400 to 1449 intervals were declining (-0.33\%). For calculation methods, see explanation in Appendix 1.

\section{Uncertainty: High}

Douglas and MacWilliams (2015:146) note that "direct evidence of pilgrimage from communities across the region to Paquimé is intrinsically difficult to demonstrate." We also did not find evidence of non-local architectural or material culture styles entering the region as one would expect to find if substantial immigration was occurring.

\section{Political Insecurity}

Indicator: social stratification.

Question: To what extent did individuals/groups have different levels of access to structural, ritual, or socioeconomic resources? Was it increasing?

Sample proxies: architecture within settlements increasingly differentiated, exclusive spaces, differential burial treatments.

\section{Coding: High}

Evidence supporting high political insecurity preceding depopulation in the Casas Grandes subregion includes:

1. Differential architecture indicating social stratification. Whalen and Minnis (2001a) identify two distinct types of domestic architecture in the Casas Grandes core and immediately surrounding area (within $\sim 30 \mathrm{~km}$ ). Differences are identified by thick vs. thin walls and room elaboration. They argue that thick-walled architecture in the hinterlands represents nodes of power and authority connected to the core area. They also argue that 
the over-building of the Casas Grandes primate center in addition to its sheer size and Mesoamerican-style ritual architecture conveyed a strong symbolic message of authority. Whalen and Minnis (2001b:335, 338) also note that the Casas Grandes core area had more ovens and architecture relating to food production than other settlements and this high amount of public architecture indicates centralization.

2. Prestige good distribution. Elite households are presumed to have existed at Casas Grandes due to the large amount of hoarded shell artifacts (Minnis and Whalen 2003:1; Whalen 2013; Whalen and Minnis 2001b). Whalen and Minnis (2001b:339) suggest that the hoarded prestige goods were then distributed by the elite. Exotic items also appeared most frequently at the primate center of Casas Grandes and less so in settlements in the Middle and Outer Zones (Whalen and Minnis 2001b:325, 335). Settlements in the Middle and Outer zones had more common and crudely worked shells, indicating that the settlements in the periphery did not receive as prestigious of items as those in the Inner zone (Whalen and Minnis 2001b:349).

3. Presence of ball courts. Whalen and Minnis (1996) argue that the presence of multiple ball courts around Casas Grandes are evidence for rivalry and competition between elites as a method of building power and prestige.

4. Differential burials. The items associated with Burial 44-13 at Paquimé have been interpreted to indicate a high-status burial (Ravesloot 1988:32-34; VanPool and VanPool 2007 both as cited by Waller et al. 2018:413). There was also a difference in the amount of grave goods between the articulated and disarticulated remains, which suggests a differentiation in status (Waller et al. 2018:416). Rakita (2001:230,231) also notes that during the Medio period, males often had more grave goods than females and speculates that this difference is indicative of "perceived status." Based on analysis of grave good frequency, Rakita (2001:272, 273) and Ravesloot (1988) concluded that the distribution of burial goods during the Medio period was indicative of a hierarchical society. Within burials, Ravesloot (1988) also notes that status differentials at Casas Grandes can be reflected through the differing locations of burials and post-mortem processing.

5. Bioarchaeological evidence of health differentiations according to social status. The articulated remains at Burial 44-13 showed evidence of less nutritional stress and overall better health due to their higher status (Waller et al. 2018:417). The disarticulated remains at Burial 44-13 also appeared to be of lower status (possibly of non-local origin) and had significant trauma that indicated ritual violence on the part of an elite class (Waller et al. 2018 and sources therein).

6. Higher prevalence of administrative functions in the Inner Zone. Whalen and Minnis (2001b:321-322) identified a pattern in the Inner Zone of the Casas Grandes region where higher-order settlements had more administrative functions than other settlements in the area. They also identified a scalar hierarchy of the sites surrounding Casas Grandes.

7. Iconography used to support power. Rakita (2009 as cited in Munson and Hays-Gilpin 2017:670) states that elites used imagery in order to support their power. Mesoamerican 
motifs are also cited as evidence of control by high status individuals (Whalen and Minnis 2017; Whalen and Minnis 2001b:344, 356, 357).

8. Spanish accounts of differential burials. Bartolome de las Casas described special burial treatment for high-status members of society (de las Casas 1967 as quoted in Ravesloot 1988:75).

\section{Uncertainty: Moderate}

Douglas (1992:18) analyzed the distribution of non-local ceramics in rooms at Casas Grandes and found that there was "limited variability in nonlocal ceramic distribution that can be related to social differences." Whalen (2013:631) does not believe that the large amounts of shells at Casas Grandes had other uses besides simply being a prestige item. Whalen and Minnis (2001b:336) also note that there is no pattern for exclusive use of areas at Casas Grandes, although the practice did occur. Based on Ravesloot's (1988) mortuary data, Whalen and Minnis (2001b:336, 357, 358) do not believe that the system of social differentiation, although present, was not very elaborate. However, the vast majority of the evidence does suggest that there was social stratification at Casas Grandes.

\section{Acknowledgements}

We thank the Colorado College students who have participated in this research by assisting with the coding of the insecurities and robust discussions of the research design. The 2018 coding team included Rayan Asfari, Breanna Conwell, Anna Doctor, Rowan Frederiksen, Rebecca Glazer, Trevor Hightower, Rachel Mintz, Shelby Patrick, Katie Pell, Willa Serling, Jake Shapiro, and Jasmin Thibou. The 2019 team included Caroline Alba, Dane Anderson, Josh Birndorf, Emily Faulks, Spencer Fier, Tyrien Fixico, Emily Gardner, Brian Leech, Shelby Patrick, and Clara Stein.

\section{LITERATURE CITED}

Abbott, D. R., editor. 2003. Centuries of decline during the Hohokam Classic period at Pueblo Grande. Tucson, University of Arizona Press.

Abbott, D. R. and M.-E. Walsh-Anduze. 1995. Temporal patterns without temporal variation: The paradox of Hohokam red ware ceramics. Pages 88-114 in B. J. Mills and P. L. Crown, editors. Ceramic production in the American southwest. Tucson, The University of Arizona Press.

Abbott, D. R., C. N. Watkins, and S. E. Kelly. 2012. Persistent connectivity across west-central Arizona during the fourteenth century: a ceramic perspective on the Verde confederacy model. Pages 47-62 in W. G. Russell and M. J. Hoogendyk, editors. Prehistoric cultures of the Perry Mesa region: proceedings of the Perry Mesa symposium. Friends of Agua Fria National Monument. 
Adams, K. R., K. A. Kuckelman, and V. E. Bowyer

2007 Archaeobotanical Remains. In The archaeology of Sand Canyon Pueblo: intensive excavations at a late-thirteenth-century village in southwestern Colorado, edited by K. A. Kuckelman. Available: http://www.crowcanyon.org/sandcanyon.

Adler, M. A. 1994. Population aggregation and the Anasazi social landscape: a view from the Four Corners. Pages 85-101 in W. H. Wills and R. D. Leonard, editors. The ancient Southwestern community: models and methods for the study of prehistoric social organization. Albuquerque, University of New Mexico Press.

Adler, M. A. 2017. The built environment. Pages 585-610 in B. J. Mills and S. Fowles, editors. The Oxford Handbook of Southwest Archaeology. Oxford, Oxford University Press.

Adler, M. A., T. Van Pool, and R. D. Leonard. 1996. Ancestral Pueblo population aggregation and abandonment in the North American southwest. Journal of World Prehistory 10(3):375-438.

Allen, W., C. F. Merbs, and W. H. Birkby. 1985. Evidence for prehistoric scalping at Nuvakwewtaqa (Chavez Pass) and Grasshopper ruin, Arizona. Pages 23-42 in C. F. Merbs and R. J. Miller, editors. Health and disease in the prehistoric Southwest. Tempe, Arizona State University.

Allison, J. R. 2010. The end of farming in the "Northern Periphery" of the Southwest. Pages 128155 in T. A. Kohler, M. D. Varien and A. M. Wright, editors. Leaving Mesa Verde: Peril and change in the thirteenth-century Southwest. Tucson, University of Arizona Press.

Allison, J. R. 2019. The northern frontier in the history of the greater Southwest. Pages 281-307 in K. G. Harry and B. J. Roth, editors. Interaction and connectivity in the greater Southwest. Louisville, Colorado, University Press of Colorado.

Anderson, K. M. 1992. Tuzigoot burials. Tucson, National Park Service, Western Archaeological and Conservation Center.

Anyon, R. and S. A. LeBlanc. 1980. The architectural evolution of Mogollon-Mimbres communal structures. Kiva 45(3):253-277.

Anyon, R. and S. A. LeBlanc. 1984. The Galaz ruin: a prehistoric Mimbres village in Southwestern New Mexico. Albuquerque: The Maxwell Museum of Anthropology and University of New Mexico Press.

Arakawa, F. 2012. Cyclical cultural trajectories: a case study from the Mesa Verde region. Journal of Anthropological Research 68(1):35-69.

Bartlett, J. 1854. Personal narratives of explorations and incidents in Texas, New Mexico, California, Sonora and Chihuahua. New York: D. Appleton.

Baustian, K. M., R. P. Harrod, A. J. Osterholtz and D. L. Martin. 2012. Battered and abused: analysis of trauma at Grasshopper Pueblo (AD 1275-1400). International Journal of Paleopathology 2(102-111). 
Bayman, J. M. 2001. The Hohokam of Southwest North America. Journal of World Prehistory 15:257-311.

Bayman, J. M. 2002. Hohokam craft economies and the materialization of power. Journal of Archaeological Method and Theory 9:69-95.

Berlin, G. L., D. E. Salas, and P. R. Geib. 1990. A prehistoric Sinagua agricultural site in the ashfall zone of Sunset Crater, Arizona. Journal of Field Archaeology 17(1):1-16.

Billman, B. R. 2008. An outbreak of violence and raiding in the central Mesa Verde region in the 12th century AD. Pages 41-69 in D. L. Nichols and P. L. Crown, editors. Social violence in the prehispanic Southwest. Tucson, The University of Arizona Press.

Blackiston, A. H. 1906. Ruins of the Cerro de Montezuma. American Anthropologist 8:256-261.

Blackiston, A. H. 1908. Ruins of the Tenaja and the Rio San Pedro. Records of the Past 11(1):282-290.

Blake, M., S. A. LeBlanc, and P. E. Minnis. 1986. Changing settlement and population in the Mimbres valley, SW New Mexico. Journal of Field Archaeology 13:439-464.

Bocinsky, R. K. and T. A. Kohler. 2014. A 2,000-year reconstruction of the rain-fed maize agricultural niche in the US Southwest. Nature Communications 5:1-12.

Boomgarden, S. A., D. Metcalfe, and C. Springer. 2014. Prehistoric archaeology in Range Creek Canyon, Utah: A summary of activities of the Range Creek field station. Utah Archaeology 27(1):9-32.

Brand, D. D. 1933. The historical geography of northwest Chihuahua. Department of Geography. Berkeley, University of California, Berkeley.

Cameron, C. M. 2006. Leaving Mesa Verde. Pages 139-148 in D. G. Noble, editor. The Mesa Verde world. Santa Fe, School of American Research Press.

Cameron, C. M. and S. G. Ortman. 2017. Movement and migration. Pages 715-728 in B. J. Mills and S. Fowles, editors. The Oxford Handbook of Southwest Archaeology. Oxford, Oxford University Press.

Carpenter, J. and G. Sanchez. 2016. The Sahuaripa Valley. Pages 12-13 in Archaeology Southwest Magazine. Archaeology Southwest.

Carpenter, J., G. Sánchez, J. Watson, and E. Villalpando. 2015. The La Playa archaeological project: binational interdisciplinary research on long-term human adaptation in the Sonoran desert. Journal of the Southwest 57(2/3):213-264.

Casserino, C. M. 2009. Bioarchaeology of violence and site abandonment at Casas Grandes, Chihuahua, Mexico. Department of Anthropology. Eugene, University of Oregon.

Cerezo-Román, J. I. 2016. Transformation by fire. Pages 22-23 in Archaeology Southwest Magazine. Archaeology Southwest. 22-23. 
Chiykowksi, T. 2016. Women on the move. Page 20 in Archaeology Southwest Magazine. Archaeology Southwest.

Clark, J. J. 2001. Tracking prehistoric migrations: pueblo settlers among the Tonto basin Hohokam. Tucson, AZ: University of Arizona Press.

Clark, J. J. 2020. Life of the Gila: mapping identities and worlds over a millennium. Available at: https://www.archaeologysouthwest.org/2020/02/13/life-of-the-gila-mapping-identities-andworlds-over-a-millennium/ [Accessed May 28, 2020].

Clark, J. J. and D. R. Abbott. 2017. Classic period Hohokam. Pages 353-380 in B. J. Mills and S. Fowles, editors. The Oxford Handbook of Southwest Archaeology. Oxford, Oxford University Press.

Clark, J. J., J. A. Birch, M. Hegmon, B. J. Mills, D. M. Glowacki, S. G. Ortman, J. S. Dean, R. Gauthier, P. D. Lyons, and M. A. Peeples. 2019. Resolving the migrant paradox: two pathways to coalescence in the late precontact US Southwest. Journal of Anthropological Archaeology 53:262-287.

Cohen, M. N. 1977. The food crisis in prehistory. New Haven, Yale University Press.

Colton, H. S. 1946. The Sinagua: a summary of the archaeology of the region of Flagstaff, Arizona. Flagstaff: Museum of Northern Arizona.

Coltrain, J. B. and S. W. Leavitt. 2002. Climate and diet in Fremont prehistory: economic variability and abandonment of maize agriculture in the Great Salt Lake basin. American Antiquity 67(3):453-485.

Cook, E. R., R. Seager, R. R. Heim Jr., R. S. Vose, C. Herweijer, and C. Woodhouse. 2010. Megadroughts in North America: placing IPCC projections of hydroclimatic change in a longterm palaeoclimate context. Journal of Quaternary Science 25:48-61.

Cordell, L. 1997. Archaeology of the Southwest. Second ed. San Diego: Academic Press, Inc.

Cordell, L. S., D. E. Doyel, and K. W. Kintigh. 1994. Processes of aggregation in the prehistoric Southwest. Pages 109-134 in G. J. Gumerman, editor. Themes in Southwest prehistory. Santa Fe, Advanced Seminar Series, School of American Research.

Courtright, S. and R. Neily. 2012. Dacite and the development of the stone camp Pueblo community. Pages 225-240 in W. G. Russell and M. J. Hoogendyk, editors. Prehistoric cultures of the Perry Mesa region: Proceedings of the Perry Mesa symposium. Friends of Agua Fria National Monument.

Cowgill, G. L. 1975. On causes and consequences of ancient and modern population changes. American Anthropologist 77:505-525.

Craig, D. B. and M. K. Woodson. 2017. Preclassic Hohokam. Pages 323-352 in B. J. Mills and S. Fowles, editors. The Oxford Handbook of Southwest Archaeology. Oxford, Oxford University Press. 
Crown, P. L. 1991. The role of exchange and interaction in the Salt-Gila basin Hohokam prehistory. Pages 383-416 in G. J. Gumerman, editor. Exploring the Hohokam: prehistoric desert peoples of the American Southwest. Albuquerque, University of New Mexico Press.

Crown, P. L. and S. K. Fish. 1996. Gender and status in the Hohokam pre-Classic to Classic transition. American Anthropologist:803-817.

Cummings, L. S. 1994. Anasazi diet: variety and nutritional analysis. Pages in A. Hutchinson and J. E. Smith, editors. Proceedings of the Anasazi symposium 1991. Mesa Verde, CO, Mesa Verde Museum Association.

Dean, J. S. 2006. Subsistence stress and food storage at kiet siel, northeastern Arizona. Pages 160-179 in D. E. Doyel and J. S. Dean, editors. Environmental change and human adaptation in the ancient American southwest. Salt Lake City, The University of Utah Press.

Dean, J. S. 2010. The environmental, demographic, and behavioral context of the thirteenthcentury depopulation of the northern Southwest. Pages 324-345 in M. D. Varien, T. A. Kohler, A. M. Wright, editor. Leaving Mesa Verde: peril and change in the thirteenth-century Southwest. Tucson, The University of Arizona Press.

Dean, J. S. and J. C. Ravesloot. 1993. The chronology of cultural interaction in the Gran Chichimeca. Pages 83-103 in A. I. Woosley and J. C. Ravesloot, editors. Culture and contact: Charles c. Di peso's Gran Chichimeca. Albuquerque, University of New Mexico Press.

Dean, R. 2007. Hunting intensification and the Hohokam "collapse". Journal of Anthropological Archaeology 26:109-132.

Di Peso, C. C. 1974. Casas Grandes: a fallen trading center of the Gran Chichimeca. Dragoon, AZ: Amerind Foundation.

Dodd, W. A. 1982. Final year excavations at the Evans mound site. Salt Lake City: University of Utah Press.

Doelle, W. H. and H. D. Wallace. 1991. The changing role of the Tucson basin in the Hohokam regional system. Pages 279-346 in G. J. Gumerman, editor. Exploring the Hohokam: prehistoric desert peoples of the American Southwest. Albuquerque, University of New Mexico Press.

Doolittle, W. E. 1980. Aboriginal agricultural development in the valley of Sonora, Mexico. Geographical Review 70(3):328-242.

Doolittle, W. E. 1984. Settlements and developments of "statelets" in Sonora, Mexico. Journal of Field Archaeology 11(1):13-24.

Doolittle, W. E. 1988. Pre-hispanic occupance in the valley of Sonora, Mexico: archaeological confirmation of early Spanish reports. Anthropological Papers of the University of Arizona 48:187.

Doolittle, W. E. 1993. Canal irrigation at Casas Grandes: a technological and developmental assessment of its origins. Pages 133-151 in A. I. Woosley and J. C. Ravesloot, editors. Culture 
and contact: Charles C. DiPeso's Gran Chichimeca. Albuquerque, University of New Mexico Press.

Douglas, J. E. 1992. Distant sources, local contexts: Interpreting nonlocal ceramics at paquimé (Casas Grandes), Chihuahua. Journal of Anthropological Research 48(1):1-24.

Douglas, J. E. and A. C. MacWilliams. 2015. Society and polity in the wider Casas Grandes region. Pages 126-147 in P. E. Minnis and M. E. Whalen, editors. Ancient Paquimé and the Casas Grandes world. Tucson, The University of Arizona Press.

Downum, C. E., P. R. Fish, and S. K. Fish. 1994. Refining the role of Cerro de Trincheras in southern Arizona settlement. Kiva 59(3):271-296.

Downum, C. E., P. R. Fish and S. K. Fish. 2009. Refining the role of Cerro de Trincheras in southern Arizona settlement. Kiva 75(2):261-287.

Doyel, D. E. 2006. Settlement history and environmental variability in the upper little Colorado river valley, Arizona. Pages 136-159 in D. E. Doyel and J. S. Dean, editors. Environmental change and human adaptation in the ancient American southwest. Salt Lake City, The University of Utah Press.

Driver, J. C. 2002. Faunal variation and change in the northern san juan region. Pages 143-160 in M. D. Varien and R. H. Wilshusen, editors. Seeking the center place: Archaeology and ancient communities in the Mesa Verde region. Salt Lake City, The University of Utah Press.

Duff, A. I., K. R. Adams, and S. C. Ryan. 2010. The impact of long-term residential occupation of community centers on local plant and animal resources. Pages 156-179 in T. A. Kohler, M. D. Varien, and A. M. Wright, editors. Leaving Mesa Verde: peril and change in the thirteenth century Southwest. Tucson, The University of Arizona Press.

Ekholm, G. 1939. Results of an archaeological survey of Sonora and northern Sinaloa. Revista Mexicana de Antropologia 3(1):7-11.

Elson, M. D. 1998. Expanding the view of Hohokam platform mounds: an ethnographic perspective: Tucson, The University of Arizona Press.

Ember, C. R. and M. Ember. 2009. Cross-cultural research methods. Lanham, MD, Altamira Press.

Ezzo J. A. Jr. and T. D. Price. 2002. Migration, regional reorganization, and spatial group composition at Grasshopper Pueblo, Arizona. Journal of Archaeological Science 29:499-520.

Fink, M. T. 1991. Prehistoric irrigation canals and their possible impact on Hohokam health. Pages 61-88 in C. D. Breternitz, editor. Prehistoric irrigation in Arizona: Symposium 1988. Phoenix, AZ, Soil Systems, Incorporated.

Fish, P. R. 1989. The Hohokam: 1,000 years of prehistory in the Sonora desert. Pages 19-64 in L. S. Cordell and G. J. Gumerman, editors. Dynamics of southwest prehistory. Washington, D.C., Smithsonian Institution Press. 
Fish, P. R., S. K. Fish, and E. Villalpando. 2007. Introduction. Pages 1-9 in S. K. Fish, P. R. Fish and M. E. Villalpando, editors. Trincheras sites in time, space, and society. Tucson, University of Arizona Press.

Fish, S. K. and P. R. Fish. 2004. In the Trincheras hinterland: initial insights from full-coverage survey. Pages 47-63 in G. E. Newell and E. Gallaga, editors. Surveying the archaeology of northwest Mexico. Salt Lake City, University of Utah Press.

Gallaga, E. 2004. A spatial distribution analysis of shell and polychrome ceramics at the Cerro de Trincheras site, Sonora, Mexico. in G. E. Newell and E. Gallaga, editors. Surveying the archaeology of northwest Mexico. Salt Lake City, University of Utah Press.

Gallaga, E. and G. E. Newell. 2004. Introduction. Pages 1-26 in G. E. Newell and E. Gallaga, editors. Surveying the archaeology of northwest Mexico. Salt Lake City, University of Utah Press.

Gilman, P. A., M. Thompson and K. C. Wyckoff. 2014. Ritual change and the distant: Mesoamerican ideology, scarlet macaws, and great kivas in the Mimbres region of Southwestern New Mexico. American Antiquity 79(1):90-107.

Glowacki, D. 2015. Living and leaving: a social history of regional depopulation in thirteenthcentury Mesa Verde. Tucson: University of Arizona Press.

Glowacki, D. M. 2010. The social and cultural contexts of the central Mesa Verde region during the thirteenth-century migrations. Pages 200-221 in T. A. Kohler, M. D. Varien, and A. M. Wright, editors. Leaving Mesa Verde: peril and change in the thirteenth-century southwest. Tucson, University of Arizona Press.

Graulich, M. 2000. Aztec human sacrifice as expiation. History of Religions 39(4):352-371.

Graves, W. M. and S. Van Keuren. 2011. Ancestral Puebloan villages and the panoptic gaze of the commune. Cambridge Archaeological Journal 21:263-282.

Graybill, D. A. 1989. The reconstruction of prehistoric salt river streamflow. In D. A. Graybill, D. A. Gregory, F. L. Nials, S. K. Fish, C. H. Miksicek, R. E. Gasser, and C. R. Szuter editors. The 1982-1984 excavations at Las Colinas: environment and subsistence. Tucson, Cultural Resource Management Division, Arizona State Museum, University of Arizona. 25-38.

Graybill, D. A., D. A. Gregory, G. S. Funkhouser, and F. L. Nials. 2006. Long-term streamflow reconstructions, river channel morphology, and aboriginal irrigations systems along the Salt and Gila rivers. Pages 69-123 in D. E. Doyel and J. S. Dean, editors. Environmental change and human adaptation in the ancient American Southwest. Salt Lake City, The University of Utah Press.

Grigg, D. B. 1976. Population pressure and agricultural change. Progress in Geography 8:133176.

Guebard, M. C. 2016. During the migration time: oral history, violence, and identity in the prehistoric Verde Valley. Kiva (3):259-277. 
Gumerman, G. J. and J. S. Dean. 1989. Prehistoric cooperation and competition in the western Anasazi area. Pages 99-148 in L. S. Cordell and G. J. Gumerman, editors. Dynamics of Southwest prehistory. Washington, D.C., Smithsonian Institution Press.

Gunnerson, J. H. 1960. The Fremont culture: internal dimensions and external relationships. American Antiquity 25(3):373-380.

Haas, J. and W. Creamer. 1996. The role of warfare in the Pueblo III period. Pages 205-213 in M. A. Adler, editor. The prehistoric Pueblo world, A.D. 1150-1350. Tucson, University of Arizona Press.

Haas, J. and W. Creamer. 1996. The role of warfare in the Pueblo III period. Pages 205-213 in M. A. Adler, editor. The prehistoric Pueblo world, A.D. 1150-1350. Tucson, The University of Arizona Press.

Hammond, G. P. and A. Rey. 1928. Obregon's history of 16th century explorations in western America. Los Angeles: Wetzel Publishing.

Hantman, J. L. 1983. Social networks and stylistic distributions in the prehistoric plateau Southwest. Ph.D. dissertation, Arizona State University, University Microfilms, Ann Arbor.

Haury, E. W. 1985. Mogollon culture in the Forestdale valley, east-Central Arizona. Tucson: University of Arizona Press.

Hegmon, M., J. Arneborg, L. Comeau, A. J. Dugmore, G. Hambrecht, S. Ingram, K. Kintigh, T. H. McGovern, M. C. Nelson, M. A. Peeples, I. Simpson, K. Spielmann, R. Streeter and O. Vésteinsson. 2014. The human experience of social change and continuity: The Southwest and North Atlantic in "interesting times" ca. 1300. Pages 53-68 in S. Kulyk, C. Tremain, and M. Sawyer, editors. Climates of change: the shifting environments of archaeology, proceedings of the 44th annual Chacmool conference. University of Calgary.

Hegmon, M., M. C. Nelson, and S. M. Ruth. 1998. Abandonment and reorganization in the Mimbres region of the American southwest. American Anthropologist 100(1):148-162.

Hegmon, M., M. C. Nelson and K. G. Schollmeyer. 2016. Experiencing social change: life during the Mimbres Classic transformation. Archaeological Papers of the American Anthropological Association 27:54-73.

Hegmon, M., M. A. Peeples, and LTVTP collaboration. 2018. The human experience of social transformation: insights from comparative archaeology. PLOS One 13(11):1-29.

Helms, M. W. 1979. Ancient Panama: chiefs in search of power. Austin: University of Texas Press.

Hernandez Espinoza, P. O. 2017. La modificación intencional del cráneo más allá de la frontera norte de mesoamérica. Pages 709-750 in V. Tiesler and C. S. Sanchez, editors. Modificaciones cefálicas culturales en mesoamérica: Una perspectiva continental. Mexico City, Universidad Nacional Autónoma de México. 
Hill, J. B., J. J. Clark, W. H. Doelle, and P. D. Lyons. 2004. Prehistoric demography in the Southwest: migration, coalescence, and Hohokam population decline. American Antiquity 69(4):689-716.

Hill, J. B., P. D. Lyons, J. J. Clark, and W. H. Doelle. 2010. Depopulation of the northern Southwest: a macroregional perspective. Pages 34-52 in A. K. Timothy, M. D. Varien, and A. M. Wright, editors. Leaving Mesa Verde: peril and change in the thirteenth-century southwest. Tucson, The University of Arizona Press.

Hill, J. B., P. D. Lyons, J. J. Clark, and W. H. Doelle. 2015. The "collapse" of cooperative Hohokam irrigation in the Lower Salt River valley. Journal of the Southwest 57(4):609-674.

Hill, J. B., D. Wilcox, W. Doelle and W. Robinson. 2012. Coalescent Communities Database version 2.0. Tucson, Archaeology Southwest.

Hinkes, M. 1983. Skeletal evidence of stress in subadults: trying to come of age at Grasshopper Pueblo. Department of Anthropology. Tucson, University of Arizona.

Hohmann, J. W. 1983. Sinagua social differentiation: inferences based on prehistoric mortuary practices. Arizona Archaeological Society.

Ingram, S. E. 2008. Streamflow and population change in the Lower Salt River valley of central Arizona, ca. A.D. 775 to 1450. American Antiquity 73(1):136-165.

Ingram, S. E. 2014. Climatic, demographic, and environmental influences on central Arizona settlement patterns. Pages 23-51 in D. Abbott and K. A. Spielmann, editors. Alliance and landscape on Perry Mesa in the fourteenth century. Salt Lake City, University of Utah Press.

Irwin-Williams, C. and P. H. Shelley. 1980. Investigations at the Salmon site: the structure of Chacoan society in the northern southwest.

James, S. R. 2003. Hunting and fishing patterns leading to resource depletion. Pages 70-81 in D. R. Abbott, editor. Centuries of decline during the Hohokam Classic period at Pueblo Grande. Tucson, University of Arizona Press.

Janetski, J. C. 1997. Fremont hunting and resource intensification in the eastern Great Basin. Journal of Archaeological Science 24(12):1075-1088.

Janetski, J. C. and R. K. Talbot. 1997. Social and community organization. in R. K. Talbot, J. C. Janetski, D. E. Newman, L. D. Richens, J. D. Wilde, S. B. Baker, and S. E. Billat, editor. Clear Creek Canyon archaeological project, volume 5: results and synthesis. Provo, Brigham Young Museum of Peoples and Cultures Technical Series.

Janetski, J. C., R. K. Talbot, D. E. Newman, L. D. Richens, and J. D. Wilde. 2000. Clear creek canyon archaeological project: results and synthesis. Salt Lake City: University of Utah Press.

Johansson, L. D., K. K. Richards, and J. R. Allison. 2014. Wolf village (42UT273): a case study in Fremont architectural variability. Utah Archaeology 27(1):33-56. 
Johnson, C. D., T. A. Kohler, and J. Cowan. 2005. Modeling historical ecology, thinking about contemporary systems. American Anthropologist 107(1):96-107.

Kamp, K. A. and J. C. Whittaker. 1990. Lizard man village: a small site perspective on northern Sinagua social organization. Kiva 55(2):99-125.

Kamp, K. A. and J. C. Whittaker. 2009. A Sinagua acropolis: architectural adaptation at New Caves, Arizona. Kiva 74(3):281-304.

Kantner, J. 2004. Ancient Puebloan Southwest. Cambridge: Cambridge University Press.

Kelley, J. H. and M. T. Searcy. 2015. Beginnings: the Viejo period. Pages 17-40 in P. E. Minnis and M. E. Whalen, editors. Ancient Paquimé and the Casas Grandes world. Tucson, The University of Arizona Press.

Kohler, T. A. and M. H. Matthews. 1988. Long-term Anasazi land use and forest reduction: a case study from southwest Colorado. American Antiquity 53(3):537-564.

Kohler, T. A., S. G. Ortman, K. E. Grundtisch, C. M. Fitzpatrick and S. M. Cole. 2014. The better angels of their nature: declining violence through time among prehispanic farmers of the Pueblo southwest. American Antiquity 79(3).

Kohler, T. A., M. D. Varien, A. Wright, and K. A. Kuckelman. 2008. Mesa Verde migrations new archaeological research and computer simulation suggest why ancestral Puebloans deserted the northern Southwest United States. American Scientist 96(2):146-153.

Kohler, T. A. and C. R. Van West. 1996. The calculus of self-interest in the development of cooperation: sociopolitical development and risk among the northern Anasazi. Pages 169-196 in J. A. Tainter and T. Bonnie Bagley, editors. Evolving complexity and environmental risk in the prehistoric Southwest. Reading, MA, Addison-Wesley Publishing Company.

Kowalewski, S. A. 2007. Concluding observations: perspectives from the hill towns of Oaxaca. Pages 247-267 in S. K. Fish, P. R. Fish, and E. Villalpando, editors. Trincheras sites in time, space, and society. Tucson, University of Arizona Press.

Kruse-Peeples, M. and C. Strawhacker. 2012. Prehistoric settlement organization across Perry Mesa: considerations of settlement size, distribution, and chronology. Pages 257-282 in W. G. Russell and M. J. Hoogendyk, editors. Prehistoric cultures of the Perry Mesa region: proceedings of the Perry Mesa symposium. Agua Fria Chapter, Arizona Archaeological Society.

Kuckelman, K. A. 2006. Ancient violence in the Mesa Verde region. Pages 127-136 in D. G. Noble, editor. The Mesa Verde world. Santa Fe, School of American Research Press.

Kuckelman, K. A. 2010. The depopulation of Sand Canyon Pueblo, a large ancestral Pueblo village in southwestern Colorado. American Antiquity 75(3):497-525.

Kuckelman, K. A., R. R. Lightfoot, and D. L. Martin. 2002. The bioarchaeology and taphonomy of violence at Castle Rock and Sand Canyon pueblos, Southwestern Colorado. American Antiquity 67(3):486-513. 
Kuckelman, K. A. and D. L. Martin. 2007. Human skeletal remains. In K. A. Kuckleman editors. The Archaeology of Sand Canyon Pueblo: intensive excavations at a late-thirteenth-century village in southwestern Colorado. Cortez, Crow Canyon Archaeological Center.

Kwiatkowski, S. M. 2003. Evidence for subsistence problems. Pages 48-69 in D. Abbott, editor. Centuries of decline during the Hohokam Classic period at Pueblo Grande. Tucson, University of Arizona Press.

Lamb, S. M. 1958. Linguistic prehistory in the Great Basin. International Journal of American Linguistics 24(2):95-100.

Lambert, P. M. 1999. Human skeletal remains. in B. R. Billman, editor. The Puebloan occupation of the Ute Mountain piedmont, vol. 5: environmental and bioarchaeological studies. Phoenix, Soil Systems, Inc.

Las Casas, B. D. 1967. Apologética historia sumaria. México: unam.

LeBlanc, S. A. 1989. Cultural dynamics in the southern Mogollon area. Pages 179-208 in L. S. Cordell and G. J. Gumerman, editors. Dynamics of Southwestern prehistory. Washington, D.C., Smithsonian Institution Press.

LeBlanc, S. A. 1999. Prehistoric warfare in the American southwest. Salt Lake City: University of Utah Press.

Lipe, W. and S. G. Ortman. 2000. Spatial patterning in northern San Juan villages, A.D. 10501300. Kiva 66(1):91-122.

Lipe, W. D. 1995. The depopulation of the northern San Juan: conditions in the turbulent 1200s. Journal of Anthropological Archaeology 14:143-169.

Lipe, W. D. 2002. Social power in the central Mesa Verde region, AD 1150-1290. Pages 203232 in M. Varien and R. H. Wilshusen, editors. Seeing the center place: archaeology and ancient communities in the Mesa Verde region. Salt Lake City, University of Utah Press.

Lipe, W. D. 2006. Notes from the north. Pages 261-313 in S. H. Lekson, editor. The archaeology of Chaco Canyon, an eleventh-century Pueblo regional center. Santa Fe, School of American Research Press.

Lippmeier, H. S. 1991. A preliminary assessment of the relative health status between Classic and post-Classic populations of Southwestern New Mexico. Department of Anthropology. Buffalo, SUNY Buffalo.

Loendorf, C. and B. V. Lewis. 2017. Ancestral O'odham: Akimel O'odham cultural traditions and the archaeological record. American Antiquity 82(1):123-139.

Longacre, W. A. 1975. Dynamics at the Grasshopper Pueblo, Arizona. Memoirs of the Society for American archaeology. 
Lowell, J. C. 2010. Survival strategies of gender-imbalanced migrant households in the Grasshopper region of Arizona. in B. J. Roth, editor. Engendering households in the prehistoric Southwest. Tucson, University of Arizona Press.

Lyneis, M. M. 1995. The virgin Anasazi, far western Puebloans. Journal of World Prehistory 9:199-241.

Madsen, D. B. and L. M. W. Lindsay. 1977. Backhoe village. Department of Development Services, Division of State History. 3-119.

Madsen, D. B. and S. R. Simms. 1998. The Fremont complex: A behavioral perspective. Journal of World Prehistory 12(3):255-336.

Martin, D. L. 1994. Patterns of health and disease: stress profiles for the prehistoric Southwest. Pages 87-108 in G. J. Gumerman, editor. Themes in Southwestern prehistory. Albuquerque, University of New Mexico Press.

Martin, D. L. and N. J. Akins. 2001. Unequal treatment in life as in death: trauma and mortuary behavior at La Plata (AD 1000-1300). Pages 223-248 in D. R. Mitchell and J. L. BrunsonHadley, editors. Ancient burial practices in the American southwest: archaeology, physical anthropology, and Native American perspectives. Albuquerque, University of New Mexico Press.

Martin, D. L., N. J. Akins, B. J. Crenshaw, and P. K. Stone. 2008. Inscribed in the body, written in the bones: the consequences of social violence at La Plata. Pages 98-122 in D. L. Martin and P. L. Crown, editors. Social violence in the prehispanic Southwest. Tucson, The University of Arizona Press.

McClelland, J. A. 2015. Revisiting Hohokam paleodemography. American Antiquity 80(3):492510.

McGuire, R. H. 1983. Breaking down cultural complexity: inequality and heterogeneity. Advances in Archaeological Method and Theory 6:91-142.

McGuire, R. H. and E. Villalpando C. 1998. Cerro de Trincheras: A prehispanic terraced town in Sonora, Mexico. Archaeology in Tucson 12(1):1-7.

McGuire, R. H. and E. Villalpando, editors. 2011. Excavations at Cerro de Trincheras, Sonora, Mexico, volume II. Tucson, Arizona State Museum, The University of Arizona.

McGuire, R. H. and E. Villalpando. 2016. The Trincheras tradition. Archaeology Southwest Magazine. Archaeology Southwest, pp. 18-20.

McGuire, R. H. and M. E. Villalpando. 2015. War and defense on Cerro de Trincheras in Sonora, México. American Antiquity 80(3):429-450.

Medina Martin, C. and M. Sanchez Vargas. 2007. Posthumous body treatments and ritual meaning in the Classic period northern Peten: a taphonomic approach. Pages 102-119 in V. 
Tiesler and A. Cucina, editors. New perspectives on human sacrifice and ritual body treatments in ancient Maya society. New York, Springer.

Meighan, C. W., N. E. Coles, F. D. Davis, G. M. Greenwood, W. M. Harrison, and E. H. MacBain. 1956. Archaeological investigations in Iron county, Utah. Salt Lake City, University of Utah Press.

Meko, D. M., C. A. Woodhouse, C. A. Baisan, T. Knight, J. J. Lukas, M. K. Hughes and M. W. Salzer. 2007. Medieval drought in the upper Colorado river basin. Geophysical Research Letters 34(10):L10705-5.

Mills, B. J., J. J. Clark, M. A. Peeples, W. R. Haas Jr., J. M. Roberts Jr., J. B. Hill, D. L. Huntley, L. Borck, R. L. Breiger, A. Clauset, and M. S. Shackley. 2013. Transformation of social networks in the late pre-Hispanic US Southwest. Proceedings of the National Academy of Sciences 110(15):5785-5790.

Minnis, P. E. 1989. The Casas Grandes polity in the international Four Corners. Pages 149-195 in K. L. S. Upham, and R.A. Jewett, editor. The sociopolitical structure of prehistoric Southwestern society. Boulder, Westview Press.

Minnis, P. E. and M. E. Whalen. 2003. The Casas Grande community. Archaeology Southwest Magazine. Archaeology Southwest. 1-3.

Minnis, P. E. and M. E. Whalen. 2015. Ecology and food economy. Pages 41-57 in P. E. Minnis and M. E. Whalen, editors. Ancient Paquimé and the Casas Grandes world. Tucson, The University of Arizona Press.

Muir, R. J. 1999. Zooarchaeology of Sand Canyon Pueblo, Colorado. Department of Archaeology. Simon Fraser University. 220.

Muir, R. J. and J. C. Driver. 2002. Scale of analysis and zooarchaeological interpretation: Pueblo III faunal variation in the northern San Juan region. Journal of Anthropological Archaeology 21(2):165-199.

Munson, M. K. and K. Hays-Gilpin. 2017. Iconography. Pages 663-682 in B. J. Mills and S. Fowles, editors. The Oxford Handbook of Southwest Archaeology. Oxford, Oxford University Press.

Neily, R. J. 1983. The prehistoric community on the Colorado plateau, an approach to the study of change and survival in the northern San Juan area of the American southwest. Department of Anthropology. Carbondale, IL, Southern Illinois University.

Nelson, B. A. and S. A. LeBlanc. 1986. Short-term sedentism in the American Southwest: the Mimbres valley Salado. Albuquerque: Maxwell Museum of Anthropology.

Nelson, M. C. and M. Hegmon. 2001. Abandonment is not as it seems: an approach to the relationship between site and regional abandonment. American Antiquity 66(2):213-235. 
Nelson, R. S. 1981. The role of a pochteca system in Hohokam exchange. Department of Anthropology. New York City, New York University.

Newell, G. E. and E. Gallaga. 2004. Surveying the archaeology of northwest Mexico: University of Utah Press.

Nisengard, J. E. 2006. Communal spaces: Aggregation and integration in the Mogollon region of the United States Southwest. Department of Anthropology. Norman, OK, University of Oklahoma. 552.

Novak, S. 1995. A view to the west: violence in the Fremont culture area. 53rd Annual Plains Anthropology Conference. Laramie, WY.

Novak, S. 1998. Patterns of violence in the Fremont culture area. Pages in K. Lupo and M. Leach, editors. Invisible no more. Salt Lake City, University of Utah Press.

Oakes, Y. R. and D. A. Zamora. 1999. Volume 1. Defining the Mogollon: Museum of New Mexico, Office of Archaeological Studies.

Offenbecker, A. M. 2018. Geographic origins, status, and identity at Paquimé, northwest Chihuahua, Mexico. Department of Anthropology and Archaeology. Calgary, University of Calgary.

Offenbecker, A. M., J. H. Kelley and M. A. Katzenberg. 2015. The relationship between violence and geographic origins at Casas Grandes, Chihuahua, Mexico: preliminary results from strontium isotope analysis. 80th Meeting of the Society for American Archaeology. San Francisco.

Olsen, J. W. 1990. Vertebrate remains from Grasshopper Pueblo, Arizona. Ann Arbor: University of Michigan Press.

Ortman, S. G. 2012. Winds from the north: Tewa origins and historical anthropology. Salt Lake City: University of Utah Press.

Pailes, M. C. 2014. Social network analysis of early Classic Hohokam corporate group inequality. American Antiquity 79(3):465-486.

Pailes, M. C. 2015. The political landscapes of eastern Sonora, Mexico: A reconsideration of scale and organization. Latin American Antiquity 26(4):530-549.

Pailes, M. C. 2016. The Moctezuma valley. Archaeology Southwest Magazine. Archaeology Southwest. 14-15.

Pailes, M. C. 2017a. Archaeology of the Sierra Madre Occidental: Research in the Moctezuma Valley of eastern Sonora, Mexico. Tucson: University of Arizona.

Pailes, M. C. 2017b. Northwest Mexico: The prehistory of Sonora, Chihuahua, and neighboring areas. Journal of Archaeological Research 25:373-420. 
Pailes, M. C. 2020 or 2021 [in press]. What's really important in the ethnohistory of Sonora? Pages in J. Carpenter and M. Pailes, editors. Borderlands histories: ethnographic observations and archaeological interpretations. Salt Lake City, University of Utah Press.

Pailes, M. C., J. Carpenter and G. Sanchez. 2016. Proposal for support for scientific research for the Sahuaripa project investigating cultural continuity in the Serrana de Sonora. Sonora, Mexico, National Science Foundation.

Pailes, M. C., J. Carpenter and G. Sanchez. 2021. Casas Grandes culture in the Sonoran Sierra Madre Occidental. Pages in C. S. VanPool and T. L. VanPool, editors. Archaeology of the Casas Grandes region.

Pailes, R. A. 1980. The upper Rio Sonora valley in prehistoric trade. New Frontiers in the Archaeology and Ethnohistory of the Greater Southwest:20-39.

Pailes, R. A. 1984. Agricultural development and trade in the Rio Sonora. Prehistoric Agricultural Strategies in the Southwest, Arizona State University Anthropological Research Papers (33):309-326.

Pailes, R. A. and D. T. Reff. 1985. Colonial exchange systems and the decline of Paquimé. Westview Press, Boulder. 353-363.

Pilles, P. J. 1996. The Pueblo III period along the Mogollon rim: The Hohanki, Elden, and Turkey Hill phases of the Sinagua. Pages 59-72 in M. A. Adler, editor. The prehistoric Pueblo world, A.D. 1150 - 1350. Tucson, University of Arizona Press.

Phillips, D. 2009. Archaeology and prehistory of northwest Mexico: A "rough essay" [online]: University of New Mexico. Available at: https://www.unm.edu/ dap/nwm/trin.html [Accessed December 20, 2019 2019].

Phillips Jr., D. A. 1989. Prehistory of Chihuahua and Sonora, Mexico. Journal of World Prehistory 3(4):373-401.

Phillips Jr., D. A. 2008. The end of Casas Grandes. Society for American Archaeology. Vancouver, British Columbia, Canada. 1-21.

Phillips Jr., D. A., H. J. Wearing and J. J. Clark. 2018. Village growth, emerging infectious disease, and the end of the Neolithic demographic transition in the southwest United States and northwest Mexico. American Antiquity 83(2):263-280.

Pilles, P. J. 1996. The Pueblo III period along the Mogollon rim: The Honanki, Elden, and Turkey Hill phases of the Sinagua. Pages 59-72 in M. A. Adler, editor. The prehistoric Pueblo world, A.D. 1150 -1350. Tucson, The University of Arizona Press.

Pilles, P. J. 2015. The Tuzigoot phase of southern Arizona. Journal of Arizona Archaeology 3(1, 2):100-116. 
Plog, F. 1989. The Sinagua and their relations. Pages 209-262 in L. S. Cordell and G. J. Gumerman, editors. Dynamics of Southwest prehistory. Washington, D.C., Smithsonian Institution Press.

Preucel, R. W. 2005. Ethnicity and Southwestern archaeology. Pages 174-193 in L. S. Cordell and D. D. Fowler, editors. Southwest Archaeology in the twentieth century. Salt Lake City, University of Utah Press.

Price, T. D., C. M. Johnson, J. A. Ezzo, J. Ericson and J. H. Burton. 1994. Residential mobility in the prehistoric Southwestern United States: A preliminary study using strontium isotope analysis. Journal of Archaeological Science 21:315-330.

Rakita, G. F. M. 2001. Social complexity, religious organization, and mortuary ritual in the Casas Grandes region of Chihuahua, Mexico. Department of Anthropology. The University of New Mexico. 412.

Rakita, G. F. M. 2009. Ancestors and elites: emergent complexity and ritual practices in the Casas Grandes polity. Lanham, MD: Altamira Press.

Ravesloot, J. C. 1988. Mortuary practices and social differentiation at Casas Grandes, Chihuahua, Mexico. Tucson: The University of Arizona Press.

Ravesloot, J. C. and P. M. Spoerl. 1987. The role of warfare in the development of status hierarchies at Casas Grandes, Chihuahua, Mexico. 20th Annual Chacmool Conference. Calgary.

Reed, E. K. 1958. Excavations at Mancos canyon, Colorado. University of Utah, Anthropological Papers 35.

Reid, J., and Stephanie Whittlesey. 1997. The archaeology of ancient Arizona. Tucson: University of Arizona Press.

Reid, J. J. 1989. A Grasshopper perspective on the Mogollon of the Arizona mountains. Pages 65-98 in L. S. Cordell and G. J. Gumerman, editors. Dynamics of Southwest prehistory. Washington, D.C., Smithsonian Institution Press.

Reid, J. J., D. A. Graybill and A. C. Seiferle-Valencia. 2006. Subsistence management strategies in the Grasshopper region, east-Central Arizona. Pages 124-135 in D. E. Doyel and J. S. Dean, editors. Environmental change and human adaptation in the ancient American Southwest. Salt Lake City, The University of Utah Press.

Rice, G. E. 2001. Warfare and massing in the Salt and Gila basins of Central Arizona. Pages 289-330 in G. E. Rice, and Steven A. LeBlanc, editor. Deadly landscapes: case studies in prehistoric Southwestern warfare. Salt Lake City, The University of Utah Press.

Richards, K. K., J. R. Allison, L. D. Johansson, R. K. Talbot and S. M. Ure. 2019. Houses, public architecture, and the organization of Fremont communities. Pages 201-228. Communities and households in the greater American Southwest: new perspectives and case studies.

Louisville, CO, University Press of Colorado. 
Riggs, C. R. 2001. The architecture of Grasshopper Pueblo: Dynamics of form, function, and use of space in a prehistoric community. Salt Lake City: University of Utah Press.

Rogers, M. J. 1945. An outline of Yuman prehistory. Southwestern Journal of Anthropology 1(2):167-198.

Russell, W. G. and N. Nez. 2012. Ritual racetracks of the Perry Mesa region. Pages 105-134 in W. G. Russell and M. J. Hoogendyk, editors. Prehistoric cultures of the Perry Mesa region: Proceedings of the Perry Mesa symposium. Friends of the Agua Fria National Monument.

Russell, W. G., N. Nez, C. Caseldine, A. Simon, J. Freeman and G. Trask. 2012. The Horseshoe Peak site and diachronic landscape use on the middle Agua Fria river. Pages 163-180 in W. G. Russell and M. J. Hoogendyk, editors. Prehistoric cultures of the Perry Mesa region: Proceedings of the Perry Mesa symposium. Friends of the Agua Fria National Monument.

Schollmeyer, K. G. 2011. Large game, agricultural land, and settlement pattern change in the eastern Mimbres area, southwest New Mexico. Journal of Anthropological Archaeology 30(3):402-415.

Schwindt, D. M., K. Bocinsky, S. G. Ortman, D. M. Glowacki, M. D. Varien and T. A. Kohler. 2016. The social consequence of climate change in the central Mesa Verde region. American Antiquity 81(1):74-96.

Seymour, D. J. 2012. Gateways for Athabascan migration to the American southwest. Plains Anthropologist 57(222):149-161.

Shafer, H. J. 2003. Mimbres archaeology at the Nan ranch ruin. First ed. Albuquerque: University of New Mexico Press.

Sheridan, S. G. 2003. Childhood health as an indicator of biological stress. Pages 82-106 in D. A. Abbott, editor. Centuries of decline during the Hohokam Classic period at Pueblo Grande. Tucson, University of Arizona Press.

Shields, W. F. 1967. 1966 excavations: Uinta basin, miscellaneous collected papers 15. University of Utah Anthropological Papers 89.

Simms, S. R. 1986. New evidence for Fremont adaptive diversity. Journal of California and Great Basin Anthropology 8(2):204-216.

Simms, S. R. and M. E. Stuart. 2002. Ancient American Indian life in the Great Salt Lake wetlands: archaeological and bioarchaeological evidence. Utah Geological Survey. 71-83.

Spangler, J. D. 1999. Old paradigms and new perspective: radiocarbon dates, acquired wisdom and the search for temporal order in the Uintah basin. in D. B. Madsen and M. D. Metcalfe, editors. Intermountain archaeology. Salt Lake City, University of Utah Press.

Spangler, J. D. 1999. One-pot pithouses and Fremont paradoxes. in D. B. Madsen and M. D. Metcalfe, editors. Intermountain archaeology. Salt Lake City, University of Utah Press. 
Spurr, K. and S. Deats. 2015. A summary of prehistoric mortuary patterns in the middle Verde Valley of Arizona. Journal of Arizona Archaeology 3(1, 2):22-42.

Stark, M. T., J. J. Clark and M. D. Elson. 1995. Causes and consequences of migration in the 13th century Tonto basin. Journal of Anthropological Archaeology 14:212-246.

Stewart, T. 2006/2007. Who were the Fremont? American Archaeology. The Archaeological Conservancy. 26-33.

Stiger, M. A. 1979. Mesa Verde subsistence patterns from Basketmaker to Pueblo III. Kiva 44(2/3):133-144.

Stodder, A. L. 1987. The physical anthropology and mortuary behavior of the Dolores Anasazi: An early Pueblo population in local and regional context. Pages 339-504 in K. L. Petersen and J. L. Orcutt, editors. Dolores archaeological program supporting studies: settlement and environment. Denver, US Bureau of Reclamation Engineering and Research Center.

Stone, T. 2003. Social identity and ethnic interaction in the western pueblos of the American Southwest. Journal of Archaeological Method and Theory 10(1):31-67.

Swanson, S. 2003. Documenting prehistoric communication networks: a case study in the Paquimé polity. American Antiquity 68(4):753-767.

Talbot, R. K. 2019. The late Fremont regional system. Pages 378-405 in K. Harry and B. J. Roth, editors. Interaction and connectivity in the greater Southwest. University Press of Colorado.

Talbot, R. K. and J. D. Wilde. 1989. Giving form to the formative: shifting settlement patterns in the eastern Great Basin and northern Colorado Plateau. Utah Archaeology 2(1):3-18.

Teague, L. S. 1993. Prehistory and the traditions of the O'odham and Hopi. Kiva 58(4):435-454.

Thomson, M. J., J. Balkovič, T. Krisztin and G. M. MacDonald. 2019. Simulated impact of paleoclimate change on Fremont native American maize farming in Utah, 850-1449 CE, using crop and climate models. Quarternary International 507:95-107.

Tiesler, V. 2007. Funerary or non-funerary? New references in identifying ancient Maya sacrificial and post-sacrificial behaviors from human assemblages. Pages 14-44 in V. Tiesler and A. Cucina, editors. New perspectives on human sacrifice and ritual body treatments in ancient Maya society. New York, Springer.

Tuggle, H. D. and J. J. Reid. 2001. Conflict and defense in the Grasshopper region of eastCentral Arizona. Pages 85 - 107 in S. A. LeBlanc and G. E. Rice, editors. Deadly landscapes: case studies in prehistoric Southwestern warfare. Salt Lake City, University of Utah Press.

Turner II, C. G. and J. A. Turner. 1999. Man corn: cannibalism and violence in the American Southwest. Salt Lake City: University of Utah Press.

Turner II, C. G. and J. A. Turner. 2011. Man corn: cannibalism and violence in the prehistoric American Southwest. Salt Lake City: University of Utah Press. 
Turner, C. G., M. H. Regan and J. D. Irish. 1994. Physical anthropology and human taphonomy. Pages 559-589 in R. Ciolek-Torrello and J. R. Welch, editors. The Roosevelt Rural Sites Study: changing land use in the Tonto basin. Tucson, Statistical Research.

Upham, S. 1982. Polities and power: An economic and political history of the western Pueblo. New York: Academic Press.

Ure, S. M. and S. Stauffer. 2010. The function of the central structure in Fremont community organization. Great Basin Archaeology Conference, Layton, UT.

Valehrach, E. M. and D. S. Valehrach. 1971. Excavations at Brazaletas Pueblo. Arizona Archaeology 6:1-43.

Van West, C. R., and Jeffrey S. Dean. 2000. Environmental characteristics of the A.D. 900-1300 period in the central Mesa Verde region. Kiva 66(1):19-44.

VanPool, C. S. and T. L. VanPool. 2007. Signs of the Casas Grandes shamans. Salt Lake City: University of Utah Press.

Varien, M. D. 2006. Turbulent times in the Mesa Verde world. Pages 39-48 in D. G. Noble, editor. The Mesa Verde world. Santa Fe, School of American Research Press.

Varien, M. D. 2010. Depopulation of the northern San Juan region: historical review and archaeological context. Pages 1-33 in Timothy A. Kohler, Mark D. Varien and A. M. Wright, editors. Leaving Mesa Verde: Peril and change in the thirteenth-century southwest. Tucson, The University of Arizona Press.

Varien, M. D., W. D. Lipe, M. A. Adler, I. M. Thompson and B. A. Bradley. 1996. Southwestern Colorado and southeastern Utah settlement patterns: A.D. 1100 to 1300. Pages 86-113 in M. A. Adler, editor. The prehistoric Pueblo world, A.D. 1150 to 1350. Tucson, University of Arizona Press.

Varien, M. D., S. G. Ortman, T. A. Kohler, D. M. Glowacki and C. D. Johnson. 2007. Historical ecology in the Mesa Verde region: Results from the Village Ecodynamics Project. American Antiquity 72(2):273-299.

Villalpando, E. and R. H. McGuire. 2017. Sonoran pre-Hispanic traditions. Pages 381-396 in B. J. Mills and S. Fowles, editors. The Oxford Handbook of Southwest Archaeology. Oxford, Oxford University Press.

Vivian, G. 1959. The Hubbard site and other tri-walled structures in New Mexico and Colorado. Archaeological Research Series. Washington, D.C., National Park Service.

Wallace, H. D. and W. H. Doelle. 2001. Classic period warfare in southern Arizona. in G. E. Rice and S. A. LeBlanc, editors. Deadly landscapes: Case studies in prehistoric southwestern warfare. Salt Lake City, University of Utah Press.

Wallace, H. D. and J. P. Holmlund. 1984. The Classic period in the Tucson basin. Kiva 49(34):167-194. 
Waller, K. D., A. M. Offenbecker, J. H. Kelley and M. A. Katzenberg. 2018. Elites and human sacrifices at Paquimé: A bioarchaeological assessment. Kiva 84(4):403-423.

Waters, M. R. 2006. Prehistoric human response to landscape change in the American southwest. Pages 26-45 in D. E. Doyel and J. S. Dean, editors. Environmental change and human adaptation in the ancient American Southwest. Salt Lake City, The University of Utah Press.

Watkins, C. N. 2010. Settlement patterns, agriculture, and land tenure in Fremont community organization. Great Basin Anthropological Conference. 1-23.

Watkins, C. N. 2016. The Fremont bird cult. Electronic document, https://www.academia.edu/33340311/The_Fremont_Bird_Cult [accessed ca. 5 May 2019].

Watson, J. T. and C. Garcia. 2016. Postclassic expansion of Mesoamerican biocultural characteristics into Sonora, Mexico. Journal of Field Archaeology 41(2):222-235.

Whalen, M. E. 2013. Wealth, status, ritual, and marine shell at Casas Grandes, Chihuahua, Mexico. American Antiquity 78(4):624-639.

Whalen, M. E., A. C. MacWilliams and T. Pietzel. 2010. Reconsidering the size and structure of Casas Grandes, Chihuahua, Mexico. American Antiquity 75(3):527-550.

Whalen, M. E. and P. E. Minnis. 1996. Ball courts and political centralization in the Casas Grande region. American Antiquity 61(4):732-746.

Whalen, M. E. and P. E. Minnis. 2001. Architecture and authority in the Casas Grandes area, Chihuahua, Mexico. American Antiquity 66:651-668.

Whalen, M. E. and P. E. Minnis. 2001. The Casas Grandes regional system: a late prehistoric polity of northwestern Mexico. Journal of World Prehistory 15(3):313-364.

Whalen, M. E. and P. E. Minnis. 2017. Chihuahuan archaeology. Pages 397-410 in B. J. Mills and S. Fowles, editors. The Oxford Handbook of Southwest Archaeology. Oxford, Oxford University Press.

Whalen, M. E. and T. Pietzel. 2015. Settlement patterns of the Casas Grandes area. Pages 103125 in P. E. Minnis and M. E. Whalen, editors. Ancient Paquimé and the Casas Grandes world. Tucson, The University of Arizona Press.

White, T. D. 1992. Prehistoric cannibalism at Mancos 5MTUMR-2346. Princeton: Princeton University Press.

Whittlesey, S. M. 1994. Ceramics. Pages 377-468 in R. Ciolek-Torrello and J. R. Welsh, editors. The Roosevelt Rural Sites Study: changing land use in the Tonto basin. Tucson, Statistical Research.

Whittlesey, S. M. and J. J. Reid. 2001. Mortuary ritual and organizational inferences at Grasshopper Pueblo, Arizona. Ancient burial practices in the American Southwest: archaeology, physical anthropology, and Native American perspectives:68-96. 
Wilcox, D. R., Gerald Robertson Jr. and J. S. Wood. 2001a. Antecedents to Perry Mesa: Early Pueblo III defensive refuge systems in western Central Arizona. Pages 109-140 in G. E. Rice and S. A. LeBlanc, editors. Deadly landscape: case studies in prehistoric Southwestern warfare. Salt Lake City, University of Utah Press.

Wilcox, D. R. and J. Haas. 1994. The scream of the butterfly: competition and conflict in the prehistoric Southwest. Pages 211-238 in G. J. Gumerman, editor. Themes in Southwest prehistory. Santa Fe, School of American Research Press.

Wilcox, D. R. and J. P. Holmlund. 2007. The archaeology of Perry Mesa and its world. Flagstaff: Ralph M. Bilby Research Center, Northern Arizona University.

Wilcox, D. R., G. Robertson Jr. and J. S. Wood. 2001. Organized for war: the Perry Mesa settlement system and its central-Arizona neighbors. Pages 141-194 in G. Rice and S. Leblanc, editors. Deadly landscapes: case studies in prehistoric Southwestern warfare. Salt Lake City, University of Utah Press.

Wormington, H. M. 1955. A reappraisal of the Fremont culture. Supplementary Reports. The Denver Museum of Natural History. 1-88.

Wright, A. 2020. Life of the Gila: The Patayan world [online]. Tucson: Archaeology Southwest. Available at: https://www.archaeologysouthwest.org/2020/02/20/life-of-the-gila-the-patayanworld/ [Accessed May 28, 2020]. 
Appendix 3. Depopulation dates, citations, and discussion

The identification of the dates and duration of SW/NW depopulation must be built from multiple references as no single source of these dates and data exist.

Table A3.1. Table 1. Depopulation dates, notes, and citations.

\begin{tabular}{lcc}
\hline \hline Archaeological Culture Areas & Depopulation (start and end dates) & Duration, years \\
\hline Fremont & 1150 to $1300^{1}$ & 150 \\
Ancestral Puebloan & 1240 to $1285^{2}$ & 45 \\
Mogollon & 1325 to $1450^{3}$ & 125 \\
Hohokam & 1375 to $1450^{4}$ & 75 \\
Sinagua and Central AZ & 1375 to $1425^{5}$ & 50 \\
Trincheras & $?$ to $1450^{6}$ & - \\
Casas Grandes & $?$ to $1450^{7}$ & - \\
Rio Sonora & No evidence of population decline & \\
Patayan & No evidence of population decline & \\
\hline
\end{tabular}

1. Fremont: We selected the 1150 CE start date based on Allison's (2019:286, Fig. 13.3) identification of a significant drop in radiocarbon dates associated with the use of maize agriculture around this time and a similar drop (but not as substantial) in overall radiocarbon dates (mostly charcoal) also around this time (Allison 2010:137-139). Depopulation in the Range Creek drainage has been dated to ca. 1200 (Boomgarden et al. 2014), providing additional support for a longer rather than shorter depopulation period. Uncertainty: Moderate due to the reliance on radiocarbon samples. The end date of ca. 1300 is more secure than the start date, which might have begun as early at 1125 based on Allison's (2019) maize radiocarbon data.

2. Ancestral Puebloan: Varien (2010:27), relying on tree-ring cutting dates, determined that population decline in the Northern San Juan region "began sometime after AD 1225 and continued until about AD 1285." Glowacki (2015:56) determined that the people across the Northern San Juan emigrated with increasing frequency after 1240, although there was subregional variation in the pace and timing. We selected 1240 as the start date, following Hegmon et al. (2018) and Clark et al. (2019). Limited migration from the Mesa Verde core area occurred during the twelfth and early thirteenth centuries (Clark et al. 2019:275). Depopulation 
of the northern portion of the Ancestral Puebloan culture area is coincident with population increases in other locations within the culture area, such as the Northern Rio Grande River region of New Mexico, suggesting migration to this sub-region as well as elsewhere (Clark et al. 2019, Ortman 2012). Uncertainty: Low.

3. Mogollon: The Mogollon culture area was a destination of migrants moving out of the northern SW during the late 1200s. The influx of migrants, the large geographical area, and variably occurring settlement-scale aggregations and depopulations thereafter create challenges for identifying the strong patterns and the duration of depopulation in this culture area. Our start date for depopulation is based on detailed investigations of multiple sites in the Mogollon Highlands of west central New Mexico. Oakes and Zamora (1999:46) determined that this heavily populated area within the Mogollon culture area was depopulated by 1325-1350. Our inferred population growth rates computed from room counts available through the Coalescent Communities Database (Hill et al. 2012) identified culture area declines in growth rates began during the 1350 to 1399 interval and declines persisted through the 1400 to 1449 interval. One of the largest sites, "Grasshopper" (east-central Arizona) was depopulated about 1400. Our end date for depopulation is 1450 based on mostly consistent but reduced room counts from the 1450 to 1499 through 1550 to 1599 intervals and a prevailing archaeological consensus that the pattern had ended by 1450. The settlement reorganization of the Mimbres area within the Mogollon culture area during the mid-1100s is outside of the period of declining regional-scale population levels that are the focus of this study. Uncertainty: Moderate.

4. Hohokam: Hill and colleagues (2010) conducted the most extensive study of settlement depopulation in the Hohokam core area (modern day Phoenix, Arizona). They found, "During the early fourteenth century, the largest sites controlled the intakes of the largest canal systems in the valley. By the late fourteenth century, all large sites in the central area had fallen into decline" (Hill et al. 2010:46). Also based on Hill and colleagues (2010:632, Table 5a), population estimates for 15 Classic period sites in the core area (modern day Phoenix, Arizona) peak during the 1300 to 1349 interval and decline (slightly) during the 1350 to 1399 interval. Our analysis of inferred population growth rates for the entire culture area, computed from room counts available through the Coalescent Communities Database (Hill et al. 2012), identified positive growth rates during the 1250 to 1299 and 1300 to 1349 intervals. Negative growth rates emerged sometime during the 1350 to 1399 interval. Thus, we estimate 1375 as the start of the depopulation and rely on the archaeological consensus of 1450 for the end of the depopulation, based on a lack of archaeologically visible settlement beyond this period. People persisted in the Hohokam culture area beyond the depopulation with descendants continuing to live in their ancestral homelands today (Loendorf and Lewis 2017). Uncertainty: Moderate. The lack of tree species in the culture area amenable to tree-ring dating prevents more precise dating.

5. Sinagua and Central Arizona: The approximate beginning of the depopulation of the Sinagua and Central Arizona area is 1375 based on declining room numbers during the 1350 to 1399 period documented in the Coalescent Communities Database (Hill et al. 2012). Pilles' (2015:109) estimates fairly stable total population levels during the early and late Sinagua Tuzigoot phases (1300 to 1400). This suggests relatively rapid population decline in the Sinagua area (Verde Valley) of the culture area polygon. Pilles (2015) determined a ca. 1400 depopulation date for Sinagua. The Central Arizona Tradition portion of the culture area appears to have persisted into the early 1400s with very low population levels (Hill et al. 2012, Wilcox, 
Robertson, and Wood 2001), thus we estimate that by 1425 the depopulation was nearly complete. Uncertainty: Moderate for start date; Moderate for end date. The lack of tree species in the culture area amenable to tree-ring dating prevents more precise dating.

6. Trincheras: The depopulation of the major town in the culture area, Cerro de Trincheras, has been assigned a 1450 date by McGuire and Villalpando (2016:19) and Villalpando and McGuire (2017:388). The timing of the initiation of depopulation is not known. Based on a lack of evidence for a prolonged depopulation, we expect it was relatively quick, perhaps a single human generation. Uncertainty: High for start date; Low for end date.

7. Casas Grandes: The 1450 or shortly thereafter end date is reasonably secure (Dean and Ravesloot 1993, Phillips and Carrera 2016:54, Whalen et al. 2010:546). The start of depopulation is less clear. Phillips and Carrera (2016:54) found a rapid fall-off in radio-carbon dates about 1450 in dated sites in the Casas Grandes culture area, suggesting "the entire culture ended when Paquime did." Di Peso (1974), based on archaeological excavations that revealed the presence of unburied bodies in a portion of the site, interpreted a violent attack at the end of Paquime, though this interpretation is not widely accepted (Pailes 2017). Thus, the limited evidence suggests a relatively short depopulation period. Uncertainty: High for start date; Low for end date.

8. Rio Sonora: Based on the best available evidence, populations persisted in the Rio Sonora and Serrana culture areas without evidence of significant population loss (Matthew Pailes, personal communication 1 February 2020; see also Pailes 2017). Thus, this culture area is a case of persistence and demographic stability.

9. Patayan: According to Rogers (1945) and Aaron Wright (2020, personal communication May 2020) and the best available data, the Patayan culture area did not experience depopulation similar to other culture areas within the SW/NW. Uncertainty: Moderate.

\section{LITERATURE CITED}

Allison, J. R. 2019. The northern frontier in the history of the greater Southwest. Pages 281-307 in K. G. Harry and B. J. Roth, editors. Interaction and connectivity in the greater Southwest. Louisville, Colorado, University Press of Colorado.

Boomgarden, S. A., D. Metcalfe and C. Springer. 2014. Prehistoric archaeology in Range Creek Canyon, Utah: a summary of activities of the Range Creek field station. Utah Archaeology 27(1):9-32.

Clark, J. J., J. A. Birch, M. Hegmon, B. J. Mills, D. M. Glowacki, S. G. Ortman, J. S. Dean, R. Gauthier, P. D. Lyons and M. A. Peeples. 2019. Resolving the migrant paradox: two pathways to coalescence in the late precontact US Southwest. Journal of Anthropological Archaeology

53:262-287. 
Dean, J. S. and J. C. Ravesloot. 1993. The chronology of cultural interaction in the Gran Chichimeca. Pages 83-103 in A. I. Woosley and J. C. Ravesloot, editors. Culture and contact: Charles c. Di peso's Gran Chichimeca. Albuquerque, University of New Mexico Press.

Di Peso, C. C. 1974. Casas Grandes: A fallen trading center of the Gran Chichimeca. Dragoon, AZ: Amerind Foundation.

Glowacki, D. M. 2015. Living and leaving: A social history of regional depopulation in thirteenth-century Mesa Verde. Tucson: University of Arizona Press.

Hegmon, M., M. A. Peeples, and LTVP Collaboration. 2018. The human experience of social transformation: insights from comparative archaeology. PLOS One 13(11):1-29.

Hill, J. B., P. D. Lyons, J. J. Clark and W. H. Doelle. 2010. Depopulation of the northern Southwest: A macroregional perspective. Pages 34-52 in T. A. Kohler, M. D. Varien and A. M. Wright, editors. Leaving Mesa Verde: peril and change in the thirteenth-century Southwest. Tucson, The University of Arizona Press.

Hill, J. B., D. Wilcox, W. Doelle and W. Robinson. 2012. Coalescent Communities Database version 2.0. Tucson, Archaeology Southwest.

Loendorf, C. and B. V. Lewis. 2017. Ancestral O'odham: Akimel O'odham cultural traditions and the archaeological record. American Antiquity 82(1):123-139.

McGuire, R. H. and E. Villalpando. 2016. The Trincheras tradition. Archaeology Southwest Magazine. Archaeology Southwest. 18-20.

Oakes, Y. R. and D. A. Zamora. 1999. Volume 1. Defining the Mogollon: Museum of New Mexico, Office of Archaeological Studies.

Ortman, S. G. 2012. Winds from the north: Tewa origins and historical anthropology. Salt Lake City, University of Utah Press.

Pailes, M. C. 2017. Northwest Mexico: The prehistory of Sonora, Chihuahua, and neighboring areas. Journal of Archaeological Research 25:373-420.

Pilles, P. J. 2015. The Tuzigoot phase of southern Arizona. Journal of Arizona Archaeology 3(1, 2):100-116.

Rogers, M. J. 1945. An outline of Yuman prehistory. Southwestern Journal of Anthropology 1(2):167-198.

Varien, M. D. 2010. Depopulation of the northern San Juan region: Historical review and archaeological context. Pages 1-33 in T. A. Kohler, M. D. Varien and A. M. Wright, editors. Leaving Mesa Verde: peril and change in the thirteenth-century southwest. Tucson, The University of Arizona Press.

Villalpando, E. and R. H. McGuire. 2017. Sonoran Pre-Hispanic traditions. Pages 381-396 in B. J. Mills and S. Fowles, editors. The Oxford Handbook of Southwest Archaeology. Oxford, Oxford University Press. 
Whalen, M. E., A. C. MacWilliams and T. Pietzel. 2010. Reconsidering the size and structure of Casas Grandes, Chihuahua, Mexico. American Antiquity 75(3):527-550.

Wilcox, D. R., G. Robertson Jr. and J. S. Wood. 2001. Organized for war: the Perry Mesa settlement system and its central-Arizona neighbors. Pages 141-194 in G. Rice and S. Leblanc, editors. Deadly landscapes: case studies in prehistoric Southwestern warfare. Salt Lake City, University of Utah Press. 


\section{Appendix 4. SW/NW Culture Area Polygons}

Archaeological culture area polygons are inexact and vary through time, especially after the late $13^{\text {th }}$ century migrations. Areas defined in this study represent an approximation of culture area dimensions around $1100 \mathrm{CE}$. Sharp culture area boundaries are not supported by the material culture evidence archaeologists identify on the ground (see also Main text discussion of "archaeological cultures."). These boundary variations, however, do not impact the coding results presented (Appendix 2) which are mostly built from settlement-scale archaeological data where identities are assessed. Here we identify the sources we relied on to identify the culture areas in Figures 1 through 8 (Main text) since many archaeological studies and publications use inconsistent dimensions and do not explain these dimensions. In many areas, the boundaries we use are a compromise between multiple sources.

Ancestral Puebloan (Adler et al. 1996:377, Fig. 1)

Fremont (Talbot 2019:382, Fig. 17.1)

Hohokam (Clark 2020)

Sinagua and Central Arizona (Clark 2020; Pilles 1996:60, Fig. 5.1)

Patayan (Wright 2020)

Mogollon (Clark 2020)

Trincheras (Pailes 2017:382, Fig. 3)

Rio Sonora and Serrana (Pailes 2017:382, Fig. 3)

Casas Grandes (Pailes 2017:382, Fig. 3)

\section{LITERATURE CITED}

Adler, M. A., T. Van Pool and R. D. Leonard. 1996. Ancestral Pueblo population aggregation and abandonment in the North American southwest. Journal of World Prehistory 10(3):375-438.

Clark, J. J. 2020. Life of the Gila: Mapping identities and worlds over a millennium. [online] URL: https://www.archaeologysouthwest.org/2020/02/13/life-of-the-gila-mapping-identitiesand-worlds-over-a-millennium/

Pailes, M. C. 2017. Northwest Mexico: The prehistory of Sonora, Chihuahua, and neighboring areas. Journal of Archaeological Research 25:373-420. 
Pilles, P. J. 1996. The Pueblo III period along the Mogollon rim: The Hohanki, Elden, and Turkey Hill phases of the Sinagua. Pages 59-72 in M. A. Adler, editor. The prehistoric Pueblo world, A.D. 1150 - 1350. Tucson, University of Arizona Press.

Talbot, R. K. 2019. The late Fremont regional system. Pages 378-405 in K. Harry and B. J. Roth, editors. Interaction and connectivity in the greater southwest. University Press of Colorado.

Wright, A. 2020. Life of the Gila: The Patayan world. Tucson: Archaeology Southwest. [online] URL: https://www.archaeologysouthwest.org/2020/02/20/life-of-the-gila-the-patayan-world/ 